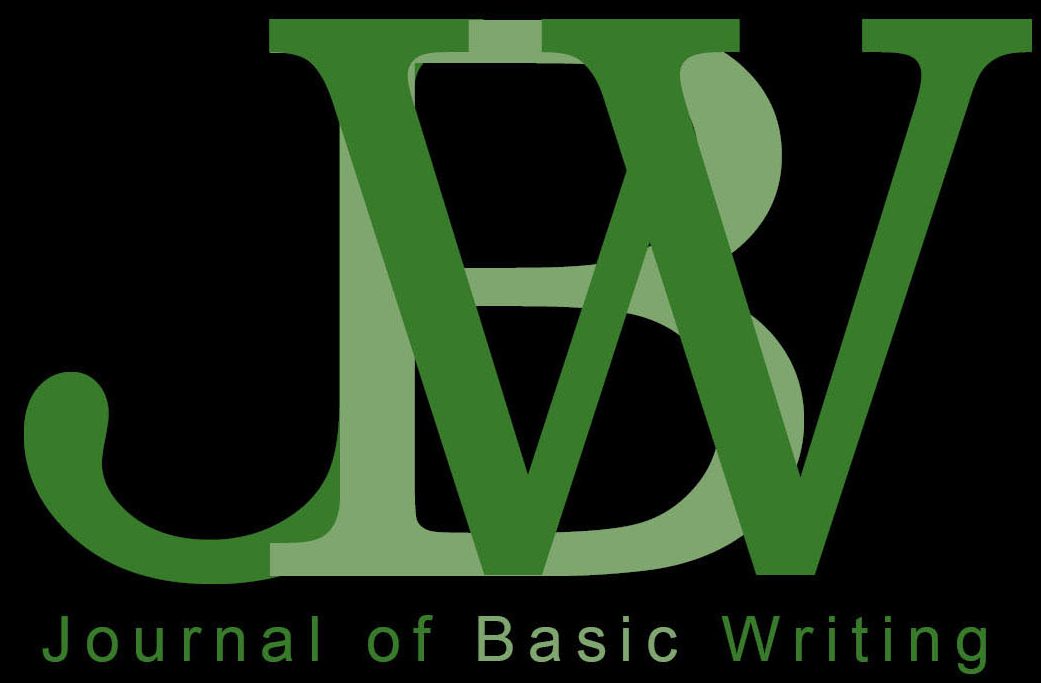

ESL Curriculum Revision:

Shifting Paradigms for Success

Doreen E. Ewert

How Antonio Graduated On Out of Here: Improving the Success of Adult Students with an Individualized Writing Course Michelle Navarre Cleary

Braiding and Rhetorical Power Players: Transforming Academic Writing through Rhetorical Dialectic Kimberly K. Gunter

Reflection Revisited: The Class Collage Jeff Sommers

Defining and Experiencing Authorship(s) in the Composition Classroom:

Findings from a Qualitative Study of Undergraduate Writing Students at the City University of New York Johannah Rodgers

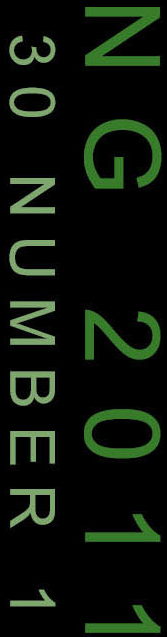





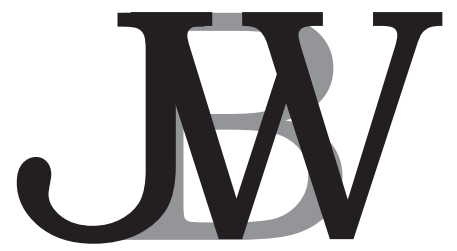

Journal of Basic Writing

$\begin{array}{ccc}\text { VOLUME } 30 & \text { NUMBER } 1 & \text { SPRING } \\ & 2011 & \end{array}$

The Journal of Basic Writing publishes articles of theory, research, and teaching practices related to basic writing. Articles are refereed by members of the Editorial Board (see overleaf) and the Editors.

\section{Hope Parisi and Cheryl C. Smith Editors}

\section{Ann Del Principe \\ Karen Weingarten \\ Associate Editor \\ Web Editor}

Rebecca Mlynarczyk and Bonne August

Consulting Editors

\section{Angela J. Francis and Corey Frost}

Editorial Assistants

The Journal of Basic Writing is published twice a year, in the spring and fall, with support from the City University of New York, Office of Academic Affairs. We welcome unsolicited manuscripts and ask authors to consult the detailed "Call for Articles" in this issue. Subscriptions for individuals are $\$ 20.00$ for one year and $\$ 35.00$ for two years; subscriptions for institutions are $\$ 30.00$ for one year and $\$ 45.00$ for two years. Foreign postage is $\$ 10.00$ extra per year. For subscription inquiries or updates, contact:

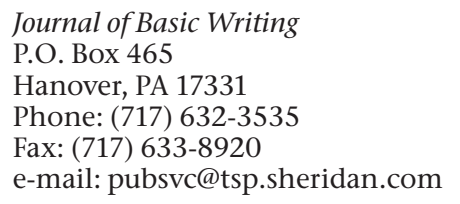

Published by the City University of New York since 1975 Cover and logo design by Kimon Frank

Copyright (C)2011 by the Journal of Basic Writing

ISSN 0147-1635 


\section{JOURNAL OF BASIC WRITING}

\section{EDITORIAL BOARD}

Linda Adler-Kassner

University of California, Santa Barbara

Chris M. Anson

North Carolina State University

Hannah Ashley

West Chester University

David Bartholomae

University of Pittsburgh

Sarah Benesch

College of Staten Island, CUNY

Susan Naomi Bernstein

Independent Scholar

Patricia Bizzell

College of the Holy Cross

Lynn Z. Bloom

University of Connecticut, Storrs

Gay Brookes

Borough of Manhattan Comm. College, CUNY

Richard Courage

Westchester Community College, SUNY

Martha Clark Cummings

Kingsborough Community College, CUNY

Donald A. Daiker

Miami University

Suellynn Duffey

Georgia Southern University

Chitralekha Duttagupta

Utah Valley University

Sarah Warshauer Freedman

University of California, Berkeley

Keith Gilyard

Pennsylvania State University

Gregory Glau

Northern Arizona University

Laura Gray-Rosendale

Northern Arizona University

Karen L. Greenberg

Hunter College, CUNY

Brenda M. Greene

Medgar Evers College, CUNY

Susanmarie Harrington

University of Vermont

\section{Myra Kogen}

Brooklyn College, CUNY

Donald J. Kraemer

California Polytechnic State University
Patricia O. Laurence

City College, CUNY

Andrea A. Lunsford

Stanford University

Jane Maher

Nassau Community College, SUNY

Paul Kei Matsuda

Arizona State University

Geraldine McNenny

Chapman University

Susan Miller

University of Utah

Sandra Murphy

University of California, Davis

Deborah Mutnick

Long Island University

Nathaniel Norment, Jr.

Temple University

\section{George Otte}

Graduate Center, CUNY

Thomas Peele

Boise State University

Elizabeth Rorschach

City College, CUNY

Wendy Ryden

Long Island University

Yolanda Sealey-Ruiz

Teachers College, Columbia University

Charles I. Schuster

University of Wisconsin, Milwaukee

Tony Silva

Purdue University

Trudy Smoke

Hunter College, CUNY

Ruth Spack

Bentley College

Lynn Quitman Troyka

Queensborough Comm. College, CUNY, ret.

Karen S. Uehling

Boise State University

Evelyn E. Webb

Miss. State Board for Comm. and Junior Colleges

Harvey S. Wiener

LaGuardia Community College, Emeritus

Vivian Zamel

University of Massachusetts, Boston 


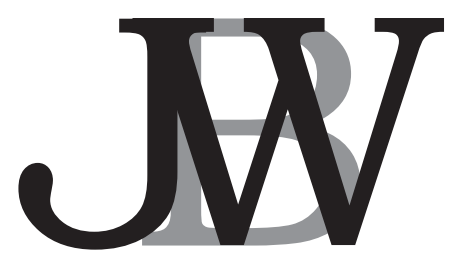

Journal of Basic Writing

Editors' Column

ESL Curriculum Revision:

Shifting Paradigms for Success

\section{Doreen E. Ewert}

How Antonio Graduated On Out of Here:

Improving the Success of Adult Students

with an Individualized Writing Course

Michelle Navarre Cleary

Braiding and Rhetorical Power Players:

64

Transforming Academic Writing through Rhetorical Dialectic

Kimberly K. Gunter

Reflection Revisited: The Class Collage

Jeff Sommers

Defining and Experiencing Authorship(s) in the

Composition Classroom:

Findings from a Qualitative Study of Undergraduate Writing Students at the City University of New York Johannah Rodgers

News and Announcements 


\title{
CALL FOR ARTICLES
}

We welcome manuscripts of 15-25 pages, double spaced, on topics related to basic and ESL writing, broadly interpreted. Submissions should follow current MLA guidelines. Manuscripts are refereed anonymously. To assure impartial review, include name(s), affiliation(s), mailing and e-mail addresses, and a short biographical note for publication on the cover page only. The second page should include the title but no author identification, an abstract of about 150 words, and a list of 4-5 key words. Endnotes should be kept to a minimum. It is the author's responsibility to obtain written permission for including excerpts from student writing.

We prefer that contributions be submitted as Word document attachments via e-mail to: hopekcc@aol.com and Cheryl.Smith@baruch.cuny.edu. If electronic submission is not possible, mail five copies of the manuscript and abstract to:

\author{
Professor Hope Parisi \\ Co-Editor, JBW \\ Department of English \\ Kingsborough Community College, CUNY \\ 2001 Oriental Blvd. \\ Brooklyn, NY 11235
}

You will receive a confirmation of receipt; a report on the status of your submission will follow in about sixteen weeks.

All manuscripts must focus clearly on basic writing and must add substantively to the existing literature. We seek manuscripts that are original, stimulating, well-grounded in theory, and clearly related to practice. Work that reiterates what is known or work previously published will not be considered.

We invite authors to write about such matters as classroom practices in relation to basic-writing or second-language theory; cognitive and rhetorical theories and their relation to basic writing; social, psychological, and cultural implications of literacy; discourse theory; grammar, spelling, and error analysis; linguistics; computers and new technologies in basic writing; assessment and evaluation; writing center practices; teaching logs and the development of new methodologies; and cross-disciplinary studies combining basic writing with psychology, anthropology, journalism, and art. We publish observational studies as well as theoretical discussions on relationships between basic writing and reading, or the study of literature, or speech, or listening. The term "basic writer" is used with wide diversity today, sometimes referring to a student from a highly oral tradition with little experience in writing academic discourse, and sometimes referring to a student whose academic writing is fluent but otherwise deficient. To help readers, therefore, authors should describe clearly the student population which they are discussing.

We particularly encourage a variety of manuscripts: speculative discussions which venture fresh interpretations; essays which draw heavily on student writing as supportive evidence for new observations; research reports, written in non-technical language, which offer observations previously unknown or unsubstantiated; and collaborative writings which provocatively debate more than one side of a central controversy. 


\section{EDITORS' COLUMN}

To glance at the articles of this issue is to realize the awesome insistence, and persistence, of its author-professionals in striving to create integrated experiences of learning. Even as we daily encounter exigencies-both institutional and social — that replicate divisions, instructors of basic writing and reading continually build the theory and pedagogy to anchor students to their lives of literacy. The gusty roarings of programs and pedagogies that sweep past students' already-there literacies are challenged to re-imagine what author Kimberly K. Gunter, in this issue, calls the "continuum" that turns writing into so many either/or-type activities: Either students are learning writing or learning reading; either they are writing personally or they are writing academically. Meanwhile, the either/or-defying qualities of students' literacies, already rich and whole when they enter our classrooms, become obscured. In response, we feel compelled to slow our own and others' movement past students' literacies-hopefully, long enough for us to recognize and re-center them as part of students' academic journeys.

For some critics and practitioners, the "whole language" approach more meaningfully engages students' own literacies as part of the process of developing academic reading and writing proficiencies. While whole language is more commonly evoked in conjunction with primary and secondary education, it offers a useful frame for thinking about the articles in this issue as they grapple with entrenched assumptions about, and continuums of, language learning that often drive our programs and practices. With first and home literacies as its starting-point, whole language acknowledges, and accounts for, the learning of language in terms of integrative activity-a process that constantly engages itself according to new input, in turn sparking new experiences of problem-solving - synthesis and re-synthesis. The process supposes an active and subjective agent at the helm, aware, interested, and creative-an agent capable of responding literately. When driving pedagogy, whole language challenges common boundaries in learning - as in, now we're reading, now we're writing; now we're writing and now we're reflecting on our writing. (How can reflecting, by way of writing, not be also writing?) Thus, whole language illuminates the possibility of both/and identities, by which students may "voice" their writing in multiple, interrelated ways, within and between the various aspects of any one (supposed as only "one") reading or writing event.

Among the articles in this issue, the first one, "ESL Curriculum Revision: Shifting Paradigms for Success," by Doreen E. Ewert, most directly highlights the theme of integration and the value of whole language. A disjointed array 
of courses at Ewert's institution, Indiana University, fragmented the experience of English language learning for the growing number of international, second-language students entering the college. Through rigorous study of the various courses and curriculum, and by adopting a team approach with colleagues similarly interested in creating a unified, context-specific experience of English language learning, Ewert drew from the best models and theories for growing a completely revised ESL literacy developmental sequence. The integration of reading and writing throughout the sequence productively re-writes a "long history of ESL and EFL instruction of focusing on discrete language skills rather than literacy" for Indiana University and within the field of first and second language acquisition. By all measures that may be garnered at this point_-test scores, grades, and student and teacher interviews-the new curriculum, now in its second year, models success for matriculating ESL international students.

Our second article, "How Antonio Graduated On Out of Here: Improving the Success of Adult Students with an Individualized Writing Course," by Michelle Navarre Cleary, also tells a story of striving to value students in terms of their unique abilities and locations within the academy. Navarre Cleary offers a relatively rare story of outreach to students as individuals-students who, as adults, have traveled particular roads, coursing academia first on its terms and finally on their own. Like the innovation of Ewert at IU, Writing Workshop at DePaul University's School for New Learning accommodates students not sufficiently served by current programs for writing and advancement. Navarre Cleary designed Writing Workshop to suit adult learners at any number of stages along the ladder of college writing, from students who typically might be deemed "basic" to more advanced students, like Antonio, who as a senior was stuck on a final project. Again, the focus is holistic-on a writer and his particular experiences and priorities, not some pre-set or modulized agenda. And as students accrue the benefits of individualized instruction, teachers unexpectedly confront assumptions about "instruction." Citing the challenge of teaching in an individualized context, Navarre Cleary quotes Deborah Brandt to say, “the habit of automatically seeing 'teachers' and 'students' and 'classroom organization' must be problematized. That [we] can take such categories so easily for granted. . . only speaks to how widely sanctioned and understood are the roles of teachers and students and classroom life in general, how well embedded and routinized they are in normal life." In pushing back on entrenched categories in higher education to build holistic frameworks of teaching and learning, we find challenges to be attributes of promise. 
Kimberly K. Gunter offers a compelling case study to support a holistic valuation of literacy learning in our third article, "Braiding and Rhetorical Power Players: Transforming Academic Writing through Rhetorical Dialectic." Contesting the rivalry she observes between modes of writing in the academy-whether "personal" or "privileged"-Gunter imagines academic writing as braiding, an integrative process that resists configuration as either this or that. She further urges us to imagine possibilities for student writing beyond the transactional-poetic continuum, proposing a "slicker" kind of surface "along, around, and about which writing might skate." Further, she states, "[w] e can overlay on that continuum, whose gauge is now free to roam, the genre of academic writing, which will. . contain. . possibilities that were before constrained or, depending on the classroom, unimaginable." Referencing theories of mixed and hybrid discourse and alt/dis, Gunter presents Laura, a student who enrolled in her LGBTQ-themed writing class. Laura was out as a lesbian in her writing class but remained conflicted by the intersections of her identity/ies, including her identity as an Army cadet. As Laura eventually accepts her teacher's invitation to braid identities rhetorically, new possibilities emerge; she is better able to theorize her experience as a lesbian and a soldier. As a rhetorical strategy, braiding engages a "multiplicity of discourse and [students'] own multiple subjectivities." As Gunter notes, such opportunity benefits students from mainstream cultures, who may find it new and thus particularly challenging, as well as students from marginalized communities-those more apt to already employ a "discursive survival strategy" - like so many basic writers.

Our fourth article, "Reflection Revisited: The Class Collage," by Jeff Sommers, similarly addresses the bifurcation of experience in writing instruction by re-exploring the convention of reflection within many writing courses. Too often, Sommers attests, the potential for reflection to affect meta-consciousness in and about writing, and oneself as a writer, languishes in courses where reflection slides to the last weeks, or embeds a performance for convincing evaluators that the student is worthy of "passing." Current notions of reflection, such as Donald Schön's reflection-in-action and reflection-on-action, and Kathleen Blake Yancey's reflection-in-presentation, affirm the role of reflection in writing classrooms, but still link reflection to the writer's cognitive development. As Sommers shows, instructors can get students beyond descriptions of new writing abilities. His class collage activity repurposes reflection as a holistic pedagogy, spanning the semester, for students to examine and re-examine their beliefs about writing as well as those of their classmates. In a communal frame, students consider what it means 
to value, or not, the aspects of writing that students experience in the course. The approach engages both students' prior experience as writers (resisting the notion that they are novices) and their capacity to philosophize, encouraging students to substantiate and explain their claims for writing. This process eschews potentially lock-step methodologies for reflection-for example, teach, write, reflect. For Sommers, reflection is a fully integrative activity, enfolding the writing experiences of the entire semester and writing community.

Finally, in our fifth article, "Defining and Experiencing Authorship(s) in the Composition Classroom: Findings from a Qualitative Study of Undergraduate Writing Students at the City University of New York," Johannah Rodgers further complicates notions of student reflection on writing experience, broadly conceived. At the point of effectively having completed their writing courses as adult students at The City College of New York's Center for Worker Education, students consider how and whether they view themselves as authors and/or writers. In this study, Rodgers probes the literary and academic traditions that influence the ease and resistances with and by which students relate to notions of authorship, proving the persistent impact of these traditions on students' writerly identities today. The underlying question for Rodgers is one of authority: To what extent, and under what influences, will or may students claim a sense of writerly authority? And if such a claim is indeed an end of all writing instruction, how must we (re)configure our writing classrooms?

Exploring how students "experienc[e] authorship" is ultimately a fitting way to capture this issue's concern with holistic literacy learning for college, bringing us full circle, back to Ewert's concern over the fragmented experience of English language learners at her institution. In Rodgers' move toward "authorship-as-experience," we are urged against pedagogies that seem to push students toward one or the other identity, thereby limiting their opportunities for making meaning. In holistic frameworks, identity is plural-encouraged by multiplying, not minimizing, the contexts that enable new subject positions.

We would like to close by welcoming a new addition to our editorial team. Professor Ann Del Principe of CUNY's Kingsborough Community College will be joining JBW as Associate Editor. Annie comes to us with a strong background in composition, rhetoric, and basic writing. At Kingsborough, she is Director of the Freshman English Program. Her research interests include writing assessment, play theory in the writing classroom, and students' literacy experiences in community colleges. We look forward to many fruitful collaborations with Annie and future JBW authors. 


\title{
ESL Curriculum Revision: Shifting Paradigms for Success
}

\author{
Doreen E. Ewert
}

\begin{abstract}
The early success of the revised ESL literacy development curriculum for international undergraduates at a large Midwestern university suggests that a curriculum which integrates reading and writing activity around meaning-making tasks with texts and focuses on fluency before accuracy is preferable to a skill-based curriculum. Support for this approach is found both in first and second language literacy development research, yet it has not been widely adopted in ESL developmental writing programs. Although only in the second year of implementation, test scores, grades, and student and teacher interviews indicate the revised curriculum is well-serving the developmental academic literacy needs of these matriculated ESL international students. Students are demonstrating reading and writing with greater ease and speed. They understand and produce texts with greater rhetorical awareness and have developed strategies for talking about and working with a variety of academic text-types. The development of these literacy practices has been well-received by teachers and students, and has prepared the latter to participate success fully in the required first year composition course.
\end{abstract}

KEYWORDS: ESL; literacy; adult; fluency; reading; writing; curriculum; university

\section{Introduction}

Investigations of second language writing and writers over the last several decades have revealed an increasingly complex landscape for university-level writing programs to negotiate. The international students with whom we work come with considerable variation in their literacy competencies in both their first languages and in English. Many international students have had six to ten years of classroom instruction in English and even experiences in US high schools and community colleges before they enter US universities. Despite this backdrop of apparent proficiency, a high percentage of students who enter research universities still struggle to adequately comprehend and produce academic texts, not simply because they

Doreen E. Ewert is Associate Professor and Director of English Language Instruction in the Department of Second Language Studies at Indiana University where she teaches graduate courses in TESOL and directs the curriculum and teacher development for several English language development programs. Her research interests include teacher development, classroom curriculum design and implementation, and second language literacy development.

(C) Journal of Basic Writing, Vol. 30, No. I, $201 \mathrm{I}$ 
may lack control over lexico-grammatical features, but because they have limited experience with English academic texts and limited knowledge of literacy expectations in US universities.

The field of L2 writing is making strides in acknowledging and addressing this relatively new emphasis on academic literacy over mere language competence. For several decades, evidence has been growing of the efficacy of integrating reading and writing that emphasizes meaning-oriented engagement with texts through content-learning (Brinton, Snow and Wesche; Carson, "Reading for writing"; Fitzgerald and Shanahan; Grabe; Hudson; Kern) Thus, it is surprising how many ESL courses for matriculated secondlanguage learners still focus on discrete and sometimes decontextualized reading and writing skills rather than on skill-integration and fluency development, which form the basis of literacy (Kern). In this paper, I explore how one large research university has attempted to address this problem as it created a curriculum to propel newly matriculated ESL-level students through an academic literacy experience that provides them with the tools they need to begin to read and write alongside American undergraduates. Our implementation of a curriculum that focuses on fluency development through meaning-oriented reading and writing activity around thematic texts has promoted the development of academically literate behaviors ahead of the lengthier process of linguistic accuracy development in a second language. Participating in the practices of a literate community provides not only the foundation for attending to language development but also the relevance and purpose for that development.

Within this dynamic context of second language writers and writing, I began work at Indiana University in 2007 as the Director of English Language Instruction. One component of my responsibilities has been the oversight of the program of support courses for international English-as-a-second language (ESL) undergraduate students. Since the home department (Second Language Studies) had recently undergone significant academic and structural reorganization, and the ESL curriculum had not undergone review for some time, when I arrived, my departmental assignment included a rigorous examination of the curriculum. Familiarization with the nature of the curriculum, the profile of the students for whom the courses were created, the test that placed them in the courses, and the subsequent courses for which our curriculum was meant to prepare them soon revealed that a revision of the curriculum was in order. This determination was significantly shaped by my own perspective on the nature of adult second language literacy development as I had come to understand it from my previous teaching, research, and 
program direction. However, it was also shaped by the concerns of teachers in the program, other faculty, administrators, and advisors.

After a year of investigation, planning, and review, a substantial revision of the literacy component of the ESL curriculum was implemented. This new curriculum made significant shifts in several aspects: first, it moved from discrete-skills to integrated-skills; second, the emphasis was shifted away from a focus on grammatical and lexical accuracy toward a focus on fluency and rhetorical facility; and third, the original group of five disconnected courses was replaced by three sequential courses. A complete revamping of a long-standing program was obviously not without obstacles, but the combination of several elements-principles that were clearly grounded in current theory, a willing and able local community of practitioners, and enthusiastic administrative support-made implementation possible. This paper presents the story of why and how a new curriculum came into being and the impact it is having on a range of stakeholders. It begins with a description of the initial context, the key players, and the processes involved in the development of the revised curriculum. This is followed by a description of the new curriculum with evidence from qualitative and quantitative inquiry regarding its impact. The paper concludes with a discussion of these results and a reflection on the process of development and implementation.

\section{The Initial Context}

The origin and development of the ESL developmental program in place when the curriculum review began is shrouded in the mist of institutional history. Suffice it to say, what was previously called the "Semi-Intensive English Program" grew up alongside the Intensive English Program that was instituted at Indiana University in the I970s. The Semi-Intensive Program had a rather tenuous status within the university. In fact, all entering international students not from English-speaking countries were required to take a test during their orientation and, if the results of that test showed evidence of very weak English skills, advisors in the University Division (the home department of entering undergraduate students before entering their major departments) were notified, and they took it upon themselves to advise the student to sign up for the number of courses that were suggested by the test. However, there was little oversight, and what existed was left mainly to the advisors, who had large numbers of students to tend. There were some administrative checks in the way that students were coded by the registrar, but on the whole, tracking was minimal. 
During the aforementioned departmental restructuring, as the current program for ESL developmental courses was being conceived to replace the "Semi-Intensive Program," many issues warranted review. None was more important than the gate-keeping English proficiency test that placed students in first-year composition or developmental ESL courses. However, it soon became apparent that the test itself could not be reconceived until we understood the nature of the classes into which the students were to be placed. As the new curriculum would be literacy-rather than skill-based, the assessment tool and the criteria for assessment would need radical reassessment. Clearly then, the development of curriculum and the placement test had to be developed in tandem.

At Indiana University, all international students for whom English is not the first language must take an English proficiency test before registering for classes. Until the fall of 2008, this proficiency test included multiplechoice components for assessing grammatical accuracy, and reading and listening comprehension, as well as a timed essay. The essays were evaluated with a modified trait-based rubric that weighted accuracy of language and structure over content and development. The combined test results determined whether students would be required to take anywhere from zero to eight ESL support courses, each of which ran for eight weeks. For literacy development, courses included Reading Skills, Expository Reading, Grammar Review, Sentence Writing, and Paragraph Writing. Students scoring the most poorly on the reading test were placed into Reading Skills followed by Expository Reading, and students scoring below a certain level on the grammar section of the test were required to take Grammar Review, while those scoring most poorly on the written essay were also required to take Grammar Review along with Sentence Writing and Paragraph Writing. Thus depending on the scores in the separate sections of the proficiency exam, a student could be required to take some or all of the reading or writing courses with little or no regard for sequencing, often with a more elementary course, such as Sentence Writing, being taken simultaneously with a more advanced course, such as Paragraph Writing.

Students were expected to complete these required courses in the first year, but if students did not pass or finish the courses, they received a grade of Incomplete and were allowed to retake them and sometimes long after their actual need for the course. Other undergraduate courses could be taken concurrently with these ESL courses, the only limitation on course enrollment being that if any of the reading or writing courses were required, a student would not be allowed to enroll in the university's required first year 
English composition course (usually WI3IML, a variation of the course for multi-lingual writers) until the following semester. However, there was (and is) no gate-keeping mechanism to assure that students have taken or passed the required classes or that they can demonstrate sufficient competence to continue unassisted in their coursework.

Coincidentally, for several decades, the number of sections of the developmental ESL courses had been fixed. This meant that whatever the overall results of the English proficiency exam were for the entire cohort, only a set number of students (beginning with those who scored the lowest) were given a recommendation to take the ESL courses. As long as the number of international students did not substantially change from year to year, this approach to providing support courses was not without its merits. Having a guaranteed number of sections of these courses was administratively and financially expeditious, as the department could guarantee classes for the university and in return be guaranteed a certain number of assistantships for the graduate student-instructors who made up the bulk of the instructors, which greatly facilitated course scheduling. Furthermore, since the international students being placed into these classes had already been accepted into Indiana University, the focus on the students with the weakest English skills in a particular incoming class was an acceptable approach to dealing with the goal of helping the students to get by. As long as there were few complaints or protests from faculty or departments about students failing to live up to expectations, the system seemed to be working.

Two things made this halcyon state of affairs impossible to maintain. First, during the reorganization of the Second Language Studies department, new policies and standards were implemented to increase integration of the ESL program within the College of Arts and Sciences. This integration included making transparent to the administrators in the College the methods of testing, placement, instructor selection, curricular development, and other aspects which had never been of great interest to them in the past. Second, with the advent of a new president, there was a heightened emphasis on international recruiting, especially in areas such as China, that promised rich new fields of student prospects. At the same time, this heightened recruitment led to an influx of students whose English language and academic literacy backgrounds were ever more varied.

The literacy curriculum in place when I arrived could only be inferred from the titles, a handful of syllabi, and textbooks of the five courses related to reading and writing. There were no documents available to indicate the rationale or guidelines for course design or program integration of courses. 
The course titles suggested a traditional instructional approach which favored intensive practice in specific sub-components of reading and writing, as well as practice in discrete grammatical topics. The grammar course was what it was-a brief review course in the major aspects of English grammar. For the other courses, there were no stated objectives or curricula to describe the overall goals or objectives. Each instructor was basically left to her own devices to construct a course that she felt fit the needs of the students. Of course, a stream of "institutional history" gave the courses some consistency, but whenever a strong new teacher persisted over several semesters, the course essentially became what she made it. There was virtually no guidance at that point from the top, primarily because the person charged with directing the program was completely on his own in running it, with little support from the department or the university, and was simply trying to keep his head above water as he managed all the testing, placement, instructor assignments, etc. by himself (no one was surprised when he had a heart attack not long before he retired). To explain the problems I encountered when I arrived in the department is in no way to take away from his long, dedicated direction of the program, but it was universally agreed that the program had to be completely recast to the new demands being made on it.

The syllabi extant from previous instructors reveal courses focused on multiple components of language learning, some well-grounded in current approaches for the development of English for Academic Purposes, but, again, unrelated to each other and evincing considerable variation in the scope and rigor of sections of the same course. One cause of variation was the high turnover rate in instructors since these 2-credit, 8-week courses were taught by Associate Instructor graduate students. Another cause of variation was that these courses could be taken simultaneously and ideally completed within the student's first semester of study at Indiana University, thus eliminating the possibility of sequencing the courses as prerequisites for one another or closely linking their goals and objectives.

The syllabi for the courses Sentence Writing and Paragraph Writing did include drafting and revising of longer texts with some attention to the rhetorical modes, such as process, comparison, or argument. However, through semi-structured interviews with the small cohort of instructors who were teaching these courses when I arrived, it was evident that, as a group, they had struggled to manage the many demands of the courses. Each teacher first developed the ideas of what they thought needed to be taught, found or created materials consonant with their vision, and finally tried to have the students engage in multi-draft writing with sufficient peer and instructor 
ESL Curriculum Revision: Shifting Paradigms for Success

feedback. Some spoke of being "overwhelmed" with the task and others spoke of just following the syllabi of previous teachers even though they did not always represent the teachers' own ideas of literacy development. Based on the prospect of an integrated curriculum, clearer course goals, and program cohesion, the teachers were open to revision.

Although I was responsible for the review of the curriculum, it goes without saying that it is a wasted effort if it occurs in isolation from those who will be affected by it. As I began to make inquiries into the nature of the curriculum in use, the test that placed students into it, and the literacyfocused course students would take after our courses, I was fortunate to meet three individuals who would join me as part of the unofficial team for the project. One member of the small cohort of ESL literacy instructors was responsible for the essay rater training for the English proficiency exam and for some time had coordinated the writing curriculum of the Intensive English Program for pre-matriculated students at Indiana University. With his interest and knowledge about second language writing and his concern for the coherence of the courses, he willingly became an active discussant in my year-long process of reviewing the literature and the local context, and in envisioning possible revisions of the curriculum.

The other two team members were, like me, new faculty at Indiana University. One is a member of my own department whose area of expertise is high-stakes language testing. He had been given the task of checking the validity and reliability of the English Proficiency Exam and initiating changes if necessary. The other is a faculty member in the English Department, whose area of expertise is Composition and Rhetoric, and who also had experience with second language writers. She had been tasked with coordinating the curriculum for all the sections of the first-year composition course designed for international students. The three of us began our work at Indiana University without any awareness of what the others were engaged in, but, as I began to investigate the ESL curriculum, the necessity for collaboration with these individuals became quickly apparent. This grouping was perhaps fortuitous in that at least one of us had a fairly long history with the program and was familiar with its workings and how it had developed, while the other three were, as mentioned, new to IU, and so they came with totally fresh ideas. Indeed, the faculty member from the English department shared with me two important features: first, she also had recently finished her dissertation and received her $\mathrm{Ph}$. D. and was full of fresh stimulation from her own research, and, second, she was also charged with reconfiguring a program that dealt with non-native English speaking 
students, in her case the previously mentioned Multi-lingual Wi3I classes. Thus, we were in similarly challenging and demanding positions, and found the sharing of our ideas to be immensely fertilizing.

Although other faculty, administrators, and university advisors were occasionally consulted through the review and design process, it was these individuals I sought out most regularly to discuss ideas and swap drafts of curricular documents that shaped the initial formulation of the revised literacy curriculum. This was a period of high energy and enthusiasm with little consideration of complications that implementation would later reveal. The only constraints we labored under were the necessity to design a curriculum with no more than the number of ESL courses previously offered and to make it possible for students to complete these courses in no more than one academic year.

\section{Insights from Second Language and Literacy Acquisition}

Perhaps the greatest amount of time during the first few months of curricular investigation was a review of the literature on second language literacy development in order to provide guiding principles for both the review and potential reshaping of the curriculum. This process was greatly aided by the opportunity in my first semester to teach a course and pursue research on second language adult literacy development. Both activities considerably facilitated establishing the guiding principles for the revision of the curriculum.

Central to the revision of the curriculum was our team's recognition of the reciprocal processes of reading and writing. Several models of the interrelatedness of reading and writing have been proposed in both first language and second language reading and writing research, as well as the relationship between first and second language literacy. Competing models of these inter-related processes emphasize different features and directionalities of influence between them (for a review of these models see Hudson). Generally, however, the models portray both first and second language readers and writers as active participants, using similar complex cognitive processes to construct meaning by drawing on similar knowledge bases (Fitzgerald and Shanahan). Second language learners, like first language learners, select, organize, and connect information with prior knowledge in a specific context using specific strategies to accomplish the goal of meaning-making in both reading and writing tasks. Although there is much about second language literacy yet to be investigated, researchers and teachers alike have indicated 
that it is more productive to concentrate on the similarities between second language reading and writing than on the differences (Eisterhold; Grabe; Zamel) and thus at least avoid "the inefficiencies and arbitrary distinctions that persist when instruction in the two is separated" (Hudson 286).

This insight from the literature suggests a refocusing of attention on literacy development as a unified whole rather than on reading and writing as two separate components. Richard Kern's definition of academic literacy captures this integration. He defines it as contextualized engagement with academic and discipline-based texts through interpretation and production that necessitates and motivates both learning and thinking (I6). This definition does not preclude attention to the linguistic dimensions of literacy but rather gives greater attention to the sociocultural and cognitive/metacognitive dimensions. In other words, the interpretive, collaborative, culturallysensitive, problem-solving nature of working with texts for both readers and writers is of at least as much, if not more, importance than language features and conventions. This is an especially relevant insight regarding second language readers and writers since communicating in another language “often involves shaping one's expression differently, thinking differently, indeed sometimes seeing the world differently" (303). Although theory and research provide substantial justification for integrating reading and writing instruction for second language literacy development, this approach is not as well-established among ESL programs for international undergraduates as it is for domestic basic writers, an increasing number of whom are multilingual. Such may be a consequence of the long history in both ESL and EFL instruction of focusing on discrete language skills rather than literacy, and it may also reflect the history of investigations into second language writing, which tend to follow in time the investigations into first language writing. While it has become common practice in first year composition courses to take a literacy-based or genre-based approach to reading and writing texts, it is still not common in the courses for students who do not yet meet the language expectations of first year composition courses. It is commonly assumed that if students do not have sufficient vocabulary, comprehension, or writing skills, they need to find remedial support in courses focused on these individual weaknesses. This assumption does not consider the varied experiences academically-ready learners have had with a great variety of texts over a long period of time.

A second principle that emerged from a review of the literature is that fluency precedes accuracy in second language development. The concept of fluency is part of the construct of language proficiency accounting for the 
ability to read and write with ease and with a high level of comprehension in reading (Stanovich) and comprehensibility in writing (McGowan-Gilhooly, "Fluency Before"). The development of reading and writing fluency in the first language is a long, incremental process that begins with oracy and continues over many years of schooling with countless implicit and explicit activities around texts. In the case of second language literacy development, the focus instead is often on explicit tasks that emphasize accuracy in comprehension and production of short decontextualized texts, which leads to disfluent reading and writing behaviors. Reading becomes the context for learning individual vocabulary words and writing becomes the context for producing correct grammatical sentences, neither promoting academic literacy.

Support for giving attention to fluency before accuracy in literacy development can be found in several areas. In first language contexts, studies of reading fluency practices such as reading repetition, reading under time pressure, and extensive reading suggest benefits for increasing reading comprehension (National Reading Panel). Less research has been done in second language literacy contexts, but there is also evidence of the positive effects of fluency-building activity on the reading comprehension of second language learners through practices such as extensive reading (Day and Bamford; Grabe). In terms of writing development, expressivist and process orientations, which include such practices as free-writing, journaling, pre-writing, and drafting, support building fluency before attending to accuracy. As Mayher, Lester, and Pradl point out in Learning to Write/Writing to Learn, developing writers can gain a "sense of comfort, confidence and control" when they are given opportunities to express their ideas quickly and continuously without fear of having their incomplete language systems critiqued for inaccuracies (4).

From research on the acquisition of form in a second language, we find evidence for the benefits of developing fluency through meaningful communicative activity before attending explicitly to the accuracy of specific linguistic features (Ellis; Doughty and Williams). In general, early or regular attention to errors has not been shown to change the route or rate of development and often reduces motivation to communicate in the target language. The point is not that language concerns should not be addressed at all in the early stages of second language literacy development, but rather that fluency development should be emphasized. Considering the accuracyoriented English courses most of our students experienced before arriving in the US and at our university, it seemed particularly important to maximize 
ESL Curriculum Revision: Shifting Paradigms for Success

confidence and production by focusing on fluency first in order to motivate literate engagement with texts.

A third research-based insight important to our team is based on investigations of the nature of academic literacy tasks and research on how second language learners negotiate their education in the academy. Second language learners at the university level come with prior experiences, values and knowledge of literacy activity which may contrast significantly with those of US universities. Although it is impossible to define academic literacy as a unified or static phenomenon, a literacy curriculum for second language learners needs to consider academic conceptualizations, purposes, and expected achievements of interacting with texts. Linda Blanton's list of "literate behaviors" and Joan Carson's analysis of tasks typical of three disparate undergraduate majors have both been instructive in coming to understand the discourse community these ESL writers are attempting to join. According to Blanton ("Discourse, Artifacts"), literate behaviors that promote text interactions across the disciplines include interpreting texts in light of personal experience and vice versa, linking texts with each other, synthesizing texts to build new assertions, extrapolating from texts, and creating unique texts through these other behaviors (226). However, the tasks most common to undergraduate education are those that focus on learning-reading to learn, writing to learn, reading and writing to prepare for listening to learn. The demonstrations of learning are most often not in formal research papers or essay tests, but in multiple-choice and short or long answer tests (Carson, "A task analysis"). Arguments for attending to identifiable features of specific disciplinary genre exist, but the disparate goals, experiences, and language abilities of the international students in these courses suggest a more general approach that assists these learners in coming to understand, comment on, reformulate, and generally use reading and writing for learning

We realized that in order to effectively draw from these first and second language and literacy development theories, we needed a compatible teaching methodology. We found this in the long-established approach to English for Academic Purposes of content-based instruction. By engaging learners in sustained language activity around thematically-related texts for the purpose of content learning, this approach to English language development supports the integration of reading and writing, fluency and accuracy development, but in the context of learning a particular content, which is the norm for university courses. Developmental writing classes for native speakers often provide readings from a variety of disciplines and from 
a variety of genre, but, in fact, the content of the courses is still writing. In contrast, content-based instruction for language learners embeds the writing and language instruction into thematic content. Fredricka Stoller contends that by reading in one thematic domain, concepts and language are recycled in such a way that learners build up conceptual and linguistic knowledge with which to read and write more fluently and to think more critically in particular subject areas, which goes beyond the known value of content as a means to keep learners motivated to learn.

Other already implemented curricular models proved to be highly instructive and motivating as well. Two models in particular took on this role during the revision process. The first, the Integrated Reading/Writing program at San Francisco State University, has demonstrated for almost ten years that, by combining reading and writing development as linked processes in literacy development, basic writers not only pass the revised course sequence at higher rates than those in a traditional remediation sequences but also have higher retention rates in and beyond those courses. In designing their curriculum, Sugie Goen-Salter and Helen Gillotte-Tropp made explicit the value of writing as a means to understand texts and the value of reading as a means to understand the choices writers make. Goen-Salter more recently reiterated the purpose of the integrated curriculum as an effort to "break down the barrier between text reception and text production, by inviting students to look at a text they read for clues to its production, and a text they produce for clues to how it might be perceived" (86).

Finally, although fluency has not been a common focus in university ESL or basic writing programs, particularly in regard to reading, the demonstrated success of the Fluency First curriculum at City College New York is a compelling example of how a focus on fluency can benefit pre-academic basic writers, many of whom are not native speakers of English. Adele MacGowanGilhooly ("Fluency First") and her colleagues, in response to persistently low pass rates of ESL and basic writing students on the university's required skills assessment tests in writing and reading, developed a new curriculum by "reversing the traditional grammar-focused approach to ESL and creating a sequence of three courses around the concepts of fluency, clarity, and correctness" (39), an ordering of instructional emphases first posed by Mayher, Lester, and Pradl. What started as an attempt to engage reluctant learners to read, write, and talk about several longer narrative and descriptive texts to build fluency in the lowest level of their basic writing three-course sequence soon extended to a revision of the other two courses around the goals of clarity and accuracy, respectively. Students read extensively, often around 
themes, in each course, but across the sequence the reading focus changed from popular fiction to academic texts and the writing focus moved from personal response to academic argument ("Fluency Before"). The "overwhelming success" in raising the pass rates on the skills assessment test for these students is largely attributed to the "massive amounts of spontaneous language used in the classroom" around reading and writing texts and tasks (45). The focus on fluency first and the sequencing of the three developmental courses in the City College New York program were particularly instructive in redesigning our own curriculum.

Although the bulk of the students in the programs at San Francisco State and City College New York are not international students, the multilingual and diverse literacy experiences they bring are not entirely dissimilar to those of the second language international undergraduates entering Indiana University. One significant difference, however, is that many international students have had very limited oracy experiences in English, thus complicating the development of academic discursive practices. The success of these programs was demonstrated in the pre- and post-test correlations of the students in the different program types. Unfortunately, this method of analysis was not possible at Indiana University since, not only was there no required exit test at the end of the literacy development courses, there was little data on previous students' placement exam results which could be correlated with retention or achievement. Based on the model of these two programs, though, an internal exit exam was designed in the curriculum, so that some measurement of impact could be assessed.

\section{Insights from the Local Context}

Simultaneous to the review of the literature, I gathered information to develop a profile of the current students, the placement exam they took, and the nature of the subsequent first-year composition course our courses were meant to minimally prepare them for. The student profile had begun to change in the middle of the last decade as a result of the university's efforts to recruit a higher number of international students. Without a TOEFL score requirement for undergraduate admission, and the SAT being waived for students in countries where the test was unavailable or the test scores were not trusted, students with a much wider range of English proficiencies from some regions of the world applied and were accepted in considerably greater numbers than in the past. The increasing majority of students who are required to take English language support courses at IU comes from East 
Asia. As a group, these students have in the past been characterized as highly motivated learners, with deep LI content knowledge and literacy, and well developed L2 metalinguistic knowledge, but as less proficient in L2 oral skills and unfamiliar with target culture academic expectations. While these characteristics are better construed as tendencies on continua rather than as givens (Matsuda), the degree of variability along these continua is rapidly increasing when the range of second language experiences of recent international students is taken into consideration. Many more have been studying English since the beginning of their elementary education. Others have been adding test preparation and supplemental courses to their mandatory English language curriculum. Still others have been attending English-medium high schools and colleges in their home countries or in the US and Canada before arriving on university campuses. It is no wonder that this population displays more widely varying oral and literate proficiencies than in the past.

Directly or indirectly, when the old system of courses was still in place, I began to hear faculty and administrators around campus complain about the less than acceptable literacy and oracy abilities of incoming international students in their classes and programs. I was invited to discuss the placement exam and our courses with specific schools or interest groups (i.e. Campus Curriculum Committee, Office of the Vice Provost for Academic Affairs, University Division Advisors) during 2007 and 2008 and the voiced concern was similar: more students seem to need more help with their language skills than in the past. Ongoing conversations with the coordinator of the first year composition curriculum for multilingual writers confirmed these same concerns, and in-class surveys of all the sections of the first-year composition courses for multilingual writers in 2007 and 2008 revealed considerable diversity in learner types by location of prior education, types of proficiency measures taken, and academic literacy experiences. The general proficiency of the learners was also very diverse since the cohort included those who just barely passed the placement exam and those who passed with ease.

As I reviewed the Indiana English Proficiency Exam, it became evident that validity and reliability had to be strengthened necessitating substantial changes in the nature of the exam. Only two components of the exam could be described as performance-based, listening and writing, and yet, even in these two areas, a clear correlation between them and placement in developmental courses was not evident. The writing of a timed 45-minute essay on an argument prompt alone did not provide much information on literacy proficiency for academic purposes, and the listening score did not lead to a course on listening development. The necessary revision of the test fortunately took 
place in tandem with the curricular changes that were starting to take shape. For the rest of the academic year, the high-stakes language tester and I met regularly to discuss the relationship between not only the components of the test and the curriculum but also the assessment criteria for new performance-based components in the test. Much of the discussion and drafting was focused on how to weight criteria and design a scoring mechanism that would combine the results of the multiple-choice reading comprehension component and the holistically-assessed writing component.

\section{The Revised Curriculum}

By Spring 2008, a curriculum was emerging to guide the curricular revision. After numerous drafts with feedback from the review team members and workshops with instructors on the principles and potential practices of the new curriculum, the curriculum was put into the hands of a relatively new cohort of graduate and adjunct instructors in Fall 2008 for implementation. Only one teacher remained who had taught in the previous curriculum although all of the teachers had had experience teaching in developmental writing programs for matriculated students. However, the teachers new to our program had worked previously in programs that took a discrete skills approach to writing development with heavy emphasis on grammatical accuracy. In some sense, this was a new approach for all of them.

Each of the three courses in the sequence emphasizes several aspects of literacy development. First, each level has one underlying literacy goal of fluency, clarity, or accuracy through integrated reading and writing tasks with a variety of texts. Second, the students engage in a range of writing tasks that reflect an increasing degree of cognitive difficulty, beginning with personal responses, followed by paraphrase and summary, and finally with argument and evaluation in persuasive, researched writing. Discussion and writing are used to both comprehend and respond to the texts. Finally, students are engaged in a multi-draft writing process at every level, with peer and teacher feedback. Each of these courses meets for Ioo minutes, twice a week for an eight-week period of time.

In the first level course, Academic Literacy Development I, it is not uncommon to find ESL learners who have never read a complete English text of more than a few paragraphs and who have never written a single text of more than a few paragraphs in English. Since the primary goal of this course is to increase the students' fluency in reading and writing, they are encouraged to make connections between their own experiences and those expressed in 
narrative and descriptive texts and to attempt to get a sense of the authors' voice and intentions. A daily ten-page reading requirement, along with freewriting to guided prompts in the first ten minutes of the twice-weekly class, presses the students to build reading and writing speed while maintaining a high level of comprehension and comprehensibility although not necessarily lexico-grammatical accuracy. The means by which these goals are addressed include reading and discussing two primarily narrative full-length English texts, which currently are Tuesdays with Morrie (Albom) and A Walk Across America (Jenkins). The universal themes of identity, relationships, and transitions motivate student participation in class. In addition to three in-class essays and shorter writing practice activities, they produce two longer papers, one narrative and the other descriptive, through a multi-draft process with peer and instructor feedback.

Since the majority of students needing ESL literacy courses initially test into the second level, Academic Literacy Development 2, the goals of helping students to gain confidence in their second language literacy and to increase awareness of American university literacy expectations remain the same as in Academic Literacy Development I. However, now the learners focus more on clarity through careful paraphrasing and summarizing of both fiction and non-fiction texts, paying more attention to capturing the intentions and arguments of the authors rather than responding personally. Faithfully reporting the ideas of others is foundational to many types of academic writing, in particular research writing. In Academic Literacy Development 2, students read one novel and several genres of literary and expository texts, such as speeches, poetry, news reports, and journal articles, as well as multimedia resources such as podcasts and videos that follow-up on many of the themes and topics of the novel. The novel currently in use, A Lesson Before Dying (Gaines), provides links among the various genre of reading and writing in the course while building knowledge and understanding of American history and culture. Since for many students, this is the first course they are required to take in the literacy sequence, free-writing on assigned topics related to the readings, several in-class essays, and a multi-draft approach to writing projects are again the means by which to build up fluency and to generate ideas for writing.

Students who test into the highest level of the sequence, Academic Literacy Development 3, have generally demonstrated fluency and clarity in their reading and writing skills. However, the presentation of their ideas is limited in sophistication, particularly due to limited evidence and support and to the lack of accuracy in language and expected writing conventions. 
In other words, if the linguistic errors were overlooked or mentally corrected while reading a student's writing, the reader would find a relatively coherent text with an articulated purpose and some organization but insufficient development and formal accuracy. In terms of reading, these learners can determine the general meaning and components of an argument but have less facility with implicit meanings and complex argumentation. Attending to accuracy includes using appropriate rhetorical moves, relevant and supportive evidence from multiple academic sources while avoiding plagiarism, more varied vocabulary, a wider range of grammatical structures, and following a particular style sheet.

The means by which these goals are addressed include daily reading assignments from a full-length non-fiction text on a theme, numerous nonfiction articles on related topics, and the student-selected articles needed for the researched paper related to the theme. A popular topic that has generated much public debate is particularly useful for helping students to develop skills in evaluating the credibility and usefulness of multiple sources since it is relatively easy to access reliable material at a range of reading levels through university databases and the internet. The current topic in use is climate change with the text Our Choice (Gore). By investigating the rhetorical moves the author uses to present a position and persuade the reader, the students prepare to use multiple sources to argue a position on a related topic. The use of these sources provides the context in which to address concerns of plagiarism and the use of appropriate citation. As in the other levels, fluency activities and in-class essays are included, but more attention is spent on achieving formal accuracy in the multi-draft writing process.

\section{Evaluation of the New Curriculum}

As noted, Indiana University does not require an exit exam for students taking these required ESL developmental courses. Thus, it has not been possible to make comparisons of student outcomes between the previous and current curricula. Nonetheless, four semesters of placement and end of session in-class essay data, the first year composition grades of students who have completed at least one literacy development course, end-of-session student interviews, and teacher interviews, provide evidence to suggest some real and perceived benefits of the new curriculum.

The student data included in this analysis was drawn from students who had an English proficiency writing test score from the beginning of a particular semester and a final in-class essay for that same semester. Ideally, 
we would have been able to administer both the reading and the writing components of the placement exam and combine their scores as we had in the placement exam at the beginning of the semester, but this was precluded by time, expense, and the need to avoid over-exposure of the small number of reading test forms. The in-class essays were administered as part of the final exam for the course by the course instructor and then rated by trained and recalibrated raters from the same pool used for the placement exam. Every essay was read by two raters, and, if they did not agree on a score of one to five, a third (or fourth) rater also read the essay to assure that at least two raters gave the essay the same score.

Without comparative data from the old curriculum (before the Fall of 2008), strong claims for the efficacy of the new curriculum cannot be made. However, the data suggest that the curriculum does promote writing development. The aggregate results for each semester of the 2008-o9 and the 2009-Io academic years are presented in Table I.

Table I. Aggregate Comparison of Placement and In-class Holistic Writing Score for 2008-20I0

\begin{tabular}{|l|l|l|l|l|}
\hline & $\begin{array}{l}\text { August }^{\mathrm{a}} \\
\text { IEPE }\end{array}$ & $\begin{array}{l}\text { December } \\
\text { In-Class Essay }\end{array}$ & $\begin{array}{l}\text { January } \\
\text { IEPE }\end{array}$ & $\begin{array}{l}\text { May } \\
\text { In-Class Essay }\end{array}$ \\
\hline $2008-2009$ & $\begin{array}{l}2.35^{\mathrm{b}} \\
(\mathrm{N}=94)\end{array}$ & $\begin{array}{l}3 \cdot 7 \mathrm{I} \\
(\mathrm{N}=94)\end{array}$ & $\begin{array}{l}2.55 \\
(\mathrm{~N}=29)\end{array}$ & $\begin{array}{l}3 . \mathrm{I} 4 \\
(\mathrm{~N}=29)\end{array}$ \\
\hline $2009-2010$ & $\begin{array}{l}2.6 \mathrm{I} \\
(\mathrm{N}=\mathrm{I} 64)\end{array}$ & $\begin{array}{l}3.48 \\
(\mathrm{~N}=\mathrm{I} 64)\end{array}$ & $\begin{array}{l}3.00 \\
(\mathrm{~N}=\mathrm{I} 5)\end{array}$ & $\begin{array}{l}4.33 \\
(\mathrm{~N}=\mathrm{I} 5)\end{array}$ \\
\hline
\end{tabular}

${ }^{\text {a }}$ Note: Most international students enroll in the Fall semester.

${ }^{\mathrm{b}}$ Note: All results are statistically significant (Paired T-test: $\left.\mathrm{t}<0.000\right)$.

The grade distribution in the first year composition course between those who went immediately to this course and those who took one to three ESL literacy development courses was less similar in the first year of implementation than in the second, but in both cases, the students who were exempt from the ESL received more As and withdrew less frequently (see Table 2). However, the fact that the students who had to take ESL courses achieved a grade of $\mathrm{B}$ or better to the same degree as the exempt students is encouraging. Although the GPA mean for the first year composition course is higher for the ESL-exempt students (3.05 and 3.7) than the ESL-required students (2.65 and 3.I5), the ESL-required students are holding their own. 
ESL Curriculum Revision: Shifting Paradigms for Success

Table 2. Grade Distribution of ESL-Exempt and ESL-Required Students in First Year Composition for Multilingual Writers

\begin{tabular}{|l|l|l|l|l|}
\hline & \multicolumn{2}{|l|}{$2008-2009$} & \multicolumn{2}{l|}{ 2009-2OIO } \\
\hline & $\begin{array}{l}\text { ESL-Exempt } \\
(\mathrm{N}=\mathrm{IO} 7)\end{array}$ & $\begin{array}{l}\text { ESL-Required } \\
(\mathrm{N}=79)\end{array}$ & $\begin{array}{l}\text { ESL-Exempt } \\
(\mathrm{N}=\mathrm{I} 32)\end{array}$ & $\begin{array}{l}\text { ESL-Required } \\
(\mathrm{N}=\mathrm{I} 38)\end{array}$ \\
\hline A & $46.73 \%$ & $\mathrm{I} 8.99 \%$ & $44.70 \%$ & $34.06 \%$ \\
\hline B & $33.64 \%$ & $5 \mathrm{I} .90 \%$ & $43.18 \%$ & $42.75 \%$ \\
\hline C & $7.48 \%$ & $\mathrm{I} 6.46 \%$ & $9.09 \%$ & II.59\% \\
\hline D & $\mathrm{I} .87 \%$ & $\mathrm{I} \% 27 \%$ & $2.27 \%$ & $2.17 \%$ \\
\hline F & $2.80 \%$ & I.27\% & $0.76 \%$ & I.45\% \\
\hline W & $7.48 \%$ & IO.I3\% & $5.30 \%$ & $7.97 \%$ \\
\hline
\end{tabular}

The results of oral interviews with students and teachers over the same semesters also suggest the curriculum is promoting literacy development. Eighty-seven students enrolled in literacy courses in Fall 2009 volunteered to be interviewed regarding their experience. To a person, they all reported high levels of satisfaction with the course in which they were currently enrolled. They generally reported improvements in their writing both in speed and quality and a higher reading speed with comparable or better comprehension than before the courses began.

In each level, when asked which task was most beneficial for them, the students mentioned the free-writing activity:

Student \#2 (Japanese) Academic Literacy Development I

I think free writing is good cause we can think by ourselves, no stress. I never thought how to improve writing skill before, but now I respond freely to reading in writing.

Student \# 45 (Korean) Academic Literacy Development 2

It kind of really helped me a lot cause in a free-writing I wrote like IIo in Io minutes, but later I could write like 3 Io in Io minutes... Writing enough amount of English will help me in my courses, to write a lot of essays...Quality is definitely better...I have all my writings with me and I've read it and now it's totally different. I guess the reason for that is I read, we read in class, cause usually in high school I didn't read any English books, but in Level 2 there was 
book to read that we have to read, so after reading the novel, cause to read a lot you have more to say... I couldn't believe that I could write this well compared to the time when I came here.

\section{Student \#25 (Chinese) Academic Literacy Development 3}

I really like the part of Level 3 is free-writing. That's a really good part. I think like, sometimes you don't know what to right down like even though when you start a paper, you know, like, I have no focus point, whatever, I don't have it organized so far, and even free-writing for a couple of minutes you can find out some really good points. That's a really good thing, and free-writing you can do it all the time, like every day. It's not a great deal and you are training your writing skill. You will like improve it is better for your thinking your thought. That's a great deal of fun. I like that one... I also use free-writing in my other classes now.

Writing faster was stated as the most notable indication of improvement, but when pushed to elaborate on why writing faster was of value, students indicated writing faster would help them considerably in other university tasks such as written exams and papers in other classes. However, additional benefits were mentioned, such as "thinking free" (Student \#2), "better quality" (Student \#45), and "find out some really good points" (Student \#25).

Students in Academic Literacy Development I noted additional benefits in being able to read more quickly, to focus on the main point, to describe a person's emotions, and to think "by ourselves." The comments by Student \#I5 are representative of these benefits:

\section{Student \# I5 (Chinese)}

Before I learned Level I my teachers focus on grammar and after Level I the most of things I many by myself because I read a book and then write a journal, write what about what did I thought, what did I think and then I am in the book and I can feel how the author feel, yeah, and I think it is very useful because I am not only read the wonderful story but I learn the grammar and some vocabulary...I think I read the story carefully and slow because I want to feel what the author's feel and I think read more quickly now compared to before. 
ESL Curriculum Revision: Shifting Paradigms for Success

In Academic Literacy Development 2, most of the students mentioned the value of free-writing for writing and thinking faster, as in the following example:

\section{Student \#I9 (Hindi)}

If you consistently do your free-writes, you develop your confidence in writing your thoughts down and that will help you in all your writing...Register, content, format...actually the very basic writing techniques have improved papers in my other classes.

However, at this level, one-third of the students made specific reference to improvements in reading comprehension, as represented in the next example:

\section{Student \#29 (Mon, Burmese)}

When we are reading, when I get a novel, I want to know everything. I can't be patient, so I don't want to eat or do anything, I just want to read the book, but in this class, well, what we do, after each 8 or Io pages, we have to stop and then write a journal, one page of journal, so it's really difficult for me at first time because I don't want to stop. I want to know what happens ahead, but I had to do that. I had to push myself to stop and think about it really think about the details, and so it has really improved me from other courses because that's what other instructors want. I mean they want you to think about it after you read it. I think it changed me that.

Additionally, ten of the twenty-one respondents noted improvement in the organization of their writing, from "arrangement of the parts of the paper" (Student \#9), to "make it more clear" (Student \#29), to providing "more detailed content" (Student \#5). Eight of the twenty-one respondents made specific reference to how the reading and writing skills and strategies developing in the academic literacy course were helping them in other courses they were taking.

In Academic Literacy Development 3, fifty-six of the sixty respondents noted improvement in how to write a research paper. These comments ranged from being "more logical" (Student \#58) and having "better coherence of points" (Student \#I8), to "how to use example to support main idea" (Student \#35), and "how to quote, cite, APA form" (Student \#32). The following two examples illustrate some of these features: 
Student \#I8 (Cantonese)

In ESL class [before] we write essay but not research. We write on own topic and our own idea....This class really help me to write more...I was trying to write long papers but even when page limit was two pages I feel difficult, now every time I write five pages. This class is really teaching me how to write a paper after reading something... and how to use that so somehow if you use someone else's work and use their idea to prove your idea it's a better paper. It's all about evidence and strong points.

\section{Student \#56 (Chinese)}

Purpose is to go over the important writing process, revising, how to avoid plagiarism, research and college level academic writing... I never studied how to use APA style...also in-class essay guide was very helpful before that I didn't know how to write in-class essay. I made progress especially in writing, I was writing really slow before that but when I take this class I had to do free-writing and it helped improve by writing speed and build up the habit to revise my papers.

The mention of the writing process and revising in the previous example is not found in the comments of students in the first two levels of the literacy sequence, but about one-third of the respondents at this level make some reference to the fact that "revising can help the paper" (Student \#30).

It is possible that only those students who were happy with their courses elected to be interviewed although all students were offered one percent extra credit for participating in the interviews. Nonetheless, it is evident that many students value what they are learning, see improvements in their abilities, and feel more confident about their literacy activities in English.

A second source of evaluation comes from self-reports of teachers in the ESL courses. These instructors report noticing differences between those students who have completed more than one level in the sequence and those entering at a higher level. The continuing students demonstrate greater confidence, better writing ability, and a clearer understanding of university tasks and performance expectations:

If I could generalize, the students who start in Level One and are now in Level Three have lower general English proficiency but better academic skills, and the students who start in Level Three have 
ESL Curriculum Revision: Shifting Paradigms for Success

higher English, but their academic skills are not as good...We joke [that] we teach following instructions. And in Level One and Two, they kind of get that academic expectation down, and by the time they get to Level Three, they read the assignment sheets. The people who come in...they have some fluency, but not the skills to apply it. (ESL Teacher Interview, March 2009)

Teachers have also noted that students who have taken at least one or more literacy development course have developed a vocabulary for talking about reading and writing that indicates their increasing participation in a "literacy community." In regard to students who had completed the first course and were entering the second, one teacher commented:

It was a really smooth transition...I felt like the academic, or the literacy community is really important. I've just noticed...we have better discussions in class. I think their writing has tended to be more responsive.... They were all very comfortable and I think they were more enthusiastic and better able to respond to the book. We were able to get started writing right away without whole lot of explanation and just sort of the sense of this is what we do, we read and write together....They seemed to have very good control over both of those and the connection between the two, and like it was they had no problem telling me what they needed. (ESL Teacher Interview, May 2009).

Finally, interviews with instructors of the first year composition course for multilingual writers also indicate that with each successive ESL literacy course, teachers find it easier to work with these students because they are already familiar with the language and practices of interacting with texts, a multi-draft writing process, the literacy expectations of the university, and both the confidence and vocabulary for addressing their ongoing literacy development needs. This puts them at an advantage in comparison with the international and sometimes domestic long-term English learners for whom this is the first contact with university writing. As one teacher noted:

Ever since the [literacy] courses have been revised, I've definitely noticed my students who have taken them have been much better prepared for WI3I. It's a huge leap because I remember thinking that the students who had taken the old version of those classes 
were still noticeably behind the others, as opposed to now, when many of them are actually better prepared than their classmates (First Year Composition, WI3IML instructor, Email communication, September 2009).

Another indicated that there is much greater variation among the students who enter WI3I directly without [ESL-literacy] coursework in terms of proficiency and experience with university literacy tasks whereas the students coming from [the third course] "fluently navigate through my class" (WI3IML instructor interview, June 20I0). Since there had been no articulation of the developmental ESL courses with the first year composition courses in the past, and the teaching cohorts of both programs are constantly in flux with graduate students coming and going, it is impossible to get an in-depth comparative analysis of the old and new curricula from the faculty.

\section{Discussion}

The implementation and investigation of this curriculum is ongoing, but the initial data from student tests and grades as well as the perceptions of students and teachers has been gratifying. By engaging in the literate behaviors of comprehending and responding to specific texts, the students' reading and writing activities remain integrated. By emphasizing fluency and clarity before accuracy, the students' work with texts increases in purpose and focus. However, there are ongoing challenges in implementing this curriculum.

For many students, this is a novel approach to language development and one that does not seem to match with their previous expectations for reducing what they often believe to be their biggest limitation, lexicogrammatical accuracy. The request for more grammar instruction is often heard when students first begin one of the courses. Convincing them of the efficacy of our approach is a challenge, but the fact that students report such satisfaction with the fluency activities and with learning how to use sources is encouraging.

The grade distributions of international students in the first year writing course for multilingual writers show that all of the second language international students still have to work hard at comprehending complex academic texts and producing linguistically clear and accurate papers in English. However, from the teachers' perspectives, the students who have 
ESL Curriculum Revision: Shifting Paradigms for Success

taken the ESL literacy courses have developed strategies for talking and working with academic texts such that working with these students goes more smoothly.

The student and teacher interviews suggest a number of ways in which the courses might be strengthened. Quite a few students indicated that they thought more discussion about the reading texts, particularly in the final literacy course, would have promoted not only their comprehension but also their ability to formulate their points of view for writing. A number of students also thought that more individual conferencing with the teachers about their writing would be beneficial.

Creating continuity through the sequence and equity among the many sections of each level is also a challenge. The cohort of teachers, advanced graduate students and adjuncts, is not static, and they each bring their own literacy beliefs and established practices, which significantly influence their teaching decisions. The regular workshops and semi-structured interviews with the teaching cohort have revealed that, in spite of regularly referring to the guiding principles, rationale, and suggested objectives and means, the teachers struggle to sufficiently promote fluency in reading and writing before attending to concerns of accuracy. It has also been difficult to assure equity across the many sections of a particular level in terms of the number and difficulty of supplemental texts, the quantity of reading and writing, and in the expectations of student outcomes in spite of the curricular documents which provide guidelines for each of these features. Another challenge for the teachers is to choose from among the many possible literacy engaging activities they have used in the past. Some of these choices become easier once a teacher has taught at least two of the three courses in the sequence and is able to see development over time. Even when the teachers understand this trajectory intellectually, it remains a challenge to not over-engage and respond to every literacy event. Some teachers find it extremely difficult when first teaching in Academic Literacy Development I, for example, not to correct sentence level errors and only respond to meaning of a comprehensible but very poorly written free-writing or journal response from a student.

In order to create continuity for the program, the teachers meet regularly each semester to discuss the courses, and make occasional adjustments in both the desired outcomes of each course and the means to accomplish them. For example, after the first semester, it became clear that too much writing and too great a variety of texts for reading were expected in the second and third courses in the sequence. Through collaboration, the teachers have reshaped the writing assignments in the second course into a series of 
shorter tasks that each support research writing, such as separate paraphrasing, summarizing, and citing sources projects, and have dropped the full research paper assignment, which then became the primary assignment of the final course. In addition, the final course has reduced the scope of the research paper assignment in order to allow for more attention to accuracy in revising and editing.

Logistically, implementation of the curriculum has not been flawless, particularly on the administrative side. University advisors were accustomed to only recommending these courses to the new students, and while there was a relatively high degree of compliance, there were students who figured out how to avoid them, and advisors were not responsible to follow up on students' actual registrations. Now the courses are required, and if a student has to take all three literacy development courses, it is impossible to complete the sequence in one semester. The long-held assumption that all required ESL literacy development courses must be completed before enrolling in first year composition is now being enforced. This now causes students to take the initial composition requirement in their second year. Particularly for transfer students, pushing this requirement into their second year at the university conflicts with the time/course requirements for applying to some majors, such as business, which is the stated desired major of up to 90\% of the new international students. There have been some very frustrated advisors and some very distraught students through this initial implementation period, but these issues have mostly been resolved. Better and regular communication between our department and university advisors has mitigated some of the frustration. The support of academic units for consistent tracking of student compliance and the modification of university computing systems to provide advisors with immediate information regarding student compliance have also reduced confusion and frustration.

The administrative kinks are getting worked out, but it is the curricular impact on student learning which is of far greater importance. Although the evidence thus far gives us some reason to be optimistic, it is impossible to know the full extent of how these courses or what elements in them benefit the learners most. Nonetheless, the instructors have expressed confidence and enthusiasm for the principles and practices of the curriculum, and most students have demonstrated development in academic literacy and expressed enhanced confidence to continue successfully in their university studies. 


\section{Acknowledgements}

My unofficial team, Sunyoung Shin, Tarez Graban, and Paul Russell, supported this curricular revision process, and me personally, in countless ways. All success is to their credit, all else I take responsibility for. Without the energy, creativity, and commitment of the teachers, Lynn Allen, Anne Marie Guerrettaz, Susan Kinnaird, Tom Lewis, Paul Russell, Suzanne Valade, Vit Vanicek, and Tara Zahler, the best intentions of the curriculum would have been unrealized. Hundreds of students and I are grateful for their hard work. I would also like to thank Craig McDonald in University Division for providing necessary data, Kathleen Bardovi-Harlig, Paul Russell, and Heidi Vellenga for comments and suggestions on early drafts, and $J B W$ reviewers and editors for feedback that brought this article to publication.

\section{Works Cited}

Albom, Mitch. Tuedays with Morrie. New York: Random House, I997. Print. Blanton, Linda L. "Discourse, Artifacts, and the Ozarks: Understanding Academic Litearcy.” Negotiating Academic Literacies. Eds. Vivian Zamel and Ruth Spack. New York: Routledge, I998. 219-36. Print.

Brinton, Donna M., Marguerite Ann Snow, and Marjorie Wesche. Content-Based Second Language Instruction. Ann Arbor: Michigan UP, I989. Print.

Carson, Joan G. "A Task Analysis of Reading and Writing in Academic Contexts." Linking Literacies: Perspectives on L2 Reading-writing Connections. Eds. Diane Belcher and Alan Hirvela. Ann Arbor: Michigan UP, 2001. 48-83. Print.

. "Reading For Writing: Cognitive Perspectives." Reading in the Composition Classroom: Second Language Perspectives. Eds. Joan G. Carson and Ilona Leki. Boston: Heinle \& Heinle, I993. 85-IO4. Print.

Day, Richard, and Julian Bamford. Extensive Reading in the Second Language Classroom. New York: Cambridge UP, I998. Print.

Eisterhold, Joan C. "Reading-writing Connections: Toward a Description for Second Language Learners." Second Language Writing: Research Insights for the Classroom. Ed. Barbara Kroll. New York: Cambridge UP, I990. 88-IOI. Print.

Ellis, Rod. "Current Issues in the Teaching of Grammar: An SLA Perspective." TESOL Quarterly 40 (2004): 83-IO7. Print. 
Doughty, Catherine, and Jessica Williams. "Pedagogical Choices in Focus on Form." Focus on Form in Classroom Second Language Acquisition. Eds. Catherine Doughty and Jessica Williams. Cambridge: Cambridge UP, I998. I97-26I. Print.

Fitzgerald, Jill, and Timothy Shanahan. "Reading and Writing Relations and Their Development." Educational Psychologist 35 (2000): 39-50. Print.

Gaines, Ernest. A Lesson Before Dying. New York: Random House, I993. Print.

Goen, Sugie and Helen Gillotte-Tropp. "Integrating Reading and Writing: A Response to the Basic Writing 'Crisis'." Journal of Basic Writing 22 (2003): 90-II3. Print.

Goen-Salter, Sugie. "Critiquing the Need to Eliminate Remediation: Lessons from San Francisco State." Journal of Basic Writing 27 (2008): 8I-IO5. Print.

Gore, Al. Our Choice. New York: Rodale Publishing, 20Io. Print.

Grabe, William. "Reading-writing Relations: Theoretical Perspectives and Instructional Practices." Linking Literacies: Perspectives on L2 Readingwriting Connections. Eds. Diane Belcher and Alan Hirvela. Ann Arbor: Michigan UP, 200I. I5-47. Print.

_. "Research on Teaching Reading." Annual Review of Applied Linguistics, 24 (2004): 44-69. Print.

Hudson, Thom. Teaching Second Language Reading. New York: Oxford UP, 2007. Print.

Jenkins, Peter. A Walk Across America. New York: Harper Paperbacks, 200 I. Print.

Kern, Richard. Literacy and Language Teaching. New York: Oxford UP, 2000. Print.

MacGowan-Gilhooly, Adele. "Fluency Before Correctness: A Whole Language Experiment in College ESL.” College English I (I99I): 37-47. Print. . "Fluency First: Reversing the Traditional ESL Sequence." Journal of Basic Writing IO (I99I): 73-87. Print.

Mayher, John S., Nancy Lester and Gordon M. Pradl. Learning to write: Writing to learn. Upper Montclair: Boynton/Cook Publishers, Inc., I983. Print.

National Reading Panel. Report of the National Reading Panel: Teaching Children to Read: An Evidence-based Assessment of the Scientific Research Literature on Reading and Its Implications for Reading Instruction. Bethesda, MD: U.S. Dept. of Health and Human Services, Public Health Service, National Institutes of Health, National Institute of Child Health and Human Development, 200o. Web. Io May 2008. 
ESL Curriculum Revision: Shifting Paradigms for Success

Stanovich, Keith. Progress in Understanding Reading: Scientific Foundations and New Frontiers. New York: Guilford, 200o. Print.

Stoller, Fredricka. "Promoting the Acquisition of Knowledge in a Contentbased Course." Content-based Instruction in Higher Education Settings. Eds. Jo Ann Crandall and Dorit Kaufman. Alexandria, VA: TESOL. (2002): I25-I38. Print.

Zamel, Vivian. “Writing One's Way into Reading.” TESOL Quarterly 20 (I992): 463-85. Print. 


\title{
How Antonio Graduated On Out of Here: Improving the Success of Adult Students with an Individualized Writing Course
}

\author{
Michelle Navarre Cleary
}

\begin{abstract}
Adult students are more anxious about writing for school, less familiar with academic conventions, and more likely to drop out than younger students. For students learning to move between personal, work, and academic discourse communities, the ongoing and explicit writing instruction argued for in the research of Sternglass, Herrington and Curtis, Carroll, and Beaufort is particularly vital. Writing Workshop at DePaul University's School for New Learning is one model for providing this instruction. The course works for students with a broad range of learning styles, prior knowledge, needs, and goals because it is individualized and because it is focused on developing writers rather than on teaching specific kinds of writing. It is open to any student struggling with writing, from incoming basic writers to seniors stuck on final projects. Writing Workshop has improved access for and the retention and success of our adult students. This article shows the need for a class like Writing Workshop, explains how it works, discusses challenges, and describes the experience of the at-risk, nontraditional, adult students in one Writing Workshop class.
\end{abstract}

KEYWORDS: access, adult students, basic writing models, individualized instruction, metacognitive skills, nontraditional students, retention, student success, transfer

I thought that I would not ever finish my degree. - Antonio ${ }^{\mathrm{I}}$

Over seven years after he started college, Antonio became the first college graduate in his family. Antonio's success is all too rare for the $40 \%$ of college students who are older than 24 ("Table I9I") and the $73 \%$ of undergraduates identified as "nontraditional" by the National Center for Education Statistics (NCES) (Choy I-3), where NCES defines nontraditional students as having one or more of the following seven characteristics: "financial independence, part-time attendance, delayed enrollment, full-time work,

Michelle Navarre Cleary is Assistant Professor and Writing Coordinator at DePaul University's School for New Learning, where she developed a writing program for adult students. Previously, she was an Assistant Professor at Olive-Harvey College, a community college on Chicago's far south side. Her research interests focus on understanding the writing development and improving the teaching of adult students.

(C) Journal of Basic Writing, Vol. 30, No. I, 20II 
dependents, single parenthood, and lack of a high school diploma" (Choy II). Antonio was a financially independent, part-time student, and full-time employee who helped support his younger siblings. Like Antonio, most adult students have more than one of the NCES characteristics of nontraditional students. Like many adult students, Antonio almost did not graduate. By the fall of 2009, he had spent two quarters, and much of his two faculty advisors' patience, trying to write a final project that he did not understand how to approach. That fall, he was one of five students in my Writing Workshop class - a class designed to meet the needs of incoming basic writers as well as students like Antonio who were struggling with advanced writing tasks.

Writing Workshop provides students who need the structure and credit hours of a course with individualized writing instruction at any point in their studies. Developed in response to specific local conditions, Writing Workshop offers a flexible way to support basic writers across the curriculum. It is grounded in research that demonstrates both the importance of writing support for retaining incoming adult students and the necessity of ongoing, direct writing instruction for all students. By providing this direct instruction and coaching students on how to use self-assessment and feedback on their writing, the course has improved the success of our adult students as they move between personal, work, and academic discourse communities.

\section{ADULT AND NONTRADITIONAL LEARNERS IN THE WRITING CLASSROOM}

Study after study shows that students complete college at lower rates than their peers if they are 25 or older (Murtaugh, Burns, Schuster 368; Swail I8-I9; McGivney 35), they are financially independent (Hoachlander, Sikora, Horn 60; Choy I8), they attend school part-time (United States; Adelman xxi; Pusser et al. 5; Hoachlander, Sikora, Horn 6o; Choy I8; Swail 2I), they did not enroll in college immediately after high school (United States; Adelman xx; Hoachlander, Sikora, Horn 60; Choy I8), or they work fulltime (Pusser et al. 5; Hoachlander, Sikora, Horn 60). Half of nontraditional students with four or more of the seven NCES characteristics will drop out within three years of enrolling in school for a bachelor's degree (Choy I2I3). Half with just two NCES characteristics will drop out within six years of enrolling (Swail I9). Like Antonio, many adult and nontraditional students are also first-generation students. Stunningly, first-generation students are 
7I\% more likely to drop out in their first year of college than students with two college-educated parents (Ishitani 433). The first year is pivotal for both nontraditional and adult students. Nontraditional students are most at-risk of dropping out in their first year (Choy I7), while early academic success is a crucial factor in adult students' decision to remain in school (Smith 76-77).

Given that returning students are more anxious about writing than younger students (Krause 208; Wiant II-2I, 4I-45; Sailor ix), providing them with early support for their writing is vital. For example, Gretchen Starks identified "writing and writing assignments" as a recurring theme in the decisions of adult women to stay in or leave school (3). Starks conducted in-depth interviews with seventeen "outlier" students who had either persisted despite being identified as at-risk or dropped out despite being identified as likely to graduate. Her goal was to nuance findings from large-scale quantitative studies that ignore these outlier cases. What she found was the important role writing played in persistence. Students who persisted, although they had low prior academic achievement and often difficult personal and financial situations, valued writing assignments in which they were asked "to explore their feelings, thoughts and goals" and that "helped them develop more self-confidence and awareness of their strengths and weaknesses" (Starks 5, 3). Students who did not persist, even though they had been identified as being at low risk of dropping out, "felt writing was a barrier to their ability to continue in college" (Starks 3).

Students learn to negotiate this barrier when they receive coaching on how to recognize and respond to the "contrasting and sometimes conflicting demands" of college writing assignments (Herrington and Curtis I6). Coaching includes explicit instruction that helps students analyze and address these demands. Longitudinal studies by Marilyn Sternglass, Anne Herrington and Marcia Curtis, Lee Ann Carroll, and Anne Beaufort argue that explicit instruction is needed by all students, traditional and nontraditional, throughout their time in college. Sternglass's six-year longitudinal study of nine CUNY students demonstrates that students develop as writers slowly and "neither neatly nor linearly" (xiv). She argues that "the expectation that students have become 'finished writers' by the time they complete a freshman sequence or even an advanced composition course must be abandoned" (296). Sternglass's findings are echoed by Herrington and Curtis, Carroll, and Beaufort. All of these studies show students challenged by the "truly dizzying array of writing assignments and teacher expectations about them" that students encounter "from their first semester to their last" (Herrington and Curtis 387). All conclude that students develop as writers and as 
thinkers when they receive coaching throughout their time in college that includes explicit instruction on how to respond to the variety and increasing complexity of the writing tasks they encounter.

Explicit instruction is all the more important for adult and nontraditional students. Adults are often anxious and confused about academic writing because of prior writing experiences in and out of school. From earlier schooling, many adults bring the scars of negative writing experiences (Fredericksen II6; Wiant I5; Wittman; Cox and Ebbers 354). From work and other activities, they can bring writing habits and assumptions that do not serve them well in school (Gillam; Popken; Castaldi). These students need not only encouragement but also coaching on how to recognize and move between their different discourse communities. As Teresa Lillis has shown, teachers frequently assume knowledge of academic writing conventions that nontraditional students do not have, effectively excluding them from academic literacy. She argues "that confusion is so all-pervasive a dimension of their [the students'] experiences as a group of 'non-traditional' students in higher education that it signals the need to look beyond a notion of individual confusion, towards an ideologically inscribed institutional practice of mystery" (Lillis I4). To address this confusion, Lillis calls for explicit instruction on the conventions of academic writing.

In addition to providing explicit writing instruction, coaching also prepares students to manage their own ongoing development as writers. The goal, as Beaufort states, is to teach "with an eye toward transfer of learning" in order to "set students on a course of life-long learning so that they know how to learn to become better and better writers in a variety of social contexts" (7). In each of the longitudinal studies, students are shown to find little connection between what they may figure out about academic writing in one class and what they are asked to do in the next. Carroll bluntly dismisses what she calls the "faculty fantasy" that academic writing is a discrete, unified, and easily transferable skill. She shows that, "Lessons learned in first-year writing courses do not directly transfer to students' work in their major areas of study" (9). Therefore, "Instead of mastering one particular style of writing, students needed to develop flexibility as writers, especially the ability to analyze different rhetorical situations and adapt writing strategies accordingly" (I3I). Carroll demonstrates that developing these meta-cognitive skills is as important for advanced writers as it is for beginners (I2I). Based upon her review of research on transfer and the findings of her study, Elizabeth Wardle has also concluded that, "meta-awareness about writing, language, and rhetorical strategies in FYC may 
be the most important abilities our courses can cultivate" (82). Beaufort adds that students need to analyze discourse communities and genres to transfer their knowledge and develop writing expertise. She argues that, "novice writers usually get little instruction in how to study and acquire the writing practices of different discourse communities" (II). This instruction is particularly useful for adults, who sometimes literally write in multiple discourse communities simultaneously as they use their lunch hour to squeeze in work on a school paper while responding to personal and work emails. Moreover, that school paper might be the first academic paper the student has written in over a decade, and it may well be for a course in the student's major.

Coaching to provide both direct writing instruction and teach learners to manage their own ongoing writing development informs the pedagogy of Writing Workshop. Both Beaufort and Carroll use "coaching" to describe the explicit instruction they are advocating. In their seminal study of expert performance, K. Anders Ericsson, Ralf Th. Krampe and Clemons Tesch-Römer argue that expertise is achieved through deliberate practice and that coaching is required for practice to be deliberate. As Ericsson, Krampe, and TeschRömer explain it, coaches create the conditions for deliberate practice by structuring learning that takes into account and builds incrementally from prior knowledge, by providing "individualized diagnosis" and "immediate informative feedback," by presenting learners with "alternative strategies" when they are stuck, and by teaching learners to self-assess and "proactively seek out alternative strategies" so that they can learn to coach themselves $(367,372)$. In Writing Workshop, instructors provide direct instruction in response to the writing challenges students encounter across the curriculum. Instructors also scaffold new learning that builds upon each student's prior knowledge, provide feedback that identifies individual strengths and challenges, teach multiple writing process strategies so students have a variety of ways to get themselves unstuck, and provide students with opportunities for and feedback on self-assessment.

\section{THE SCHOOL FOR NEW LEARNING:} A SCHOOL FOR ADULT LEARNERS

Writing Workshop is grounded not only in the research of Composition and Rhetoric, but also in the approach to adult learning at The School for New Learning (SNL). SNL is a liberal arts college for students 24 years old 
or older that is part of DePaul University (DPU), a private, tuition-dependent, non-profit urban university. The average age of our 3,200 active students is 40, two thirds are women, and 90\% attend school part-time (Benedetto et al.). A nationally-recognized model for adult education (Mancuso I69, "CAEL's"), SNL is one of a handful of adult undergraduates programs, including Empire State College and Alverno College, that began in the early I970s with the goal of increasing access to higher education. Grounded in the educational philosophy of John Dewey and research on adult learning and development (particularly that by Knowles, Kolb, Brookfield, and Taylor, Marienau and Fiddler), SNL stresses the importance of learning from experience, individualized learning, and lifelong learning: "The School believes that adults learn deeply by reflecting, particularly on experience, drawing meaning and transferable knowledge from all they have done" (Foundations Io). Those who have studied adult composition students confirm that "older students often use experiential writing to create for themselves a point of entry into a complex process of negotiating between lived cultures and academic knowledge" (Cassity 293, see also Belzer 42; Fredericksen II9-I2O; Morrison 33; Hurlow 66; Gillam I2-I4).

Writing Workshop, therefore, aims to scaffold students' lifelong development as writers by building on what they know, expanding their understanding of writing processes, and enhancing their self-assessment and metacognitive skills. The course allows basic and more advanced writers who find themselves struggling with new writing challenges to develop the "academic literacies needed for college coursework while actually taking ... college level ... courses" (Otte and Mlynarczyk 20). ${ }^{2}$ In Writing Workshop, instructors coach students who develop individualized learning plans and work on writing projects from other classes or that arise from their interests. Although designed for undergraduates and primarily serving our incoming basic writers, undergraduate and graduate students from across the university are taking advantage of this opportunity to receive individualized writing instruction. While most SNL classes enroll only SNL students, any DePaul student can take an SNL class. Because of the emphasis on developing selfassessment and metacognitive skills while working on writing projects that students bring to the course, Writing Workshop serves students of all ages who are lost in the "dizzying array of writing assignments" they encounter across the curriculum (Herrington and Curtis 387). 


\section{WRITING WORKSHOP}

\section{The Problem}

Like many stories of program development, this one begins with failure. In this case, the failure was of our stretch class (the only basic writing option at the time) to provide basic writers with the writing instruction they needed. The problem was not with the stretch model itself, but with our implementation of it. The immediate problem was logistic and specific to SNL. To accommodate working students, SNL offers classes online and at four campuses, some quite small. As a result, we frequently did not have enough students enrolled on any one campus for the stretch class to run, and many of our basic writing students were reluctant to take the class online. This was a particular issue because, when students come to SNL, they find themselves immediately immersed in a writing-intensive program. In their first class, students write learning autobiographies. In another introductory course, students write an eight to fifteen-page research paper. Writing assignments are by far the most common form of assessment in SNL courses. The writing-intensive nature of our program and lack of other direct writing assistance for SNL students made the need for support for struggling writers particularly pressing.

We also had a less local problem in that the stretch course was not designed to help students transfer what they knew and were learning about writing. As a result, even those who took the two-quarter stretch writing class were not well served by it. The short essays that they were practicing in the class had little connection to the rich and varied knowledge these nontraditional students brought with them to class and little bearing on the much more complex writing tasks they were being asked to complete in their other classes. The stretch instructors did not want to overwhelm basic writers with these more complex tasks, but as a result students were not getting the support they needed to move from what they already knew to what they needed to know. Because of the low enrollments and faulty design, we discontinued the stretch class and developed Writing Workshop with the backing of both full and part-time faculty who were united in their desire to increase writing support (and frustrated by course cancellations). 


\section{Models: ALP, Writing Centers, and the Studio Approach}

With the desire for a course to serve advanced as well as incoming students on all campuses, we sought new models, such as Peter Adams' Accelerated Learning Project (ALP) at the Community College of Baltimore County. In ALP, rather than taking basic writing followed by freshman composition, a cohort of eight basic writers takes a developmental English course at the same time as they are enrolled together as $40 \%$ of a freshman composition class (Adams). The same instructor teaches both the eight-student basic writing and the twenty-student freshman composition course. With ALP, Adams has increased the number of basic writing students passing freshman composition from $27 \%$ to $63 \%$ (Adams). And, he does this for less money. Despite the eight-person basic writing sections, the ALP program costs the school slightly less per successful student than the traditional developmental program. Adams argues that ALP works because mainstreaming decreases stigmatization and eliminates the loss of students who drop out before taking college composition. Moreover, he asserts that students learn from their exposure to stronger writers in their classes, small classes and cohort membership increase engagement and attachment, explicit discussion of behavioral issues helps students learn successful college behavior, and discussion of life problems that interfere with schooling helps them cope and persist. Unfortunately, ALP would not work at SNL because we do not have the critical mass at our smaller campuses even if we found a way to include the more advanced students who needed additional writing instruction after passing college composition. However, ALP's small class size, student-centered discussions, and cost-benefit argument anticipated some of the advantages of Writing Workshop.

Another model we considered was to partner with our writing center. Individualized writing instruction has been provided by writing centers for years. In I980, Lou Kelly described the credit-bearing instruction offered by the University of Iowa Writing Lab where tutors worked one-on-one with students. At Iowa, tutors started with what students knew, encouraged them to write freely about what interested them, gave them lots of practice writing, and helped them learn how to self-assess so that students might "become a perceptive and critical reader of their own writing" (Kelly II, 22, 25). Students at all levels, from new at-risk freshman to graduate students, were welcomed and could take the individualized course for two credits or for no credit. Since the course was individualized, students could repeat it, although only a limited number of credits would count toward graduation 
(Kelly I8). Like many of the students who struggle with writing at SNL, those at Iowa often were hampered by their lack of confidence and negative prior experiences with writing and writing instruction. To address students' negative perceptions of writing and lack of confidence, the Writing Lab encouraged students to "talk ... on paper" about how they felt about writing and "to write about what they know best" (Kelly Io, 22). Like the Iowa model, we developed Writing Workshop to focus on individual students, to be open to students across the curriculum, to have students write about what interested them, and to help students learn how to read and revise their own writing.

We would have liked to have used DePaul's Writing Center in a manner similar to that which Kelly describes. However, at the time, the Writing Center was almost entirely structured around the needs of DePaul's "traditional" student population. The Writing Center did not have tutors at our three suburban campuses, it had very limited weekend, evening and summer hours, and it was just beginning to experiment with online tutoring. ${ }^{3}$ In the absence of course options and Writing Center presence at our suburban campuses, a few part-time faculty had started tutoring some students. This tutoring was often uncompensated, informal, and only available when students connected with teachers willing to go the extra mile. We considered building on what these teachers had started by hiring teachers to tutor at each campus, but decided that this solution would not address the need for writing instruction in our program. In addition, while not initially a key consideration, we have come to value the combination of individual instruction and collaborative learning in Writing Workshop classes that would not have been available to students working individually with tutors.

Writing Workshop can also be understood as an "adaptation of Studio approaches" (Grego and Thompson 2I). Rhonda C. Grego and Nancy S. Thompson developed their Writing Studio at the University of South Carolina in response to the elimination of basic writing courses. In their Writing Studio, small groups of writers came together to discuss writing they were working on for other classes. The instructor assembled the agenda for each studio session from the questions and concerns students brought with them about specific pieces of writing they were working on (I2). Like the Studio approach, Writing Workshop students work in small groups on writing they bring from other classes. But Writing Workshop tweaks the model described by Grego and Thompson in two ways: First, Writing Workshop emphasizes the development of students' metacognitive and self-assessment skills, starting with having students place themselves in the class. Second, to avoid the fate of the Studio program Grego and Thompson describe, which was 
cancelled with a change of administration, Writing Workshop is located in the institutionally established space of a credit-bearing, graded course.

Besides serving incoming students who select it through our placement process, Writing Workshop is one of three options for more advanced students who need help with their writing, including a Web site for students who need the least support, the Writing Center for face-to-face and online tutoring, and Writing Workshop for students who need the structure and support of a class. Our Web site offers students guidance to help them decide whether to take Writing Workshop or go to the Writing Center. Those advanced students who take Writing Workshop do so because they want more writing instruction or because, like Antonio, they are struggling with their senior projects. For this latter group, the course is a lifeline to graduation.

\section{Structure}

Writing Workshop is a ten-week, four-credit class that counts toward graduation. ${ }^{4}$ We initially offered it for two credits with the idea that students could re-enroll each quarter until they no longer needed the scaffolding of the class. In practice, students were reluctant to take the class more than once because they only earned credit toward graduation the first time they took it. However, the two-credit class did not provide enough time for most students to accomplish their writing goals, so both students and faculty were overloaded with work. Since students were struggling to complete and teachers were declining to teach the two-credit class, we changed it to four credits. The additional two credits hours gave students and teachers the time they needed.

In Writing Workshop, each student, in collaboration with the teacher, develops and implements a plan to improve his or her writing. Students start the course by assessing their own writing and receiving an assessment from their instructor (see steps one through four in the "Writing Workshop Teacher Toolkit" at https://snlwriting.pbworks.com/w/page/I3277307/ Writing-Workshop). ${ }^{5}$ Students use these assessments to develop and implement a plan to build upon their strengths, address their most pressing challenges, and find resources for their ongoing writing development. As a result, rather than having set assignments, students work on writing tasks that are important to them. Thus, by encouraging students to write about what engages them and giving them the tools they need, Writing Workshop builds on the research of Carroll, Sternglass, Herrington and Curtis, and Beaufort and exemplifies SNL's commitment to personalized, lifelong learning. 
Because it is individualized and focused on developing writers rather than pieces of writing, Writing Workshop works for students with a broad range of learning styles, prior knowledge, goals, and needs. The course is structured so that the students who successfully complete the class have satisfied the Writing Workshop competence statement "can manage one's ongoing development as a writer using principles and tools of assessment and feedback" ("Writing Workshop"). We break this competence statement down into four criteria.

Criterion I. Can assess his or her own writing and address areas of weakness ("Writing Workshop"): Students get immediate practice and coaching on how to be realistic, comprehensive, and detailed in their self-assessments at the start of Writing Workshop. Before drafting their Writing Workshop plan, students answer thirty questions about their writing and writing process, complete a short grammar quiz, write about their goals for the class, submit writing samples, and do self-evaluations of each writing sample. The questions about writing and writing process, the grammar quiz, and the writing samples work not only as initial assessment tools, but also as a basis for learning at the start and sometimes throughout the quarter. For example, since students often see writing as simply a matter of getting "the right word," the questions about writing process reveal the many options and decisions available to them as writers. By discussing students' answers to these questions and the grammar quiz, faculty can address misconceptions about writing and give students the opportunity to identify what they already know. For instance, most students come into Writing Workshop believing that they have little understanding of grammar, so they often are surprised by how well they do on the grammar quiz. When the quiz and their writing samples have multiple, different errors, faculty prioritize and then focus on one at a time. When a number of the students in a class share a problem, we work with them in groups. We sometimes pair students, so they can teach their strengths to each other or both investigate a shared problem and then teach their classmates how to identify and correct it. In addition, students spend time during each class writing while the teacher works with students individually.

This criterion also requires that a student "can identify specific strengths in his or her writing and writing process and knows how to leverage these strengths" ("Writing Workshop"). This focus on strengths is necessary because students' ability to write, to write well, and to improve is too often undermined by their lack of confidence. Students continue to practice and develop their self-assessment skills throughout the quarter, 
doing self-evaluations of each draft, and ending with a final portfolio in which they reflect upon what they have learned. Beaufort stresses exactly this "practice of mindfulness, or meta-cognition, to facilitate positive transfer of learning" (I82). We aim to develop these meta-cognitive skills through teaching students to assess their own writing as well as the genres, rhetorical contexts, and discourse communities for and in which they are writing.

Criterion 2. Uses revision to produce significantly improved final drafts ("Writing Workshop"): The second criterion underscores the importance of revision. Some of our students have never been introduced to the idea of writing as a process; others, who "never liked to edit myself" (Antonio), resisted it. In doing their initial assessments, students are asked to think about what does and does not work in their writing process. Then, they are introduced to steps they may not have considered and to multiple strategies for dealing with process problems. Because students do several drafts, they get to see what they can accomplish when they use some of these strategies: "I can start papers quickly now. I have learned how to brainstorm first, then write my thoughts, then I can organize them so they make sense. I have learned a lot about myself. I can really write" (Tonya). Because Tonya loved to talk, being told that she could brainstorm by talking out her paper, recording herself, or writing a preliminary draft as if she were talking was a revelation. Like Tonya, Writing Workshop students benefit from experimenting with multiple ways to generate ideas for, develop, organize, revise and proofread their writing.

Criterion 3: Demonstrates improvement in writing as documented in a writing portfolio ("Writing Workshop"): Writing Workshop is not focused on teaching students how to write particular kinds of papers, but on helping them improve as writers. Because students work on assignments for other classes, they learn how to manage a variety of writing assignments, not just those writing teachers create for them. Borrowing many of Beaufort's recommendations, Dan Frazier of Springfield College in Massachusetts suggested coaching strategies to help students transfer what they learned in their freshman writing classes to their writing for other classes. Like Frazier, Writing Workshop teachers offer students coaching "grounded in the work students were doing now, helping them to understand what they knew about writing (or thought they knew) ... and adapting that knowledge to the genres and purposes they currently faced" (53). Having students work on papers for other classes also has the advantage of keeping the writing teachers exposed to the kinds of assignments and the feedback their students will encounter. 
For the final portfolio, students are asked to select from this work and use the self-assessment skills they have been practicing to demonstrate and reflect upon what they have learned. In the portfolio, students show how they have met the course criteria and the goals they set for themselves in their Writing Workshop plans. The portfolio provides a final opportunity to practice self-assessment and gives students the authority to select from their work and present themselves as writers.

Criterion 4: Presents a plan for continuous, ongoing improvement of writing ("Writing Workshop"): While the third criterion reflects back on the learning students have done in the class, the fourth asks students to present "a plan for continuous, ongoing improvement of writing" ("Writing Workshop"). This criterion helps students think deliberately about and have support for their future writing development. To meet this criterion, students explore, use, and evaluate for their classmates the writing support available to them in a handbook, online, and at the Writing Center. Like Mutiara Mohamad and Janet Boyd, our belief is that "the requirement that these students also concurrently seek existing support beyond the classroom, thirdspace support that is decentralized, is a crucial step for their sustainable success" (94). Students have reported that using these resources in class made it easier and less intimidating to use them later. We have seen increases in the number of visits to our writing Web site and in the number of our students using the Writing Center. As we promote both of these resources in a number of other ways and neither captures information about what prompted students to use them, we do not know the extent to which this criterion may be responsible for these increases. However, anecdotal evidence suggests that, while some students need additional prompts to consistently seek out resources when they need them, exposure to these resources in Writing Workshop increases students' awareness of and willingness to use them. The idea is that students who meet all four of the Writing Workshop criteria will have enough of an understanding of writing, of themselves as writers, and of the resources available to them, that they can continue to develop their writing after completing the course.

\section{THAT IT WORKS}

Writing Workshop has improved access for and the retention and success of basic and struggling writers at SNL. The improvement in access is dramatic. In all of 2005 , we offered only one on-campus section of our 
stretch class Intensive College Writing (ICW). In 2009, we offered eighteen on-campus Writing Workshop sections. We now schedule Writing Workshop on each of our campuses and often have multiple sections at our downtown campus and online. The availability of Writing Workshop classes is particularly important given our school's "commitment to the education of first generation college students, especially those from the diverse cultural and ethnic groups in the metropolitan area" ("DePaul's Mission"). Three of the five students in my Writing Workshop class were first-generation college students and all were African American or Latina students. While it was not possible to obtain data on the number of first-generation students taking Writing Workshop, the course is serving students from Chicago's "diverse cultural and ethnic groups" ("DePaul's Mission"). For example, $83 \%$ of the students who took Writing Workshop in Fall 2009 and choose to identify their ethnic group indicated that they were students of color. This is almost double the $45 \%$ of all SNL students who identified as students of color in 2008-2009. Without access to sufficient writing instruction, many of these students would be unlikely to prevail in a program in which almost all assessment is based upon written work.

Although Writing Workshop students are some of the weaker writers in a writing-intensive program, they are retained to the next quarter and to the following year at higher rates than SNL and national averages. Over seven quarters, $83 \%$ of the 178 students who passed Writing Workshop enrolled the following quarter. This retention rate is higher than the SNL term-to-term retention, which averaged 75\% in 2008-2009 (Cameron, "Enrollment"). A year later, $62 \%$ of the students who passed Writing Workshop $(n=178)$ were enrolled in classes, while the one-year retention rate for students who passed Intensive College Writing in $2005(\mathrm{n}=24)$ was $44 \%$. At SNL, the one-year retention rates range between 50 and 60\% (Cameron, "School" 5). The national one-year retention rates in 2006 for part-time students was $53 \%$ overall and $56 \%$ for students in private, nonprofit four-year colleges like SNL (Swail 2I).

Writing Workshop students are not just being retained, they are succeeding. Of I29 students who passed Writing Workshop, only $6 \%$ withdrew from classes the next quarter while $8 \mathrm{I} \%$ passed, earning an average letter grade of a B. Initial, albeit limited, data indicate that this success is enduring. Twenty-five students passed Writing Workshop in Winter and Fall 2007. Three years later, I5 Writing Workshop students remained enrolled at SNL with an average cumulative GPA of 2.88 . 


\section{CHALLENGES}

Writing Workshop offers financial and teaching challenges. Because of the level of individualization, we cap Writing Workshop classes at ten students. Because of our commitment to access at every campus every quarter, Writing Workshop classes run if even one student is enrolled. Our online and downtown campus sections are often fully enrolled, but sections at suburban campuses are usually smaller. The financial challenge is plain: how can a tuition-dependent university afford to run classes with ten or fewer students and still pay instructors enough to make it worth their while to teach these classes?

Just as Peter Adams argues for ALP, we found that the university saves money when it runs small classes in which more students succeed. Writing Workshop instructors are paid the same for teaching a full section of Writing Workshop as they would be for any other four-credit course. When there are less than ten students enrolled in a class, part-time instructors are paid per student. Because we recognize that many classes will have only a few students with whom instructors will work one-on-one, instructors earn $50 \%$ more for each of the first three students than for students four through nine.

Despite instructors being paid more than normal per student, Writing Workshop saves the university money. Even with one student, the school does not lose money when part-time faculty, who teach most SNL classes, ${ }^{6}$ teach Writing Workshop. When one student is enrolled, $60 \%$ of the student's tuition goes to the university to cover expenses. Just over $23 \%$ of the tuition covers the instructor's salary, leaving the college with a little over $16 \%$ of the tuition. When the course is fully enrolled with ten students and taught by a part-time faculty member, the college receives $22 \%$ of the students' tuition after paying the university and the instructor. While these classes do not lose money, they do generate less income for the university than the average SNL class. The loss of this additional revenue is made up for by the savings to the university through retention. When I, a full-time faculty member, teach Writing Workshop, the college only starts to make money if eight students are enrolled in the class. However, if I taught the class with just one student, the university would lose approximately $\$ 3,000$ less than if that student dropped out in their first year back to school. ${ }^{7}$

Besides economic pressures, Writing Workshop is a challenge because it is such a unique class to teach. In fact, when students and teachers enter Writing Workshop thinking of it is a class, it becomes less than it might 
be. Like the only diners in an otherwise empty restaurant, students tend to wonder what the problem is when they find only a few other students in the class. The instructor must explain that, like an exclusive restaurant, the class is designed to be small and convince students that they are privileged to have such individual attention. Similarly, teachers can find the very small classes disconcerting. One instructor recently suggested that we cancel her class. When I asked why, she replied that she had no idea how to teach only one student.

The small size of Writing Workshop classes is one way this course's uniqueness reveals how we as teachers sometimes unconsciously act from outmoded mental models. We would do well to attend to Deborah Brandt's warning to researchers that "the habit of automatically seeing 'teachers' and 'students' and 'classroom organization' must be problematized. That a researcher can take such categories so easily for granted . . . only speaks to how widely sanctioned and understood are the roles of teachers and students and classroom life in general, how well embedded and routinized they are in normal life" (346). When I observe new Writing Workshop teachers, I invariably find them standing at the front of the room, sometimes behind a podium. This has been true even when there were only two students in the class and the teachers were experienced tutors or had participated in many creative writing workshops where they sat in the round. For both students and teachers, our normative conventions of what a class should look like can inhibit success.

While approaching Writing Workshop as a class can be counterproductive, so too can imagining it as a set of individual tutorials. Initially, I had suggested that instructors of small classes might meet at different times with each student. I was wrong. Both our face-to-face and online instructors have found it important to create opportunities for students to work with each other even when they are working at different levels and on different projects. Vincent Tinto has argued for a number of years that students are more likely to persist and learn when they are actively involved in learning with their peers as well as their teachers (3-4). Coming to the same conclusions as Tinto, one of our online instructors recommended pairing students to improve learning and retention: "Some of my most improved, most focused, and hardest working students are those who have gone out and found effective exercises or readings and shared them with the class. This drive to share information and update everyone on their own progress was very motivating" (Fitzpatrick). Yet, while collaboration does result in what one instructor called "a nice bond" between students even from "quite different 
backgrounds," it does not always result in successful course completion (Triller). As one instructor explained:

I find that the social nature of writing is certainly more apparent in this workshop format and has a BIG impact on student success/retention. The social nature of my Writing Workshop courses has been vastly different, and the group dynamics in such a small course can have a drastic effect on student outcomes. For instance, students in one Writing Workshop seemed more task- and structure-oriented and held each other accountable for getting drafts done. On the other hand, my Writing Workshop students this quarter had a hard time focusing on discussion about writing and instead wanted to talk about their personal lives and experiences (and had a lot in common in this regard). (Wozniak)

So while collaboration can enhance the learning environment, it does not necessarily enhance the learning about writing, particularly in such small classes. To address this challenge, we intend to borrow some of the reflective activities Frazier found effective when working with similarly small groups of students. By using these activities and bringing together students working on different assignments for different classes, he was able to help them "reflect across disciplinary boundaries and generalize about what they're learning outside of the activity system of their work in progress" (Frazier 52).

The challenge of keeping students focused and moving forward is particularly pronounced with newer online students with weak time management skills. Online learning is not a good option for these students, and we advise them to take Writing Workshop on campus. Nevertheless, some take it online out of convenience or necessity. We have found that our online Writing Workshop students are more likely to be younger and more advanced than those in our on-campus sections. In 2009-20Io, $68 \%$ of the students from other colleges at DePaul who took Writing Workshop did so online, while only $32 \%$ of SNL students who took Writing Workshop were in online classes. Students from other colleges at DePaul are more likely to be younger and more comfortable with learning technology than incoming SNL students. Online students also tended to have completed more classes prior to Writing Workshop than on-campus students. Only 28\% of on-campus students had taken more than three classes before enrolling in Writing Workshop, while 4I\% of online students had already taken more than three classes. Despite their experience, online students were less likely 
to complete Writing Workshop successfully than on-campus students. In 2009-2010, there was little difference in the relatively few students who withdrew, received incompletes or a $\mathrm{D}$ in online and on-campus sections. However, 7\% more online than on-campus students received an F and IO $\%$ more received a failing grade of FX because they had stopped participating. This difference between online and on-campus outcomes is consistent with findings that online students in general are more likely to fail or drop than on-campus students (Bernard et al.; Carr). For those online students who did pass Writing Workshop, there was little difference between their term-toterm retention and that of students who took the course on campus.

\section{ONE WRITING WORKSHOP CLASS}

In Fall 2009, I taught Writing Workshop at our smallest campus, which had never had enough students to run the stretch class. The five students in my class, four basic writers and Antonio, exemplify the need for a class like Writing Workshop. Each student brought to the class rich life experiences, deep engagement with topics as varied as financial literacy and foster parenting, commitment to complete their degree, and fear that writing could keep them from achieving this goal.

\section{Tonya and Clarice: Returning to School as Basic Writers}

Tonya and Clarice chose Writing Workshop through our placement process. Both had decided to return to school over two decades after graduating from weak urban high schools. They attended school parttime, worked full-time, and were busy wives and mothers. Tonya was a first-generation college student who fondly remembered the high school journalism class that gave her the opportunity to interview Chicago's first African American mayor and had "notebooks filled with poetry that I have written over my life time." Like other high-achieving graduates of underperforming high schools, she was blindsided by the gap between what counted as successful writing in high school and in college. As a result, her confidence was shaken, and she was spending hours eking out one convoluted sentence at a time.

While Tonya had thrived in high school, Clarice wrote poignantly about her long history as a struggling reader and writer. At ten she realized that she was not keeping up with her classmates and went into what she 
called her "academic shell." She stopped trying and "became angry and frustrated with myself as well as with my teacher for passing me on to the next grade, knowing that I could not read or write." Nevertheless, she graduated from high school by relying upon her siblings, who "had the formats down to a science" and would transform her rough drafts into passing papers. After raising her children, Clarice decided to return to school: "It took me most of my adult life to get over the fact that I did not learn as fast or as quickly as others, but I am there now." Both Clarice and Tonya needed instruction on ways to draft and revise, on how to organize essays and support claims, and on strategies for recognizing and correcting errors, but both had much to say. Starting with encouragement and low-stakes practice and adding targeted instruction, I watched their confidence grow as they crafted increasingly powerful drafts.

\section{Marion and Marta: Nontraditional Students Confused about Academic Conventions}

While Marion and Marta did not take Writing Workshop as a result of our writing placement, they were advised to take it in their first year back in school. Marion was fifty-three years old, while Marta was in her forties. Like Tonya and Clarice, these two women worked full-time, attended school part-time, and had families. Also like Tonya, Marion was a first-generation college student. Not only did she direct a youth training center, she was also first assistant pastor at the church she ran with her husband. Since her high school graduation, Marion had taken some business-related classes and one "very difficult" basic writing class at a local community college. Marta, like Tonya and Clarice, was returning to school for the first time since graduating from high school. She worked in financial services and, in addition to school, was studying for a series of licensing exams.

As with the students Lillis profiled, Marion and Marta's main challenge was their confusion about academic writing. Because they lacked the cultural capital of those raised and educated to go to college, these women had many misconceptions about the various conventions for and uses of writing in college. For example, the first draft Marion brought to our Writing Workshop class was almost entirely copied from the web. She was not trying to cheat. In fact, she had thought a great deal about the topic, teen pregnancy, because of her work with teens at her church. However, unsure if or how she should express her own ideas in an academic paper, Marion decided to rely upon the experts much as she might quote scripture and 
spirituals in her sermons without anyone expecting her to cite her sources. In this way, Marion was operating within "the African-American oral culture and folk preaching traditions, where language and ideas are viewed as communal resources to be shared and adapted" (Johannesen I85).

Like Marion, Marta was unsure how to present the expertise she had gained outside of school to an academic audience. In Writing Workshop, Marta worked on a Prior Learning Assessment (PLA) ${ }^{8}$ paper documenting what she had learned from her years of volunteer work on financial literacy in Spanish-speaking communities. In their recent exploration of PLA, Cathy Leaker and Heather Ostman echo Sternglass, Herrington and Curtis, Carroll, and Beaufort in stressing the importance of direct writing instruction: "many of our students have a good deal of 'subject matter knowledge,' but they needed explicit direction in the particular conventions used to articulate such knowledge within 'academia'" (696). Like Leaker and Ostman's students, Marta had learned much from her volunteer work, but lacked a sense of what her audience would want to know. The first draft of her PLA essay included a long bulleted list of the community organizations with which she had worked. Because she assumed her audience would not be familiar with these organizations, she included descriptions of each. What her audience would want to know, what she did with these organizations, and what she learned from these experiences, she took for granted and so did not explain.

In Writing Workshop, Marion and Marta both learned how to convey the knowledge they had gained outside of school to academic audiences. Marion learned not only about the conventions for citing sources in academia, but also about how to draw from her experiences and stand upon her own authority: "Before I took this class I was not sure how to express myself. I was inhibited in sharing my ideas and contributing my options about a subject matter I had chosen. I have learned that expressing my ideas bring depth and substance to my papers." Marta analyzed the PLA assignment and sample essays to better understand the assessor's expectations. She then was able to significantly improve her writing by thinking "as if I was the reader" and anticipating the questions her audience might ask.

\section{Antonio: Stuck at the Finish Line}

Joining these women was Antonio, who would graduate when (and if) he completed his final project. Shortly after he began college, Antonio's parents divorced, leaving him reeling from their breakup and without 
financial support for school. He married his college girlfriend and started working two jobs as he and his wife tried to complete their degrees. As a result, "my grades started to become toasted. I could not finish classes and my instructors did not want to hear excuses." Antonio dropped out of school, but was back within a year. He was not a basic writer. Antonio had already taken a creative writing class and three academic writing classes, earning an average grade of $\mathrm{B}+$.

While the women in my class were just starting college, students like Antonio, who are further into their studies, can also need significant help with their writing. Carroll's findings speak directly to Antonio's challenges and frustrations - he was chronically overextended, confused about what he was being asked to do, and losing control of his writing as he struggled with a new and complex writing task. Like many adult students, Antonio was trying to do too much at once. Besides attending school, he was working full time, still sorting out the turmoil in his family occasioned by his parents' divorce, and had started taking classes at a bible college, which was where his primary intellectual energy was directed. As a result, he did little writing outside of class. He would frequently come early, murmuring apologies about not getting his work done, then open his laptop and start writing.

Carroll points out that students are strategic about dealing with assignments: "Students are actively involved in figuring out 'what the professor wants' and how they, as young adults, can accomplish their own goals within the college environment" (24). Carroll's research is with "traditional students," but rings all the more true for adults who try to balance school with work and family responsibilities. Certainly, by the time he came to Writing Workshop, Antonio wanted to give his professors what they wanted: "Now I simply want to get my Advanced Project done and completed so that I can graduate out of DePaul University." However, here he had a problem. He had little idea what they wanted.

Antonio told me, and his grades confirmed, that he knew how to write philosophy and political science papers, having learned to copy the writing style of the texts he read in these classes:

I noticed when I was taking only Philosophy and Political Science classes, my writing was very good at copying the styles and structure of the philosophical and political authors that I was assigned to read. ... I learned that it is common for college students to be wordy in their sentences. I personified this mistake when I would read and write about philosophy texts. (Talk about long sentences!) 
... This has lead to me often being ineffective in styles such as corporate or creative writing while as a Manager of a Zales Jewelers, or a participant in creative writing courses at the SNL.

While the strategy of imitating the style he found in some course readings had worked for Antonio, he was discovering that this style was not transferable. Nor did he have any models to copy for his Advanced Project because each student's project is unique and because his project was interdisciplinary. One of Antonio's thesis advisors was a political scientist, the other worked in public policy, and Antonio wanted to learn how to write about his faith for an academic audience. Newly immersed in born-again Christianity, Antonio struggled in particular with how to move between truth claims that were persuasive to fellow believers and those that would meet the expectations of his professors. Carroll theorizes that professors "may underestimate ... how much practice is needed to apply disciplinary specific concepts, knowledge, and conventions in writing" (6). On more than one occasion, Antonio complained that his professors' disciplinary differences resulted in feedback that was different enough to be confusing and expectations that were at odds with his earlier training.

Antonio's professors, in turn, were frustrated with his unsupported claims, convoluted sentences, and rambling, thirty-page drafts. (Nor did his last-minute work habits endear him to them.) His political science professor refused to read another draft until Antonio completed substantial revisions, while his other advisor was baffled about how to help Antonio move forward. When I first read his Advanced Project draft, I doubted the competence of the teacher who had passed Antonio in college writing even though I regularly explain to faculty members upset about students who "cannot write" that basic writing skills can suffer when students are attempting new writing tasks (Carroll 9). It was fitting then that I discovered I had been the teacher who had awarded Antonio a B- in an online college writing class over a year earlier. His papers from that class indicated that he was capable of much clearer prose than that which he was producing while muddled in his early Advanced Project drafts. The incomprehensible sentences and lack of structure in his Advanced Project were symptomatic of his struggle with this new and demanding writing task.

Antonio spent the quarter taking apart, rebuilding, and revising his Advanced Project. Watching Antonio, the other students were both encouraged to see that writing is a challenge even for advanced students and disappointed to realize that writing improvement was a long-term project that 
would extend well beyond our one-quarter class. Antonio regained some confidence in his writing abilities when he was able to offer constructive feedback to his peers. Similarly, they gained confidence in their abilities as they realized they could help Antonio with his writing. For example, Antonio's professors and I told him that his thesis statement was too general and sweeping, but he was not convinced until his classmates started telling him the many things that they thought his thesis could mean. The revised thesis became the core of his vastly improved Advanced Project, and, at the end of the quarter, he wrote that he had learned "the vital necessity for a solid, clear and concise thesis statement as the foundation for any good academic essay." Antonio also reported discovering "that I learn well through repetition and reflection." This last-minute writer had learned to "review, reflect and digest" feedback and then "dive into the next draft."

The experience of these five students underscores the need for a class like Writing Workshop that students can take at any point in their studies, because "a one- or two-semester, first-year course in writing cannot meet all the needs of even our more experienced writers ... students' complex literacy skills develop slowly, often idiosyncratically, over the course of their college years" (Carroll xi-xii). In our writing-intensive program, this need for ongoing writing support for both basic and more advanced writers was evident.

\section{CONCLUSION}

Before graduating, Antonio took an extra class, "The Christian Experience," earning an A-. When I last heard from him, he was applying to graduate programs in theology. Over a year after we finished our class, the other four students were all enrolled in classes. Marion struggled. She did not take classes the quarter after Writing Workshop and then failed the two she registered for in spring. One of these failures was due to nonattendance, indicating that her pastoral responsibilities may have interfered with school. She took the summer and fall quarters off, earning a B+ when she returned. Like Marion, Marta took big breaks between classes, taking one class the quarter after Writing Workshop and then skipping three quarters before she enrolled again. Still, Marta did well in each of her classes, receiving Bs. Tonya finished Writing Workshop saying, "I realize I haven't mastered the concept of writing, but I'm on my way. I believe with continual practice I will become a better writer in the future." She is indeed on her way. Since 
Writing Workshop, she has taken classes every quarter and has a 2.90 grade point average. Clarice, who began Writing Workshop worried that readers would not understand her, ended the class stating that "I believe that my readers will be able to comprehend what I am explaining to them ... In the future, I would like to tell me great grandmother's story in a book. How she and her siblings were born into slavery." Notably, she took only the summer off and earned the highest grade point average, 3.II7, of the five students who took Writing Workshop together.

While Writing Workshop is a challenging class to teach and we are certainly still learning how to do it well, it offers the flexibility to support increasingly diverse learners in a way that aligns with what we know about how students develop as writers. To help new faculty teach this class, we provide them with the Writing Workshop Teacher's Toolkit, talk with them about the course, and then observe them in their first quarter of teaching. This observation is low stakes in that we do not complete a written report, but instead provide teachers with verbal feedback and discuss any questions or issues they may have. We also have a meeting each spring in which we focus on topics relevant to teaching Writing Workshop, collaboratively assess several Writing Workshop portfolios, discuss our findings, and make recommendations for improving the course and our teaching. More frequent interactions among instructors would be better, and the weekly or biweekly discussions Grego and Thompson describe would be ideal, but they are not practical given that our roughly fifteen part-time Writing Workshop instructors have other jobs and do not all live in the same state.

Writing Workshop has improved access for our basic and struggling writers who are now being retained at higher rates than other SNL students. It has also started to attract students from across the university who want the opportunity to receive individualized instruction on their writing. Not only are our students succeeding, our writing instructors are gaining exposure to the writing assignments students encounter in other classes, learning about ways students struggle with these assignments, and confronting our own unconscious assumptions about how to teach writing. Writing Workshop is one model for scaffolding the writing developing of students as they make their way through college. If universities wish to retain and graduate the growing majority of "nontraditional" students, then we need more such experiments. 


\section{Acknowledgements}

Special thanks go to all of the Writing Workshop instructors and students who have contributed to the ongoing development of this course. In addition, I would like to thank the five students in my fall 2009 class for their willingness to share their writing and experiences. Finally, I am indebted to Kathryn Wozniak, Steffanie Triller, Susanne Dumbleton, Stephen North, Chip Cleary, and Hope Parisi and two anonymous reviewers for their insightful comments and suggestions on drafts of this paper.

\section{Notes}

I. Student names have been changed.

2. I use ellipses to indicate that I have removed the quotation marks from around "college level" that were in the original quote. The classes our students take while also taking Writing Workshop are, in fact, college level.

3. More recently, the DePaul Writing Center has expanded its outreach to and services for our students.

4. SNL is on the quarter system, so classes run for ten weeks with on-campus students meeting for three hours once a week in the evenings or on weekends. Online classes are asynchronous, with students expected to participate at least four times a week. Because SNL is a competence-based school, students must demonstrate fifty competencies to graduate rather than earn a certain number of credits. In most SNL classes, student can earn one competence for every two credit hours. However, students earn only one competence in Writing Workshop, Academic Writing for Adults, and Critical Thinking, all of which are four-credit classes.

5. This Toolkit includes significantly more information on the nuts and bolts of the class, including detailing of the course criteria, all of the initial assessment materials, directions for the final portfolio, and a sample syllabus.

6. SNL began as a college where practicing professionals taught adult students. Tenured and tenure-track full-time faculty were not originally part of the college, and most classes continue to be taught by part-time faculty.

7. In 2008, DePaul University's cost of attrition for first-year, full-time, firsttime undergraduates was $\$ 6.3$ million where the university spent $\$$ I6,59I per student on instruction, student services, academic support, operations and maintenance, and institutional support ("DePaul University"). 
Assuming part-time students cost half of this, the university would lose approximately $\$ 8,295.50$ for a part-time student who did not return after one year, which is just over $\$ 3$, ooo more than the $\$ 5,202$ it would cost the school for me to teach only one student in Writing Workshop.

8. Prior Learning Assessment (PLA) is used by many schools to award college credit to students, usually returning adults, for learning from their life experience. Quite frequently, students document their learning for PLA in papers.

\section{Works Cited}

Adams, Peter. "ALP: the Accelerated Learning Program." I3 October 20 oro. Screencast.com. PowerPoint.mp4. Web. I July 20 II.

Adelman, Clifford. The Toolbox Revisited: Paths to Degree Completion from High School through College. U.S. Department of Education. February 2006. Web. I8 May 2010.

Beaufort, Anne. College Writing and Beyond: A New Framework for University Writing Instruction. Logan: Utah State UP, 2007. Print.

Belzer, Alisa. “'It's Not Like Normal School': The Role of Prior Learning Contexts in Adult Learning." Adult Education Quarterly 55 (2004): 4I-59. EBSCO. Web. 2 April 2007.

Benedetto, C., J. Chen, D. Holton, D. McDermott, A. Stanford, P. Wadhwa, K. Watanuki, and G. Yanow. "Current Education Model." School for New Learning Strategic Planning Documents. Chicago: Millennia Consulting, June 20Io. Print.

Bernard, Robert M., Philip C. Abrami, Yiping Lou, Evgueni Borokhovski, Anne Wade, Lori Wozney, Peter Andrew Wallet, Manon Fiset, and Binru Huang. "How Does Distance Education Compare with Classroom Instruction? A Meta-Analysis of the Empirical Literature." Review of Educational Research 74.3 (Autumn, 2004): 379-439. JSTOR. Web. 28 February 201 .

Brandt, Deborah. "The Cognitive as the Social: An Ethnomethodological Approach to Writing Process Research." Written Communication 9.3 (July I992): 3I5-55. Sage. Web. 28 July 2 OIO.

Brookfield, Stephen. Understanding and Facilitating Adult Learning: A Comprehensive Analysis of Principles and Effective Practices. San Francisco: Jossey-Bass, I986. Print. 
"CAEL's Benchmarking Study on Best Practices for Serving Adult Learners." CAEL: The Council for Adult \& Experiential Learning. CAEL. 20Io. Web. 2 July 2 OII.

Cameron, Jaclyn. "Enrollment Flow 2oro Ad Hoc." Chicago: De Paul University, Office of Institutional Planning and Research, 28 June 20 oro. Excel.

_. "School for New Learning Success Outcomes Report 2020: Retention, Graduation, and Persistence Rates." Chicago: De Paul University, Office of Institutional Planning and Research, 28 April 2oro. PowerPoint.

Carr, Sarah. "As Distance Education Comes of Age, the Challenge is Keeping the Students." The Chronicle of Higher Education. II February 2000. Web. I March $201 \mathrm{O}$.

Carroll, Lee Ann. Rehearsing New Roles: How College Students Develop as Writers. Carbondale: Southern Illinois UP, 2002. Print. Studies in Writing \& Rhetoric.

Cassity, Kathleen J. "Bringing Lived Cultures and Experience to the WAC Classroom: A Qualitative Study of Selected Nontraditional Community College Students Writing across the Curriculum." Diss. U of Hawai'i, 2005. ProQuest. Web. 9 Dec. 2006.

Castaldi, Theresa "Adult Learning: Transferring Skills from the Workplace to the Classroom." Lifelong Learning: An Omnibus of Practice and Research I2.6 (I989): I7-I9. Print.

Choy, Susan. Nontraditional Undergraduates. U.S. Department of Education, National Center for Education Statistics. 2002. Web. I June 2010.

Cox, Elizabeth M., and Larry H. Ebbers. "Exploring the Persistence of Adult Women at a Midwest Community College." Community College Journal of Research and Practice 34.4 (2010): 337-59. Print.

“DePaul University." CollegeMeasures.org. American Institutes for Research. Web. I3 March 201 I.

“DePaul's Mission.” DePaul University. November I99I. Web. I July 20 II.

Ericsson, K. Anders, Ralf Th. Krampe, and ClemensTesch-Römer. "The Role of Deliberate Practice in the Acquisition of Expert Performance." Psychological Review Ioo.3 (I993): 363-406. Web. 2 o June 20 II.

Fitzpatrick, Kristin. "RE: for Saturday's meeting.” Message to the author. I7 April 20IO. E-mail.

The Foundations of Adult Learning Resource Book. The School for New Learning, DePaul University. I5 June 2OII. Web. 5 July 2011.

Frazier, Dan. "First Steps Beyond First Year: Coaching Transfer after FYC." WPA: Writing Program Administration 33.3 (2010): 34-57. Print. 
How Antonio Graduated On Out of Here

Fredericksen, Elaine. "Silence and the Nontraditional Writer." Teaching English in the Two Year College 25 (I998): II5-2I. ProQuest. Web. 4 Dec. 2006.

Gillam, Alice M. “Returning Students' Ways of Writing: Implications for First-Year College Composition." Journal of Teaching Writing IO.I (I99I): I-20. Web. 23 June 201 I.

Grego, Rhonda C., and Nancy S. Thompson. Teaching/Writing in Thirdspaces: The Studio Approach. Carbondale: Southern Illinois UP, 20o8. Print. Studies in Writing \& Rhetoric.

Herrington, Anne J., and Marcia Curtis. Persons in Process: Four Stories of Writing and Personal Development in College. Urbana: NCTE, 20oo. Print. Reconfiguring English Studies.

Hoachlander, Gary, Anna C. Sikora, and Laura Horn. Community College Students: Goals, Academic Preparation, and Outcomes. U.S. Department of Education, National Center for Education Statistics. June 2003. Web. I June 2 OIO.

Hurlow, Marcia. "Experts with Life, Novices with Writing." Dynamics of the Writing Conference: Social and Cognitive Interaction. Eds. Thomas Flynn and Mary King. Urbana: NCTE, I993. 62-68. ERIC. Web. 29 December 2010. Ishitani, Terry T. "A Longitudinal Approach to Assessing Attrition Behavior among First-Generation Students: Time-Varying Effects of Pre-College Characteristics." Research in Higher Education 44.4 (2003): 433-49. JSTOR. Web. I8 May 2010.

Johannesen, Richard L. "The Ethics of Plagiarism Reconsidered: The Oratory of Martin Luther King, Jr." Southern Communication Journal 60.3 (Spring I995): I85-94. Print.

Kelly, Lou. “One-on-One, Iowa City Style: Fifty Years of Individualized Writing Instruction." The Writing Center Journal I.I. (I980): 4-I9. Rpt. in Landmark Essays on Writing Centers. Eds. Christina Murphy and Joe Law. Davis: Hermagoras Press, I995. II-25. Print.

Knowles, Malcolm. The Adult Learner: The Definitive Classic in Adult Education and Human Resource Development. Amsterdam: Elsevier, 2005. Print.

Kolb, David A. Experiential Learning: Experience as the Source of Learning and Development. Englewood Cliffs: Prentice Hall PTR, I984. Print.

Krause, Kerri-Lee. "Supporting First-Year Writing Development Online." The Journal of General Education 55.3\&4 (2006): 2OI-20. Project Muse. Web. 27 December 20 oro.

Leaker, Cathy, and Heather Ostman. "Composing Knowledge: Writing, Rhetoric, and Reflection in Prior Learning Assessment." College Composition and Communication 6I.4 (20I0): 69I-7I7. Print. 
Lillis, Theresa M. Student Writing: Access, Regulation, Desire. London: Routledge, 200I. Print.

Mancuso, Susan. "Adult-Centered Practices: Benchmarking Study in Higher Education." Innovative Higher Education 25.3 (Spring 200I): I65-8I. Springer. Web. 2 July 2 OII.

McGivney, Veronica. "Understanding Persistence in Adult Learning." Open Learning I9.I (2004): 33-46. Academic Search Premier. Web. I8 May 2010. Mohamad, Mutiara and Janet Boyd. "Realizing Distributed Gains: How Collaboration with Support Services Transformed a Basic Writing Program for International Students." Journal of Basic Writing 29.I (20I0): 78-98. ProQuest Education Journals. Web. I October 20 oIo.

Morrison, Mary Kay. “'The Old Lady in the Student Lounge’: Integrating the Adult Female Student into the College Classroom." Two-Year College English: Essays for a New Century. Ed. Mark Reynolds. Urbana: NCTE, I994. 26-36. Print.

Murtaugh, Paul A., Leslie D. Burns, and Jill Schuster. "Predicting the Retention of University Students." Research in Higher Education 40.3 (I999): 355-7I. JSTOR. Web. I8 May 20 oro.

Otte, George, and Rebecca Williams Mlynarczyk. "The Future of Basic Writing." Journal of Basic Writing 29.I (20IO): 5-32. ProQuest Education Journals. Web. I October 2010.

Popken, Randall. "A Study of the Genre Repertoires of Adult Writers.” Writing Instructor I5 (I996): 85-93. WilsonWeb. Web. I7 March 2006.

Pusser, Brian, David W. Breneman, Bruce M. Gansneder, Kay J. Kohl, John S. Levin, John H. Milam, and Sarah E. Turner. Returning to Learning: Adults' Success in College Is Key to America's Future. Indianapolis: Lumina Foundation for Education, 2007. Web. I8 May 2010.

Sailor, Susan Hardee. “The Effect of Peer Response Groups on Writing Apprehension, Writing Achievement, and Revision Decisions of Adult Community College Composition Students." Diss. U of Florida, I996. UMI. Web. 29 December 2010.

Smith, Dorace F. "A Study of Characteristics That Contribute to Persistence of Adult Commuter Students Who Earn 60 or More Hours of College Credit.” Diss. Ball State U, I999. ProQuest. Web. 9 December 2006.

Starks, Gretchen. "Perceptions of Writing by Exceptional Cases of Adult Returning Women in a Rural Community College: Differences between Persisters and Leavers." Annual Meeting of the American Educational Research Association. San Francisco, CA. March 1989. ERIC. Web. I7 March 2007. 
Sternglass, Marilyn S. Time to Know Them: A Longitudinal Study of Writing and Learning at the College Level. Mahwah, NJ: Lawrence Erlbaum Associates, I997. Print.

Swail, Watson Scott. Graduating at-Risk Students: A Cross-Sector Analysis. Washington, DC: Imagine America Foundation, 2009. Education Policy International. Web. I8 May 2010.

“Table I9I. Total fall enrollment in degree-granting institutions, by sex, age, and attendance status: Selected years, I970 through 2018." Digest of Education Statistics, 2009. National Center for Education Statistics. Web. I8 December 2010.

Taylor, Kathleen, Catherine Marienau, and Morris Fiddler. Developing Adult Learners: Strategies for Teachers and Trainers. San Francisco: Jossey-Bass, 200o. Print.

Tinto, Vincent. "Taking Student Retention Seriously: Rethinking the First Year of College." The School of Education. Syracuse University. n.d. Web. 24 June 2010.

Triller, Steffanie. "RE: paper on WW." Message to the author. 25 June 20 oro. E-mail.

United States. Dept. of Education. Office of Educational Research and Improvement. National Center for Education Statistics. No. I3, Postsecondary Persistence and Attainment. 1997. Web. 21 May 20 оо.

Wardle, Elizabeth. “Understanding 'Transfer' from FYC: Preliminary Results of a Longitudinal Study." WPA: Writing Program Administration 3I.I\&2 (2007): 65-85. Web. 3 August 2 oro.

Wiant, Fredel Marie. “A Study of Collaborative Writing Response Groups and Writing Anxiety among Female Community College Re-Entry Students." Master's Thesis. U of Colorado, I997. Print.

Wittman, Eugene Michael. "Situational Factors Influencing Writing Apprehension in the Community College Composition Classroom." Diss. Abstract. North Carolina State University, I99I. ProQuest. Web. 29 December 2010.

Wozniak, Kathryn. "RE: paper on WW." Message to the author. 28 June 2oro. E-mail.

“Writing Workshop: A Toolkit for Teachers." SNL Writing. 20 June 2 oro. PBWorks. Web. 2 August 2 oro. 


\title{
Braiding and Rhetorical Power Players: Transforming Academic Writing through Rhetorical Dialectic
}

\author{
Kimberly K. Gunter
}

ABSTRACT: In this article, I revisit the Elbow/Bartholomae debate, review recent scholarship on academic writing, and discuss the ways that the mandates of traditional academic writing can further disenfranchise already marginalized students. I suggest that, due to the double consciousness with which these students often live, they come into classrooms rhetorically adept. By asking student writers to employ braiding (the braiding of subjectivities, genres, or rhetorics in single texts), we enable students to theorize experience, to contest stereotypes of "student writing," to contribute to academia via their own intellectual experimentation, and to consciously position themselves among various discourses as effective rhetorical power players. I offer the experience of one student writer (a lesbian and an Army cadet) as a case study.

KEYWORDS: academic writing; braiding; alt/dis; GLBTQ student writers; queer pedagogy.

To deny the importance of subjectivity...is to admit the impossible: a world without human beings. This objectivist position is as ingenuous as that of subjectivism which postulates human beings without a world. (Freire, Pedagogy of the Oppressed 32)

Not that we want to, but if we had to choose two rhetoric and composition scholars to face off in a Steel Cage Death Match, we would have to choose, still, Elbow and Bartholomae, right? As he climbed through the ropes of the ring, Elbow would sport a billowing sateen cape with a big red heart sewn in the middle. Those sitting ringside would spy, as Bartholomae danced through the introductions, a glittering, silver brain stitched to the seat of his trunks. "Folks, we're expecting a barnburner here tonight," a tinny announcer's voice would pour from the loudspeaker. Across the land, rhetoricians and compositionists would lean toward pay-per-view screens or (old school) bend their heads toward analogue radio dials and feel each blow.

Kim Gunter is Associate Professor of English and a writing program administrator at Appalachian State University. Her scholarly interests intersect queer studies, writing pedagogy, and writing program administration.

(C) Journal of Basic Writing, Vol. 30, No. I, 20II 
We would wince when Bartholomae landed "The ability to imagine privilege enable[s] writing" (64I) with a roundhouse to Elbow's chin. We would gasp when Elbow, at first playing rope-a-dope, delivered "It is possible to learn something and not be taught" (vii) to Bartholomae's breadbasket. No matter how each of us might score the bout, this match may end in an eternal split decision or perhaps even a draw for basic writing and composition.

On the surface, Bartholomae has hoisted aloft the belt, "World Champeen Academic Writer" inscribed in gold-plate. It is, after all, conventionalized academic discourse that we basic writing and first-year composition teachers put an awful lot of energy into: "thesis-driven argumentative essay based on sources-the type of writing espoused by Bartholomae-[is] the default form of academic writing in U.S. colleges and universities" (Mlynarczyk 22, emphasis added). Others echo Rebecca Mlynarczyk's assessment. For instance, Jeffrey Maxson avers, "academic culture privileges scientific ways of knowing, and...this leads to a peculiar kind of writing: full of disciplinespecific jargon and concepts, hedging of statements (to pre-empt attacks from critics), statistical rather than anecdotal evidence, an almost obsessive documentation (ostensibly so that readers may arrive at the same conclusions as the writer), etc." (25). Sound familiar? It should. For forty years, one of the central projects of basic writing has been to empower or (depending on to whom you're talking) to inculcate into basic writers the ability to be or at least to pass as academics. Other areas of rhetoric and composition scholarship-literacy, discourse and genre studies, Writing Across the Curriculum, style, error, English for Academic Purposes, and on and on-tangle with the conventions of academic writing that Mlynarczyk and Maxson describe and that students are so often asked to reproduce. And if composition textbooks, the faculty syllabi that I review each semester as a WPA, and even paper mills are any barometer, the current norms of academic writing aren't in any danger of waning.

The implied rigor of the academic writing genre can, for some, contrast starkly when measured against the personal writing that Elbow has championed. Mlynarczyk notes that "Elbow would like [students]...to write well-told stories, effective narratives, drawing on their own experiences, developing their own 'voices,' finding power within their 'own' ideas" (II). For many compositionists, this expressivist approach rings provincial. In a review essay where he revisits the Elbow-Bartholomae debate and underscores Elbow's continued significance to the field, Robert Yagelski writes, “...expressivism (as a 'theory' about writing and teaching) and the process movement (as a pedagogical manifestation of that theory) have long been critiqued 
within composition studies" (533). And outside composition studies, too. We increasingly work in university milieus where administrations assess our courses and their effectiveness in meeting, for instance, general education goals and outcomes or information literacy standards. Or we work on campuses where colleagues across the disciplines assume first-year composition and especially basic writing to be students' Great Acculturator into academic discourse. And this is not even to plumb the social-epistemic turn in rhetoric and composition pedagogy. Many teachers find it difficult to justify focusing precious class-time on narratives, especially beyond more approachable first assignments. Academic writing, then, has become doxa. Mlynarczyk advocates expressive journal writing as a method for helping basic writers to become comfortable with ideas prior to attempting those ideas in more formalized writing and, thus, gaining proficiency in conventionalized academic prose. She stops short, however, of naming those expressive journal entries academic in and of themselves; in fact, she can appeal to little more than basic writing and first-year composition instructors' collective common sense when she writes, "Although the forms are often blended or overlapping in college writing, most composition teachers would agree that there is a fundamental difference between a personal account of living through one's parents' divorce and an academic essay arguing to end the system of no-fault divorce in the United States" (5, emphasis added). While Mlynarczyk concedes that blending (of genres, perspectives) occurs in students' academic writing and while she values student writers' use of the personal, she does so only so that personal writing may serve students' acquisition of academese.

Elbow, though, is still swinging. There has been no TKO. And rightly so. Though the contemporary field of rhetoric and composition can be accused of over-emphasizing Bartholomae and too easily dismissing Elbow, the Elbow-Bartholomae debate persists as "a kind of defining moment in composition studies" (Mlynarczyk 8), not only due to its status as historical watershed but because teachers, especially basic writing teachers, remain torn regarding the "relative merits of these two different types of writing" (Mlynarczyk 4). Competing demands on instruction spawn ambivalence that snakes through both the field and our classrooms, an ambivalence that can at times even pit some basic writing teachers against some of our first-year composition colleagues. On the one hand, we strive to assist basic writers in passing university writing exams and in honing the error-free, correctly formatted, linearly deductive critical thinking that will guarantee success in first-year composition and beyond; on the other hand, we seek 
to heal the scars of red ink past and to believe that "The Students' Right to Their Own Language" is more than a PDF on the NCTE website.

It seems to me, then, that composition as a field has much to gain by advocating for mixed academic discourses. As the epigram at the beginning of this essay notes, Paulo Freire insisted on "the indisputable unity between subjectivity and objectivity in the act of knowing" (The Politics of Education 5I). For Freire, meaning is made through consciousness and intervention. Because knowledge requires a knower, knowledge is always imbued with subject/ivity and, thus, limitations. Therefore, all knowledge is partial (as in not-whole and also as in partial-to). However, academic genres have traditionally recognized some knowledges and rejected others. Even in basic writing, a student-centered field that practiced the Scholarship of Teaching and Learning long before it became fashionable to do so, we can sometimes focus too heavily on the intervention side of Freire's dialectic. Whether because we as individual teachers ascribe to gate-keeping models of correctness versus appropriateness of language use, or we err on the side of academic conservatism and purported rigor due to concern for students' ultimate success in the university, or course caps seem to be always increasing, we can too frequently ignore the consciousness(es) of the actual students in our classrooms.

As Mlynarczyk demonstrates, it's possible to align Bartholomae's academic writing to James Britton's transactional writing and Elbow's stories to Britton's expressive and poetic writing. Art Young, also relying on Britton, states, “...poetic to transactional writing exists along a continuum where the writer's stance toward language and audience changes the more one writes in either the spectator or the participant role" (476). Writing of Clemson University's Poetry Across the Curriculum initiative, Young continues: "Students often attest to the 'freedom' of writing poetically once they develop trust that the teacher is encouraging creativity and risk taking..." (476). I draw two lessons here. Let me start with the second one first. Second, self-conscious creativity and risk-taking ought to be embraced as essential to students' writing processes. First, writers' positions toward discourse alter depending on whether they write as detached spectators (that is, less concerned with an audience's response, as with Britton's poetic writing) or as involved participants (where they might, for instance, attempt to persuade an audience, as in Britton's transactional rhetoric).

I would extend Young here and offer that when we ask students to braid together in the same text the always already enmeshed subjective/objective-to weave, for instance, the mandates of academese with alternative 
discourses-we enable student writers to be both spectators and participants in the same document, thereby opening up academic writing by giving expression to both the subjectivities students bring into our classrooms and the interventions being made therein. Through this braiding (for instance, of memoir and argument, of narrative and criticism, of the tale of one's parents' divorce and of the depiction of no-fault divorce at the national level), student writers can make the most of the rhetorical savvy that they bring into our classrooms.

\section{Minimizing the University}

Bartholomae's arguments of the mid-8os arrived as a progressive response to some previous scholars' reductionist essentialization of basic writers as cognitively deficient. ${ }^{\mathrm{I}}$ However, limitations did remain in his pedagogical approach, or at least in how that approach was often read and implemented. ${ }^{2}$ Specifically, the edict that students write only in academese is troubling. Patricia Bizzell has admitted, "inventing the university" was "fundamentally a one-way street. Students, it seemed, had to leave behind their home discourses and conform totally to the academic" ("Hybrid" 7).

While such assimilation may have helped a basic writer to pass (that university writing exam), what did she lose in the process? Academic conventions don't only empower students to say some things. Their commands disallow students from saying other things. Linguistic codes are radically divergent, and not everything can be said in every code. I can tell you that "It will soon rain," but if I do, I haven't told you, "It's fixin' to come up a cloud." I don't know what you hear and see when I write either statement. With the latter, you probably don't see the world through my four-yearold eyes, my head thrown back to reveal grandmamma beads of dirt in the creases of my neck, a clothesline, far above, slicing the plane of my vision. You don't see on her hip my grandmother's knuckles, raw from having scrubbed a load of clothes on a washboard in the backyard, her eyes studying the horizon and judging the distance between a dark sky and the still damp overalls that hang on the line. But neither of us will see that image if I use the former phrasing. Like the excesses of identity politics, Bartholomae's injunction can bifurcate student writers' lived experiences and "appropriate" academic subject matter (see Mlynarczyk's divorce example), and Yagelski might point out that part of Elbow's opposition to conventional academic writing hinges on the erasure of epistemic knowledge that coincides with the erasure of experience. 
The field's overreliance on a narrowed conception of academic discourse erases, of course, some experiences and some epistemologies more than others. Too often, veins of not only sexism, classism, and racism but also heterosexism and regionalism run through our writing classes, and we don't even see them because they've donned the mask of academic writing, a doxa that has become naturalized, perhaps especially for those of us who make our living promulgating it. Bizzell concedes that, because the academic community is a human one, its language does change. However, “...at any given time its most standard or widely accepted features reflect the cultural preferences of the most powerful people in the community" "The Intellectual Work" I). In the academy, she notes, those people have usually been white, rich males ("The Intellectual Work" I, "Hybrid" II), and I would add that they have also been seeming-heterosexuals who speak the Midwestern dialect of the nightly news.

The demographics of the powers-that-be often stand in stark contrast, however, to the students-that-be in our classrooms. Mark T. Williams and Gladys Garcia, for instance, observe, "As writing teachers at California State University, Long Beach, where nearly 50\% of composition students are the first in their families to attend a university and just 35\% define themselves as 'White,' we frequently see many of them struggle with academic discourse" (93). Still too often, though, teachers, facing stacks of student drafts, cross out Black English Vernacular or hillbilly discourse, thinking perhaps of Horatio Alger economic mobility myths or simply faltering under grading fatigue.

What message are we sending, to students, to ourselves, and to the broader public, when we police linguistic legitimacy? Nobody comes out of her mama's womb hedging claims and citing precedents. It is trained into us. However, there is a pedagogical futility here. When an overly narrow academic discourse is prescribed, we end up creating parrots who excel in replication, not agents who can enter in, own, and alter the discourse at hand, academic and otherwise.

If we are not wary, writing pedagogy can morph into little more than teaching test-taking, a shortsighted and culturally regressive enterprise. When we mandate that students think only inside the curriculum, our writing programs-instead of the laboratories they ought to be-become little more than echo chambers for our students as we whitewash academia's picket fence (now topped with concertina wire) all over again. (I realize I'm mixing my metaphors, but I'm fired up now.) Not only do we sentence students to mime rather than become academics; we also rob the academy of the epistemic and evolving knowledges students hold and might make. 
Even if this training "works," even if basic writers' academese sails them through every class from first-year composition to senior year WID courses, by too narrowly focusing on stereotypical academic norms, we fail to foster the kind of reflective rhetorical savvy that we all need in order to grapple with larger social discourses. Kermit Campbell, for instance, argues:

...as writing teachers we cannot allow whiteness and middle-classness to go unchecked in the classroom. If we abandon the critical perspective here because we see the values of one group as superior to others', as the principle aim of composition pedagogy, then we really aren't preparing students to become-as many of my fairskinned colleagues like to say-citizens, active participants in the shaping of our democracy. (339)

Campbell here speaks to the dulling of critical thinking that occurs when we hammer into students academic discourse [in his words, "normative boundaries in student speaking and writing" (335)]. Jeffrey Maxson goes even further, remarking on the material repercussions of our single-minded reliance on a strictly sanctioned linguistic code:

In the context of a writing class, the hegemony of formal language works as an aspect of racism and classism, making it more difficult for those who speak non-standard or non-prestige dialects to achieve success in education and careers, limiting their options in society. Further, it's the discourse of education...that classifies non-standard dialects as incorrect and that positions non-standard dialect speakers as not competent, uneducated, wrong or even cognitively deficient. And this discourse is what employers and others rely on when making negative judgments of non-standard dialect speakers. (27)

Both on campus and beyond, students as writers and citizens will be asked to perform and are capable of completing myriad varieties of intellectual work. The "critical thinking" goal that we so often set for ourselves in our professional documents charges us with enabling students to do this work. However, a too narrowly conceived notion of academic writing can impede all but the most formulaic academic argumentation, disempowering intellectual experimentation, especially for students from counter-communities as they are the folks most often urged to adapt. 
This is not to say that traditional academic discourse remains inaccessible to student writers of color or student writers from Woodbury, Tennessee, for example. Jacqueline Jones-Royster has reminded us that all of the voices in which she writes are her native tongues. However, strict demarcations that delimit ways of discursively being in academia are detrimental to many students (perhaps most students, perhaps especially basic writers), for this over-emphasis on a single code prohibits the linguistic richness that students bring into our writing classes, "the primary resource they bring with them to college" (Mlynarczyck I3). Ironically, students who either cannot or will not accept a restrictive pedagogy, one that requires checking (some) subjectivities at the classroom door, these are the very students often marked as failures while students who provide canned discourse with which they feel no connection might be labeled successful. Forcing many students to choose between academic success and home or chosen alternative cultures, we not only sever academia from whole fields of knowledge that marginalized students bring with them, but we end up further marginalizing these students who could be our most fluent rhetorical power players.

\section{Challenging the University by Revising the Continuum}

If the personal is political, the personal is damn sure academic as well. That's what's always bothered me about James Britton's continuum of language-well, really, about the continuum metaphor more generally. Continua imply that their subjects can't be more than one thing. The mercury can't read 85 degrees Fahrenheit and 55 degrees Fahrenheit at the same time. But why can't writing be transactional and expressive concurrently? Why can't it be both personal and academic? Or, better yet, in basic writing, how can it ever not be?

In composition we too often regard overtly personal essays as "gimme" assignments, easily accomplished projects that are frequently assigned early in the semester and are designed to increase students' confidence and assist their transition into more difficult, more remote, more prestigious academic writing. Mlynarczyk acknowledges this bent: "Students first need to explore ideas encountered in academic work in language (whether spoken or written) that feels comfortable, not strained, in order to work toward the goal of being able to write convincingly about these ideas in more formal language" (5). What nags at me here, though, is whether Mlynarczyk is implying a hierarchy. Is the value of personal writing only that it facilitates more proficient use of academic writing? Is the essay on "no-fault divorce in the United 
States" a more inherently impressive paper, a more difficult and useful task than the "personal account of living through one's parents' divorce"? (5). More specifically, does the masking of the self and the adoption of (potentially) another's language and mores make the work more valuable?

Britton speaks to the question: "Expressive language provides an essential starting point because it is language close to the self of the writer: and progress towards the transactional should be gradual enough to ensure that 'the self' is not lost on the way: that on arrival 'the self', though hidden, is still there. It is the self that provides the unseen point from which all is viewed" (I79). I appreciate Britton's reassurances about the persistent self. However, for me, there's something of a contradiction here. On the one hand, Britton warns that a writer's development from the expressive to the transactional should be gradual for fear that otherwise the writer's self will be lost. On the other hand, for Britton, the self is "the unseen point from which all is viewed, always and forever." (Okay, I added the "always and forever," but it seems to me implied.) If the latter is the case, I ask how the self could ever be lost, no matter how fast the move from expressive to transactional writing. Or, more important still, if the self is the "unseen point from which all is viewed," something with which compositionists (if with various and sundry tweakings) have increasingly concurred, then why must the attempt be made within first-year composition and basic writing to hide that self at all?

Deborah Mutnick points not to the fact but the facticity, not the objectivity but something-like-objectivity that academic writing enables:

The omission of the "I" in written discourses achieves an effect of objectivity, omniscience, and authority. Through the elimination of agency, statements assume a facticity, a presumption of truth, that more subjective discourse self-consciously calls into question. Although the use of "I" by no means necessarily alters the substance of an argument, it does foreground the interpretive, rhetorical dimension of all communicative acts. ... Together with psychoanalytic and deconstructive theories of self and multivocal (re)constructions of self by subaltern writers, the critique of objectivist discourse invites us to explore the parameters of "I" more closely. (82, emphases mine)

There is a common, fraudulent manipulation of discourse, then, in much academic writing and a challenge from Mutnick to re-examine the role of the personal in all rhetoric. 
First, there is the mandated exclusion of the "I" [not the pronoun (though, now that I think of it, maybe that, too) but, more broadly, the seeing subject, the self]. This exclusion attempts to counterfeit objectivity (a copy itself, with no original). (And here I'm thinking not only of Freire, his interweaving of the subjective and the objective, his contention that objectivity alone is impossible, but also of Judith Butler's performativity and its exposé of mandates that compel repetition of cultural commands as if they are natural.) Through the elimination of the "I" is won authority, a conservative directive in that it demands reproduction of a discourse that has marginalized many (including many of its own makers). This conservatism is especially stark in the face of changing enrollments over the last forty years (nowhere more famously than at City University of New York). ${ }^{3}$

I'm feeling defensive (perhaps one too many department meetings with Americanists explaining to me the shortcomings of Peter Elbow), so let me clarify that my point is not that we ought always, to infinity and beyond, privilege less formal registers or expressive narratives. Yagelski characterizes Writing Without Teachers as "an argument against academic convention" (537), and to the extent that that is true, I think Elbow gets it wrong. For one thing, in some instances, some writers' subjectivities may be academic (mine, for instance, at least here and now, and Elbow's, too, given the academic conventions he himself uses). Also, in educational and socioeconomic worlds where students can be failed and fired for sounding too hillbilly or too ghetto or too faggoty, strategic uses of academic discourse can be powerful, and though some would oversimplify his work, Elbow knows that. He clarified in the twenty-fifth anniversary edition of Writing Without Teachers that he wanted only to explore "the limitations of argument, doubt, debate, and criticism" (xxi), not eradicate them, and Yagelski himself notes the "high standards of intellectual engagement" (537) to which Elbow holds learners.

In composition, then, we should, alongside traditional academic mainstays, encourage a rigorous subjectivity and call for mixed discourses. By recognizing that knowledge necessitates a knower and that writing requires a writer and by asking students to foreground these facts in their writing, we can revise Britton's continuum and thereby open up academic discourse in progressive ways. Instead of seeing writing as a gauge that slides back and forth on Britton's continuum, trapped in a furrowed channel, we might envision the continuum as a slick surface along, around, and about which writing might skate. We can overlay on that continuum, whose gauge is now free to roam, the genre of academic writing, which will no longer contain only the transactional and a passing expressive but possibilities that 
were before constrained or, depending on the classroom, unimaginable. If we then zoom out and look at academic writing from space, we see an image appearing something like a knitting needle hidden in its own ball of yarn, the continuum part of the larger mass but not definitive of it.

It's not as if academic writing isn't already a tangle anyway. Chris Thaiss and Terry Myers Zawacki's Engaged Writers, Dynamic Disciplines has ably documented not only the differences in writing found across disciplines but differences in writing found within disciplines as well. Thaiss and Zawacki note, for instance, that many academics break disciplinary conventions; their "informant" sociologist Victoria Rader did so, for instance, so that her work on homelessness would reach a broader audience (45). This redrawing of intellectual lines no doubt encourages, in mathematician Daniele Struppa's assessment, “...traditional disciplines constantly [to] evolve towards a breaking of boundaries, towards an enlargement of their objects, and, essentially, towards a more interdisciplinary view" (43). The fragmentation of writing within disciplines is important for composition teachers to remember. Too often, for fear of churning out unprepared students and perhaps for fear of hearing complaints from colleagues across campus, we basic writing teachers invoke bogeymen from business and spectres from the sciences, trying sincerely yet reactively to ready our students for every possible writing scenario or instructor they might meet, knowing that some of our campus colleagues may feel that ours are the very students who do not belong at the university in the first place. However, of Thaiss and Zawacki's informants who do write strictly within disciplinary conventions, most of these faculty "...do not necessarily want undergraduates to learn to write within these conventions. Rather, for many, it is important for students to connect what they are learning in school with either their outside experience and/or ideas in the popular media and to write about these connections in a variety of forms" (46).

Patricia Bizzell has noted the variety of intellectual approaches within single disciplines, particularly the increasing appearance of mixed discourses (what Bizzell formerly tagged as "hybrid" discourse but now refers to as "alt/dis"). Bizzell attributes the growth of these alternative discourses to the growing diversity of the academy itself, a development that basic writing both spawned from and fosters: "With the diverse population, slowly but surely, come diverse discourses from people's various home communities. Previously non-academic discourses are blending with traditional academic discourses to form the new hybrids" ("Hybrid" II). While Bizzell has focused on the alt/dis of scholars, like rhetoric and composition's Victor Villanueva 
and historian Joel Williamson, others have explored alt/dis in composition classrooms. Hannah Ashley, for instance, invoking Mikhail Bakhtin's heteroglossia and Judith Butler's performativity, has argued for classroom practices that destabilize naturalized academic conventions, "poking at fixed categories, disputing them as they are performed" (8). In doing so, Ashley advances carmen kynard's multivocal essay "New Life in This Dormant Creature': Notes on Social Consciousness, Language, and Learning in a College Classroom" as a prototype of how students might embrace play when using sources in their academic writing. According to Ashley, "Reported speech-bringing the voices of others into our own writing through quotation, citation, and paraphrase...-is, arguably, the convention most central to first-year students' classroom writing success" (9). kynard consciously plays with academic mores by elevating some of her own sources (for instance, through the use of metapragmatic verbs) while diminishing others by foregoing quotation marks, reversing nominalizations ("grammar" to "grammarizing," for example), and including ironic asides, thereby revising Britton's continuum to let the transactional and expressive skate together across the surface of her prose (I2).

According to Bizzell, mixed discourses like kynard's are gaining scholarly acceptance not because they are "more comfortable or more congenial" but because they allow "their practitioners to do intellectual work in ways they could not if confined to traditional academic discourse" ("The Intellectual" 3). Bizzell cites Williamson, for instance, an eminent, senior historian whose scholarship focuses on the American South and race relations. Williamson confesses in a Journal of American History article his own willful ignorance of racial violence; that confession then enables him to point to the willful ignorance of the entire field of Southern history. When we encourage not just scholars but also basic writers to use alt/dis, not only in early "personal" essays or in writing journals but also in privileged academic writing, part of the intellectual work these student writers do is to revise academia itself. Donald McCrary has advocated the use of alt/dis in writing classrooms and asserts, "Using hybrid discourse would allow students to identify and reconcile their encounters with different languages, to shape them into a single utterance representative of their linguistic knowledge, to make a valuable contribution to academic discourse" (75, emphasis added). "Contribution" is key. No longer must students throw back their heads to glimpse academic discourse on a mile-high pedestal. Upending banking models of education that require students only to ape (and, thus, replicate and conserve) academese creates space for students to call on the linguistic 
richness of the many cultures (including academic ones) that they always already inhabit and helps them develop a critical discursive consciousness to intervene in those cultures.

\section{Braiding Rhetoric and Rhetorical Subjects}

Rhetorical consciousness and rhetorical empowerment (that is, cognizance of and facility with the creative power of discourse) can be achieved through the rhetorical strategy of braiding. If literacy is not just a storehouse of knowledge but a social action, then literacy instruction stands as a call to action; likewise, if our classrooms privilege a naturalized, narrowly defined academic discourse, then we effectively interpellate students into a status quo that re-marginalizes many (in- and outside the classroom). However, by embracing Freire's notion of becomingness, of "men and women as beings in the process of becoming - as unfinished, uncompleted beings in and with a likewise unfinished reality" (Pedagogy of the Oppressed 84), and by pairing this concept with Freire's call to dialogue, "that truth lies in the quest and not in the result, that it is a process, that knowledge is a process, and thus we should engage in it and achieve it through dialogue" (Freire and Faundez 32), we can ask student writers to engage in such dialogue with their own multiple selves on the pages of single academic papers. We can do so by asking students to braid selves, genres, writerly purposes. By inviting student writers to braid together in the same document their own perspectives and experiences, for instance, with academic discourse community mandates, a mutually informative dialectic is created, and academic writing can be expanded in ways that student writers may find exciting, battling what April Heaney has identified as the single most salient feature of basic writing: writers' uninvestment in the writing process (34).

When student writers maintain a multifocal perspective within single texts, academic writing as a genre is opened up; specifically, it is opened up to the theorization of experience. To separate students from their lived experiences, cultural intelligences, and counter rhetorics with only the promise that they will acquire power as they adopt the language and mores of the academy is short-sided, dishonest, unnecessary, and impossible. For instance, Min-Zhan Lu discusses Mike Rose's student, Lucia. Lucia had chosen to major in psychology due to her desire to help those with mental illness, like her brother who experienced a psychotic break, and she thus had great difficulty with academic readings that sought to deconstruct mental illness altogether ( $\mathrm{Lu}$ I35). How would it even be possible for Lucia to read 
her course texts only as an academic, not as the sister of a schizophrenic? Moreover, why would we want to ask her to do so? Why trap her inside a course's curriculum? Academic writing has never been as simple as constructing a thesis and locating evidence and incorporating sources. It's more often been about constructing the correct thesis or finding the right evidence or incorporating appropriate sources, so much so that the academy has become recursive, often walling itself off from new knowledge, particularly knowledge from cultural outsiders. Narratives, students' own and others', once theorized, have the power to pierce such myopias. Braiding challenges teachers to honor or at least cope with the tension of multiplicity on the page, and it also asks individual students and (eventually) academia as a whole to incorporate and contend with the new knowledge that is made.

For students from marginalized communities, this theorization of experience already happens. It is a matter of survival. Our students use cultural catch phrases_-"driving while black," for instance, or "hasbian" (think Anne Heche)-that demonstrate that many of them have already theorized their own experiences and the lore of their communities and know what time it is. Expanding academic writing by asking students to theorize the personal reallocates power, and basic writers who are almost always more likely to be multivocal stand to become some of the most effective rhetorical power players in our classrooms. As Gloria Anzaldua has stated, "The art of composition, whether you are composing a work of fiction or your life, or whether you are composing reality, always means pulling off fragmented pieces and putting them together into a whole that makes sense" (Ikas). Thus, students who know that to "pick up a room" and to "clean" it do and do not mean the same thing begin our classes rhetorically advantaged. Asking students, first, to bring to bear a critical lens on their cultures, subjectivities, and rhetorics and, second, to braid these together in their writing (of selves and of essays) empowers students and explodes stereotypical constructions of "student writing." For basic writers, academia becomes more relevant even as it is deconstructed. Students do not simply consume and replicate a mythically homogeneous and often foreign academic writing; instead, they tell a shifting story, their own shifting stories, of survival among the multiplicities and fragmentations of multiple discourses, many cultures. We end up with texts that quote the discourse of street gangs, "the first time the Buccaneers / let you pass; / now the Buccaneers / are gonna kick your ass," and the discourses of Cicero, Gramsci, and Burke (Villanueva I). 


\section{Laura's Story: Braiding Lesbian and Soldier}

"Please don't mention my name to anyone." Laura's ${ }^{4}$ voice stopped her classmates cold. The zippers of book-bags fell silent, and the always-animated exodus of the students enrolled in my queer composition course hung there, suspended. "It could get back to my commander." It was a moment of vulnerability, not an easy place to be for a spitfire cadet from the heartland.

Laura wore her olive drab to our class every Thursday. A military scholarship recipient, she had agreed to join the Army upon completing her Bachelor's degree, a commitment she had made because she could not otherwise have afforded to attend the university. Laura participated in an arduous ROTC program; it was nothing, for instance, for her to have rappelled and visited the rifle range before our 9:30 a.m. class. Also spending many weekends in a program similar to the Reserves, Laura expected to be inducted as an Army officer upon her graduation, serving no less than four years.

During a time when abolishing the "Don't Ask, Don't Tell” policy remained unthinkable to the military and the federal branch, I designed, proposed, advertised (prodigiously), and taught our university's first GLBTQthemed composition class. With nearly all of the twenty-two students openly gay, lesbian, bisexual, and/or queer-identified, ${ }^{5}$ Laura's identity as a lesbian did not distinguish her in this writing class. Instead, her identity as a soldier did. Laura was a motivated, driven perfectionist who tried to uphold the military's expectations and mottoes. She frequently mentioned her "love of country" and "equality for all." Those declarations initially sounded canned to me. For Laura, though, patriotism was true, and it was also utilitarian, offering her a ticket out of a stifling, small-town future. Still, the risks that Laura knowingly took when registering for our course reveal the equally deep significance of her lesbian identity. Save this class, Laura squelched her lesbianism, and our classroom was, she acknowledged, "pretty much the only place I'm out," yet she chose to enroll, in the face of her own fears and serious potential material repercussions. Laura entered this class, then, in some ways bifurcated, an out Army cadet but a (generally) closeted lesbian. In retrospect, the course's design may initially have exacerbated her fragmentation, for I aimed to create a composition class where GLBTQ-identified student writers could, through the creation of braided texts (especially texts that directly addressed students' multiple subjectivities), pry open closed notions of "academic writing" and "student writer."

My primary impetus for developing this class was the continued incomprehensibility of GLBTQ-student-writer, a term that too often remains 
an oxymoron. That oxymoron pivots at both hyphens. First, even in a world where Ellen DeGeneres can be a COVERGIRL and Chris Colfer can both be and play gay, too few opportunities exist on college campuses for students to (simultaneously, openly, and comfortably) be GLBTQ and student. In the first nationwide study of the campus climate for GLBTQ students, the Q Research Institute for Higher Education found "that nearly a quarter of gay, lesbian, bisexual, and queer students...had experienced harassment at their colleges, and more than half had observed...it" (Lipka). Specifically, dormitories remain unsafe (Robinson, Lipka), and the Greek system remains unwelcoming (Hall and La France). Homophobic graffiti litters campuses (Getz and Kirkley), and spectators at college sporting events yell homophobic epithets at opposing teams (Salkever and Worthington I94). GLBTQ student centers and pride symbols are vandalized (Lipka). Student affairs professionals self-report diminished skills in working with GLBTQ students (Croteau and Talbot), and faculty make homophobic jokes and comments in lecture halls (Iconis, Gortmaker and Brown, Renn). Freedom, then, for GLBTQ students to be GLBTQ and student is impeded across the campus.

That oxymoron, though, reads another way. Even when GLBTQ students are out to roommates and teammates, for example, or enroll in GLBTQ studies programs, they often continue to face difficulty foregrounding GLBTQ subjectivities when writing for mainstream courses, perhaps especially the general education courses taken early in their academic careers. This status quo has been amply documented by composition scholars. Pamela J. Olano writes of academia's "system of monosexuality-if we are all assumed to be heterosexual, then we can eliminate that 'constant' and move to other 'more important' work" (77). Cynthia Nelson notes that her colleagues are "perturbed, by the idea that lesbian or gay identities could have any relevance to language learning. To them, gay-friendly teaching is...invasive, inserting a discourse of (homo)sex into a field in which that discourse is neither relevant nor appropriate" (373). Sarah Sloane documents one student writer's experience of being forced to write on a topic of special interest to the gay community (people living with AIDS) but feeling unable to do so as an out gay man. According to this student, "I disappeared. I went into my room and locked the door" (34), the student eventually failing his composition course. Unwittingly heterosexist classrooms (via the use of tokenizing textbooks, for instance, or through unintentionally normative paper assignments) can erase the feasibility of GLBTQ students voicing these subjectivities in the writing they produce for our classes. More generally, if Bizzell must continue to sell us on the value of alt/dis for scholars (those with 
the letters after our names, those with the most power in academic writing communities), how hard must the sell remain before many of us encourage students to foreground subjectivity, particularly alternative subjectivities, and to use alt/dis in their academic writing? Not in personal narratives abandoned early in the semester or in journal entries where reflection is warehoused, but in academic writing where prized objectivity too often remains synonymous with heterosexism? As I designed this class, then, I kept as a touchstone the goal of providing GLBTQ student writers a space to effect those subjectivities in their academic writing.

Equally important was the aim to queer subjectivity more broadly. Queer theory provides a useful poststructuralist step away from the homogenizing excesses of identity politics. Pointing to the partial and contingent status of any identity, queer theory views all subjects as discursive and as recognizable only through representation. Thus, instead of advocating an inclusive politics (or pedagogy) that attends to a natural or even stable gay and lesbian community, queering identities emphasizes the multiple subjectivities inherent in any single subject, thereby rejecting totalization and instead allowing for conditional alliances. I hoped that a queered composition course would pry apart what have become reified, trite mainstays in some composition classes (e.g., "Should gays be allowed to marry?") as well as disrupt composition's common marginalization and erasure of actual GLBTQ students. I sought that this course instead allow these student writers to encounter in the reading list, to discuss in classroom conversations, and to investigate in their writing the divergent subjectivities, theories, experiences, representations, histories, sciences, legalities, and the like that both the students and leading GLBTQ thinkers found most pertinent to GLBTQ subjects and communities.

Thus, when hammering out the course's calendar, I attempted first to queer our reading list. For instance, we read writers like Judy Grahn (who claims that everyone from Billie Jean King to Sappho shares a common gay heritage), Lillian Faderman (who claims lesbianism is but a twentieth century invention), and Kate Bornstein (who writes of her own male to female (MTF) sex change; her subsequent discovery of her own lesbianism; and her long-term relationship with a lesbian separatist who ultimately underwent her own FTM sex change only to come out as a gay man.) We read parts of Jonathan Ned Katz' Gay American History in concert with selections from Carol Queen and Lawrence Schimel's Pomosexuals: Challenging Assumptions about Gender and Sexuality. I was hoping, in other words, that every student would find parts of her- or himself reflected in some of the readings, all the 
while knowing, indeed demanding, that those readings were not congruent. This reading list, in my mind, satisfied Patricia Bizzell's directives that, when encouraging alt/dis in student writing, course readings both "focus on a cultural crux of our day, the sort of vexed problem that professional academic scholarship grapples with" and that that same crux "be carefully derived from local conditions, in what the teacher's own students might be interested" ("Hybrid" I7). As these students had chosen to enroll in this GLBTQ-themed class, I felt confident that the readings' subject matter would speak to them, though not in identical ways, and that's just what happened. For instance, students chose when they would co-lead discussions based on their interests in the day's topics or genres. Philosophical treatises, historical accounts, and creative nonfiction drew some students while clips from a recent Oprah Winfrey Show, a transcript of a Jerry Falwell sermon, and the mission statement of the Human Rights Campaign Fund interested others. Common interest, however, in no way predicted that discussion leaders would agree in their interpretations or opinions of readings, and more often, they did not. Moreover, (contested) subjectivity consciously remained our lens for investigation throughout the semester, and not only the readings but students' comments in class were interrogated along those lines by all participants.

Two things emerged. First, ours was a queered classroom, not a classroom that mandated students' queerness. Instead, the course's structure allowed the GLBQ (and the three straight) students' voices to be heard but not at the cost of one another's. When reading, viewing, listening, speaking, and writing, students were asked to consider divergent identities, both within and between subjects, even as they might sometimes self-consciously foreground (one of) their own, doing so within a diverse (sometimes heatedly so) GLBTQ academic community. Second, the classroom encouraged but did not demand braided discourse. The students were provided, as Bizzell suggests, "generically diverse" texts that showcased "a lot of examples of discursive strategies" they might adopt in their own writing ("Hybrid" I9). Students also wrote multi-draft papers in which I encouraged them to "connect the materials with their own experience. They must cite these texts and engage them rigorously; but they must [in my classes, might] also talk about their own experience in ways that feel right to them" ("Hybrid" I9). I encouraged but did not compel students to attempt braided texts because, for me, much of the power of alt/dis is that it often materializes in very different ways, and I worried that a mandate for braided texts on an assignment sheet might diminish that power by requiring and unintentionally 
stabilizing these discourses. Also, I did not want to imply that students had a single authentic self that they should invoke; in fact, while many of the students originally registered for this class because they felt disenfranchised as GLBQ students in the rest of their curricula, once in the class, students' other subjectivities often became more important with divisions along race, gender, urban/rural, and especially political lines, for example, appearing in class discussions. Finally, I didn't want to force any student into self-revelation that might feel needless or threatening.

That Laura's multiple subjectivities were (perhaps frighteningly) difficult to negotiate emerged in her writing almost immediately. In her first responses, Laura carefully summarized the readings, only occasionally venturing a tentative evaluation as to whether an author provided "enough evidence." Meanwhile, her classmates (for good or ill) submitted viscerally surging responses. One student, for example, after we read historical accounts by John D'Emilio and George Chauncey, railed at his own "socalled General Education" history class that never mentioned GLBTQ folk. Laura's first writing of the course didn't necessarily strike me as problematic. Many young students initially have difficulty discerning summaries from responses, and I wondered if, perhaps due to her single-minded pursuit of excellence, she, like some of Hannah Ashley's students, might "hold quite foundationalist beliefs about everything from thefiveparagraphessay to standard English" (7).

This disparity between Laura's writing and her classmates' became especially clear when the first draft of an early, short paper came due. Students were given only skeletal instructions-due dates; a page minimum; the proviso that papers in some way explore the readings of the course or our class discussions. I also encouraged students to turn their "lens on their uses of 'I'-which of their I's are they using, to what end?" (Ashley I3), but I didn't require this rhetorical move. Most students submitted ardent essays. For instance, one African-American student, inspired by readings from Essex Hemphill's Brother to Brother: New Writings by Black Gay Men and Kath Weston's Families We Choose, wrote of the greater importance of biological family for GLBTQ folk of color, given the racism in the white gay community, and he then reflected on his own family ties. Another student playfully argued that our campus's Women's Studies program should, per Marilyn Frye's suggestion, recruit straight women to become lesbians and then went on in a teasing daydream to imagine how her experience as a Women's Studies minor might change. Laura's first draft, however, skirted the course's theme, our readings, and our class discussions altogether. She 
instead submitted a paper explaining why Zora Neale Hurston was her favorite writer, focusing on images of nature in Hurston's fiction. When I conferenced with Laura, I commended her on taking a chance and injecting herself into this draft. I worried, though, that the draft hadn't addressed, even minimally, our course's theme and asked how she planned to enter the conversation of our class in her next draft.

Two things surfaced during our conference. First, Laura clarified that she had sought to write a good academic paper, which she described as focusing "on a proper topic, you know, that didn't use 'I' and stuff." Gently, I responded that Laura actually had used first-person pronouns and that that writerly choice was fine, that it didn't make the paper less successful or less academic. Laura then confessed that she had known all along that her draft had "no real significance to the issues that we have been discussing in class," and she went on to say, "In essence, I was taking the easy way out of facing the hardships I have in dealing with GLBTQ topics." When I asked her to talk to me about those hardships, she simply repeated, "I don't know. It's just hard." I wanted to acknowledge Laura's passion for Hurston, but I also wanted to challenge both her "book report" approach to this draft and her evasion of the class's theme. Like Bizzell, I wanted Laura to "develop a range of experimental discourses," to cultivate "a sort of craft-person attitude toward writing, in which various tools are developed and students learn to deploy them with greater facility" ("Hybrid" 20). Laura and I sat over coffee for a solid hour and brainstormed lots of revision strategies. I offered, "Could you connect images of sexuality in Hurston's novels with her images of nature?" and "When you start to have difficulty in 'dealing with GLBTQ topics,' could you start to write about that difficulty within the draft itself?" The conversation seemed to go well, and I was excited to see what Laura would come up with in her first round of revision.

When I collected the next set of drafts, however, I was surprised to find that Laura was either unable or unwilling to attempt the experimentation we'd discussed, for she had completely discarded her Hurston draft and submitted an altogether new essay, this one about her uncle Scott. Therein, Laura recounted her family's rejection of Scott, a gay man who fled to San Francisco, only returning home to the rural Midwest when he knew his death from AIDS was near. In this new draft, though, while Laura could state the fact of Scott's gayness, she did not engage it. She writes, "[Scott] loved children, roller coasters, ice cream, raking up leaves and then playing in them.... This is the way I remember him, not as a gay man with AIDS." I could see that Laura struggled in this paper to frame her uncle within the 
scaffolds of the assignment and the class and to foreground her subjectivity even more fully than she had in the Hurston text. Throughout her paper, though, she seemed either to recount her uncle as a personification of his illness or as a loving person unconnected to that illness; she could have been describing two individuals instead of a single man who lived a complex reality. Her new essay, then, mirrored the same bifurcation of subjectivity that her inability or refusal to revise that first paper had revealed. Laura could talk about "gay issues" only by segregating them and removing herself from them, or she could talk about herself and her personal life only after she'd purged "homosexuality" from it, this even after she herself had registered for a GLBTQ writing class in which she sat as a self-identified lesbian. ${ }^{6}$

Probably due as much to her aspiration to remain an "A student" as anything else, Laura was attempting in these early pieces to braid discourses, but her writing seemed to me to remain less braided than still trapped in Britton's furrowed channel, moving in some paragraphs toward the transactional and in others toward the expressive. I almost felt as if she could have formatted her writing into columns, symbolic of...her habit? her need? conventionalized academic mandates? She could admire Hurston but only if neither she nor the author's characters were sexual beings. She and her family could love her uncle as a fun-loving, gentle soul but not as a dying gay man.

Overarchingly, Laura's early writing struck me as waffling between a kind of unthinkability and a fallback on often conservative, potentially mimed positions. For instance, when she responded to portions of Randy Shilts' And The Band Played On, Laura argued, "This country must work together, not against one another, so that some day we will have a cure to combat this deadly disease." Early in our class, this seemed as penetrating as Laura was willing to be. Moreover, the tone of her language often rang similar to that of the military Code of Conduct that she quite seriously attempted to follow and that she quoted to me, saying, "I will never forget that I am an American, fighting for freedom, responsible for my actions, and dedicated to the principles which made my country free. I will trust in my God and in the United States of America." Just as the military doesn't encourage questioning of this code (for instance, problematizing what it means to be an American or just whose freedom is worth fighting for, at home or abroad), neither was Laura willing to pursue such inquiry. Thus, her closed conceptions of academic discourse; inherited, superficial rhetorics; and real-world, homophobic dictates seemed to amalgamate and create a block in Laura's writing, at least initially. However, even though her subjectivities and their 
discourses seemed early in the semester to regard one another with a kind of leprous untouchability, when I read her first writings collectively, I wondered if some of the work of braiding had not begun in that Laura as writer and subject embodied conflicting identities and beliefs and that conflict was seeping out onto the page. Perhaps students who claim subjectivities that have been overtly censured-gay students from conservative families or faiths, for instance, or rappers who can roll out social commentary in double-time triplets but who can't pass a placement exam-may particularly exhibit conflict in their writing when attempting to bring subjectivities and discourses into contact.

From my (granted, remote) perspective as her teacher, both Laura's lesbian subjectivity and her understanding of the complexity and partiality of language seemed to deepen as the semester went on. Perhaps because she was for the first time in her life publicly presenting herself as a lesbian and communing with other GLBTQ-identified folk in a challenging academic milieu, her classroom participation grew bolder. She became more likely to grapple publicly with our readings, to ask questions of other students, to challenge positions she didn't agree with, and to speak of changes in opinion that she began to experience.

This shift appeared in her writing as well. About nine weeks into our sixteen-week semester, Laura wrote a response to an interview with Marlon Riggs. Quoting Riggs, she noted the following:

In a discussion earlier in the semester, there were several of us students who arranged a "hierarchy of things that are virtuous in our character", [sic] I being one of those, saying I am female before I am lesbian. It seemed to me that my argument was sound until I read what Riggs had to say. Why should I have to put one character as more important than the other when both make up the person who I am?

Echoing the work of many GLBTQ writers of color, like Audre Lorde, who refuse hierarchy of, in Lorde's case, lesbian/black/feminist identities, this was the first of Laura's writings that pushed at what had before been stable boundaries. Here she began to reject the codification of her own subjectivities that she had previously abetted. Writing of real-world hegemony that ruled her, she lamented, "...I am supposed to be a soldier but that also means that I will have to hide my sexuality. Also, as a female, I have to work twice as hard because it is difficult for a woman to lead men who dislike 
the idea of being led by a female." What before had been neat in Laura's writing began to crumble, first, as she dropped the supposed objectivity of academese and began to interject into this reading response her own experiences and, second, as the rhetoric of the military is shown up as counterfeit and invested. It seemed to me that occurring within Laura was what Bakhtin calls a "critical interanimation of languages," the language of queer studies clashing with military discourse (296). When that critical interanimation occurred, as Bakhtin predicts, Laura appeared to realize that "the ideological systems and approaches to the world that were indissolubly connected with these languages contradicted each other and in no way could live in peace and quiet with one another" (296). Thus followed "the necessity of actively choosing one's orientation among them" (296). For Laura (as for all of us), this choosing between discourses and subjectivities was no simple task. Laura's identities began to tumble into one another in this reading response, and, just as they did, her writing for the first time criticized the authoritative superstructures that sought to prevent them from doing so.

Here Laura began, fully and more successfully, to braid discourses, almost despite herself. Bringing her full attention to and becoming angry at the rhetorical and material double-binds that sought to regulate all parts of her life, Laura began to interrogate the discourse of equality and opportunity promulgated by the military. Using the methodology, first, of juxtaposition and, second, of increasing anger, Laura's writing became more reflective, more piercing, and more vital, not just to me but to Laura herself.

Laura's criticism, however, was cast not only on what might typically be viewed as conservative forces like the U.S. Army. Laura also criticized a gay and lesbian movement that would mandate proper lesbian comportment. Approximately three weeks after she wrote the response to Riggs, Laura complained, “...one should not have to necessarily 'become involved' in order to be a homosexual. There is just too much emphasis on becoming part of an organization if you are a GLBTQ individual." This opinion would have been unpopular in our class as so many students entered the course heavily politically involved, became more politically involved after enrolling, or professed respect for their peers who did such work. For Laura, though, joining GLBTQ political or social groups could be dangerous as doing so could result not only in the end of her education but also in the end of a career in which she aspired to do well. For Laura, adopting (what she viewed as) a political identity within a GLBTQ community would be antithetical to who she considered herself to be. She maintained, “...defining oneself into a certain category or group is almost detrimental to the sense of identity one 
has for himself or herself," claiming that (some?) definitions of lesbianism (and other subjectivities) "only create barriers for an individual seeking to discover identity." While Laura's avowal (one she made early in the course) that she is innately lesbian was a position that I had pushed her to interrogate, even if she eventually maintained the belief, Laura ultimately insisted that innate lesbianism (what some might label an essentialist positionality) in the end exists as just one of many significations of lesbian, one that is ultimately as valid as political lesbian: "One should not feel that he or she must be in the political realm of sexual identity in order to take on that identity." Herein, Laura continues to grapple with larger coercive discourses, and she demonstrates increasing facility in navigating these discourses, showcasing a more confident and more complex "self-conscious performance of 'self'" in her writing (Ashley 5), demonstrating the kind of aware performance of subjectivity that so many basic writers could benefit from refining.

This increasing intricacy of her own subjectivity reveals that Laura is no more soldier than she is lesbian but perhaps no less so either. I began to rethink, then, what sounded to me as canned discourse earlier in the semester. Laura does love America, and she does want to be a good soldier, and if that discourse is inherited by her, it's no more so than, say, a stereotypical example of lesbian-feminist rhetoric might be. However, Laura is also a lesbian, and braiding together those heretofore oppositional identities and discourses did allow her to fragment her prior unadulterated acceptance of a pro-military rhetoric that erases her.

The culmination of Laura's writing came in her final paper, the longest of the semester, where she finally researched and wrote on the military's “Don't Ask, Don't Tell" policy. This last paper manifested as an attempt, if not to coalesce what had seemed to Laura and to me as oppositional soldier and lesbian subjectivities, then at least to refuse their inimical bifurcation as she braided them into a powerful dialogue. Laura began this draft by criticizing “Don't Ask, Don't Tell” as unconstitutional. Clinging to her belief in American ideals, she decried the policy as one that "does not ensure that a homosexual in the military will receive equal rights and respect as a soldier of his/her country." Laura additionally cited the hypocrisy that permeates military procedure. After noting the secrecy, fear, and ostracism that the potential dishonorable discharge of gay soldiers inflicts on these members of the military, Laura noted that the military "swears to protect the very principles...which [it]...condemns, the Constitution of the United States." Insisting on her respect for all soldiers who "serve their country with integrity, courage, and honor," Laura condemned a policy that allows the military 
to investigate a suspected gay soldier based on as scanty evidence as "appearance, hearsay, or even unjustified suspicion." Laura even went so far as to interview a career Army officer who, a lesbian herself, had been investigated purely because she was artificially inseminated. Noting that her colleague's "family and many friends were called and harassed by military officials [who tried to convince them to] divulge her sexuality," Laura protested that even this woman's barracks were searched for some proof of lesbianism. While this investigation never produced enough evidence to discharge this officer, it did succeed in "hurting her family and her dignity as a soldier." Laura reaffirmed that she takes seriously her sworn oath as stated in the military's Code of Conduct, one that pledges her allegiance to America's ideals, but she also here began to struggle on the pages of her text with the

hypocrisy of the foundations upon which our country is based, life, liberty, and the pursuit of happiness.... One should not have to hide his or her sexuality because he/she has the right to liberty and happiness. In essence, this policy creates an atmosphere in which discrimination, harassment, and even physical abuse toward lesbians and gays is tolerated and, to some degree, encouraged.

Unable to reconcile easily her soldier and lesbian subjectivities and also her belief in American ideals and her witnessing of American hypocrisy, Laura's indignation grew and crystallized in this paper, lesbian and soldier finally clashing (or perhaps merging) in her conclusion:

"I am an American, fighting for the forces which guard my country and OUR way of life. I am prepared to give my life in their defense"... is the pledge that all individuals of the military make, whether homosexual, heterosexual, black, or white. That pledge is the basis for every American soldier in the armed forces. In essence, all persons are soldiers fighting for a certain cause which they believe is moral and just. It is important that as soldiers for gay/lesbian rights, that... OUR way of life be protected and respected.

In fighting for what she deems to be moral and just, Laura has emerged a different kind of soldier here. She is, yes, a soldier who defends freedom, but now, instead of accepting the erasure of her own lesbian subjectivity, she fights for a freedom that the military would in fact oppose, the freedom for GLBTQ Americans to live in a milieu of safety, respect, and equality. She is 
not just a soldier for America, and she is not no longer a soldier for America. She is instead a soldier for a queer America.

In this braided essay, Laura demonstrates many of the characteristics of hybrid texts outlined by Patricia Bizzell. In her explication of Villanueva's Bootstraps: From an American Academic of Color, for instance, Bizzell points to Villanueva's “willingness to use a variant range of cultural references" ("Hybrid" I3) and his use of "personal experience which is absolutely taboo in traditional academic discourse" ("Hybrid" I4). Laura's essay foregrounds both of these rhetorical moves. She invokes the rhetoric of independence and freedom from elementary school history lessons even as she invokes the chants of Equality Now from gay rights marches. Using an all-caps, first-person plural possessive "OUR" in both instances, she demonstrates her own multiple subjectivities and her unwillingness to settle any longer for discourses that represent her only through the rhetorical amputation of part of her self(s). Bizzell also points to Villanueva's use of "offhand refutation" ("Hybrid" I4) and his use of humor, common moves in hybrid scholarship. While these two moves may indeed be counter to much published scholarship, Laura's use of direct confrontation and rage (in some ways the opposite of Villanueva's strategies) strikes me as counter to the genre of "student paper." Students so frequently hedge their claims for fear of "getting it wrong." Laura, however, by the end of our class, unleashes her anger and allows for no sacred discourses, refusing her obliteration whether it be for a conservative or progressive cause. Her story within this class points to, I think, the new kinds of intellectual work that Bizzell so lauds and the deep, thoughtful prose that students produce when they are asked to discern, within a single text, how they are indicted and privileged, erased and lauded by various cultural rhetorics.

\section{When the Conflict Speaks: \\ Gaining Power through the Queerness of Braiding}

Many student writers' multilvocalism readily appears in our classrooms since students from some marginalized groups disproportionately place into basic writing in the first place; their prose leaves the taste of hayseed or corn tortilla or street grime in the mouths of standardized tests readers or admissions officers. While gay and lesbian students are often a less visible minority in basic writing classrooms, they, too, enter our classes steeped in exploration of subjectivities and the languages of countercommunities. By embracing the queerness of braiding — that is, braiding's 
rejection of inherent essentials and single truths (whether those be coming out metanarratives or academia's objectivity imperative)-student writers can take advantage of their own rhetorical prowess and can challenge the heterocentrism (among other "isms") of academic discourse even as braiding helps insure their facility with the dominant discourse.

In giving students the space to challenge and claim a new facility with the norms of dominant discourse, braided texts produce at least two immediate benefits. First, student writers can call on the multiple languages they speak. As Bizzell has pointed out, "Actual humans are usually acquainted with more than one discourse, without being essentially defined by any..." ("Hybrid" Io). Braiding enables students, particularly basic writers who are so often more likely to be multivocal rhetors (and to have been punished for it), to invoke the most significant asset they bring to the writing classroom, their facility with multiple rhetorics. Second, braiding "productively, practically, assist[s] students in studying the ideological character of language, without alleging that language and literacy are fixed, essential" (Ashley 8). By encouraging students to summon in the same text multiple discourses, student writers "understand the political, material, power-laden meanings attached to language choices" (Ashley 6), a reality that many basic writers have already spied, if not before coming to college, then often in the very news of their placement. In fully recognizing the power relations inherent in language, power relations that both reflect and create the larger culture(s), students become more aware, more deliberate rhetoricians, consciously choosing the subjectivities and the rhetorical strategies they foreground in their writing.

Braided texts are challenging for students. If braided texts are not throwaway "gimmee" narratives that appear early in the semester for students to move beyond, neither are they self-indulgent, anti-intellectual essays with more therapeutic than academic value. Just as some students can effortlessly mimic academese in clichéd academic arguments, other student writers can undoubtedly trot out (what too often reads to their teachers as) the hackneyed "winning touchdown" essay. The braided paper, though, encourages students to bring discourses and selves into dialogue in order to increase their agency as writers. With dialectic as the central project, heated discussions and disagreements appear, not only between students (for instance, in classroom conversations or in peer review activities) but also within students on the pages of single papers. In some ways, then, struggle and conflict are at the core of braiding - but the conflict is empowering, allowing students to challenge dominant mores that they previously 
may have considered unassailable. Laura's story provides a "perfect storm" example-attempting to come out as a lesbian yet stay in the military, attempting to reconcile her innate lesbianism with the politicization of that identity, attempting to defend a country based on freedom that would deny her her own rights. Not every student will come into a class so bifurcated, but many basic writers will. What does it mean to have earned As in high school English classes only to place into basic writing? to be looked at with suspicion by one's family when one slips into academese at home? to study mental illness and have a schizophrenic brother? to consider no-fault divorce in the U.S. and to remember one's parents' split? By asking students to acknowledge the writer behind the writing and the larger discourse communities in play, we invite students within single texts to bring their multiple selves into dialogue and into academic discourse. Students bring their selves and the academy into dialectic, deepening their investment in their writing as they map new paths for their intellectual work.

In this way, braiding is a queer pedagogical move. As Ashley writes, "Queerness is not androgyny, a moderation between female and male, homo and hetero, depravity and prohibition. Queerness is an exposed both/ and..." (I6). The queerness of braiding, then, is that it allows students to be one thing and another in their writing. Braiding assists students in becoming critical academics (or at least in passing as them), but it also requires more than that. Just as Villanueva's Bootstraps is neither only "newyorican English" nor only "traditional academic discourse" but "a hybrid form that borrows from both and is greater than the sum of its parts, accomplishing intellectual work that could not be done in either of the parent discourses alone" (Bizzell, "Hybrid" I3), braided student texts replicate (in Laura's case) neither heterocentric, monosexual academic discourse nor monolithic gay rights discourses. And thereby, braiding offers a lens for revisiting the Elbow/Bartholomae debate and Britton's continuum. While Ashley notes that professors differ "fitfully" on whether to deconstruct academic discourse or to enforce it in hopes of students' "real world" success, braiding allows us to do both and neither.

I don't assume that braiding would work equally well for all student writers. When Laura entered our queered writing class on day one, unbeknownst to me, she was already in a frantic process of keeping rhetorical plates spinning. Those students, however, whose self-images are reflected back to them so seemingly "accurately" by mainstream culture might especially struggle with braided texts. According to Ashley, "One's thoughts, one's languages, are not one's own-an expression of self-they are imposed 
by the external exigencies of situation, convention, history, and politics" (5). Here, I concur with Ashley, and I don't. On the one hand, I agree that all language is artifice. That some students arrive in our classes having already, as a discursive survival strategy, theorized their own experiences while others have never had to do so supports the contention that language is invested and offers dispensation for some and marginalization for others. On the other hand, all of us are prone to experience our thoughts and language as "an expression of self," and students from mainstream communities may be less likely to recognize the multiplicity of discourse and their own multiple subjectivities. Of course, these may be the student writers who have the most to learn from braiding. Young writes, "For...students, who know the 'formula' when they are required to write a lab report or book review, composing a poem occasions disequilibrium because they have learned to mimic the prose of familiar 'school' discourse, and now to write poetry they must rethink form and content" (475). These students, then, when asked to create braided texts, may have to stretch heretofore atrophied rhetorical muscles, a useful if foreign task.

Writers, like McCrary's students, who have "been told that their native language was forbidden in school because it was incorrect or ignorant" and, thus, have "difficulty legitimizing their native language, let alone infusing it in their writing" (86), may also struggle with braided texts. Certainly Laura seemed to begin our class with fundamentalist beliefs about what made for good academic writing. Braiding, then, isn't only a queer move; it's also a multicultural one, and not just for the students of color who disproportionately place into basic writing classes. Williams and Garcia assert:

Ideally, home languages would receive equal consideration in the classroom, allowing students traditionally outside of academic success to define their home culture in a meaningful way for readers on campus....The optimal result would be writers who can bring their outsider identity to an insider's stance, a place where they can more effectively acknowledge the culturally plural nature of knowledge. Such positions are inherently multicultural because we must understand how the commonplaces of others help construe the discursive landscape we cross in the classroom and in the world. (IO9)

The multiculturism of all discourse, then, emphasized in writing courses through braiding, fosters critical thinking, reading, and writing for all students. 
By asking students to interweave rhetorics in which they are subjects and objects or to interweave genres that encourage one or the other of these positions (journal entries and research papers, for example), we get braided student texts that feature more complex student writing and explode stereotypes of "student essays." We can thereby reject the balkanization of Elbow and Bartholomae and of the expressive and transactional altogether. All writing in our classes should aspire to be creative and academic, personal and social, foreign and familiar. Williams and Garcia worry that "...this complex discursive balance is perhaps beyond most basic writers..." (IO8), but how often do we invite it?

Braided texts ultimately profit from students' rhetorical consciousness and also enhance their rhetorical prowess, enabling student writers to assimilate and resist various cultural rhetorics and to do so mindfully, with cognizance. By so doing, student writers become rhetorical arbitrators. They serve as such, yes, for the academy, and thereby stand in stark contrast to the student writer whose primary task is to appropriate the professor's language. But they also serve as rhetorical negotiators for themselves, in their own lives, “...students gaining flexibility, moving in and out of linguistic registers, weighing the social freight they carry" (Maxson 45). And because students' discourse becomes altered, their consciousnesses will be, too, for it's not as though linguistic codes are ever unchained from the social, but here at least with the potential for the rhetoric and the subject to become more heterogeneous, more contradictory, more always already in process-in short, more, not necessarily different. Particularly students who are now so frequently marginalized by academic discourse, who so often, by necessity, already theorize experience and play with language-these students stand to become the most savvy rhetorical power players of all, the hiphoppa with his ass in the library but still with his ear to the street, the drag queen knee-deep in her discipline and in double entendre, the basic writer who can write in the tradition of community and of campus and who can transform both as she sees fit.

\section{Acknowledgements}

For their insightful and generous feedback, I thank Hope Parisi and Cheryl Smith. 


\section{Notes}

I. For further discussion of deficit models used to describe basic writers, see Glenda Hull et al.'s “Remediation as Social Construct: Perspectives from an Analysis of Classroom Discourse" and Victor Villanueva's "Theory in the Basic Writing Classroom? A Practice."

2. Bartholomae, for instance, has puzzled:

It has been odd for me to hear myself described as someone who was advocating imitation or submission or indoctrination as desirable goals or as ends in themselves. ... I was trying to give teachers and students a sense of the landscape, of the real politics of institutional work. I hoped that in my attention to the students' prose I would show what I valued, and that I valued the work of the individual in such a setting_or at least certain forms of individual work in such a setting. ("Reconsiderations" 266)

It's the caveat, "certain forms of individual work," that has led many readers to contend that Bartholomae remains too focused on "the values and methods of the academy" ("The Tidy House" 7).

3. Prior to CUNY's I970 adoption of open admissions, 96\% of its students were white; by I998, only 32\% of CUNY's students were white (Harden). These figures would have proven the Open Admissions Policy successful to its drafters who explicitly sought "that students of color would be as well represented proportionately as white students in four-year colleges" (Gleason 488). And, of course, the adoption of open admissions at CUNY played no small part in establishing the scholarly field of basic writing and some of its early leaders, including Mina Shaughnessy. Ironic, then, framed by cries of standards and excellence, that basic writing has been phased out at CUNY's four-year colleges. To adopt incarnations of this conservatism in basic writing pedagogy is a misstep, for when we do so, we end up more closely resembling those who dismantle our programs versus those who founded them.

4. All names used in telling Laura's story are pseudonyms. I completed review by my university's Institutional Review Board and the Board's approval for this project is on file with that office.

5 . None of the students were out to me as transgendered.

6. I couldn't help but be struck by the parallelism between Laura's contortions and the maneuvers that so many basic writers must undergo. Too often, basic writers succeed as academic writers only by segregating knowledges and shedding home or alternative epistemologies, and I wondered if that rhetorical move had been instilled in Laura by previous instructors. 


\section{Works Cited}

Ashley, Hannah. "The Art of Queering Voices: A Fugue." Journal of Basic Writing 26.I (2007): 4-I9. Print.

Bakhtin, Mikhail M. "Discourse in the Novel." The Dialogic Imagination: Four Essays. Ed. Michael Holquist. Austin, TX: University of Texas P, I98I. Print.

Bartholomae, David. "Inventing the University." Cross-Talk in Comp Theory: A Reader. Ed. Victor Villanueva. 2nd ed. Urbana, IL: NCTE, 2003. 62353. Print.

. "The Tidy House: Basic Writing in the American Curriculum." Journal of Basic Writing I2.I (1993): 4-2I. Print.

Bartholomae, David, and John Schilb. "Reconsiderations: 'Inventing the University' at 25: An Interview with David Bartholomae." College English 73.3 (20II): 260-82. Print.

Bizzell, Patricia. "Hybrid Forms of Academic Discourses: What, Why, How." Composition Studies 27 (I999): 7-2I. Print.

. "The Intellectual Work of 'Mixed' Forms of Academic Discourses." Schroeder, Fox, and Bizzell I-Io. Print.

Bornstein, Kate. Gender Outlaw: On Men, Women and the Rest of Us. New York: Vintage, 1995. Print.

Britton, James. Language and Learning. London: Penguin, I970. Print.

Campbell, Kermit. “There Goes the Neighborhood: Hip Hop Creepin' on a Come Up at the U." College Composition and Communication 58.3 (2007): 325-44. Print.

Conference on College Composition and Communication. "The Students' Right to Their Own Language." NCTE. NCTE, 20ir. Web. 27 Apr. 2OII.

Croteau, James M., and Donna M. Talbot. "Understanding the Landscape: An Empirical View of Lesbian, Gay, and Bisexual Issues in the Student Affairs Profession." Toward Acceptance: Sexual Orientation Issues on Campus. Eds. Vernon A. Wall and Nancy J. Evans. Lanham, MD: University Press of America, 2000. 3-28. Print.

Elbow, Peter. Writing Without Teachers. 2nd ed. Oxford: Oxford UP, I998. Print.

Faderman, Lillian. Odd Girls and Twilight Lovers: A History of Lesbian Life in Twentieth Century America. New York: Columbia UP, I99I. Print.

Freire, Paulo. Pedagogy of the Oppressed. Trans. Myra Bergman Ramos. New rev. ed. New York: Continuum, I993. Print. 
. The Politics of Education: Culture, Power, and Liberation. Trans. Donaldo Macedo. Westport, CT: Bergin and Garvey, I985. Print. Critical Studies in Education Ser.

Freire, Paulo, and Antonio Faundez. Learning to Question: A Pedagogy of Liberation. New York: Continuum, I989. Print.

Frye, Marilyn. “A Lesbian's Perspective on Women's Studies.” Willful Virgin: Essays in Feminism. Freedom, CA: The Crossing Press, I992. 5I-58. Print.

Getz, Cheryl, and Evelyn Kirkley. "Shaking Up the Status Quo: Challenging Intolerance of the Lesbian, Gay and Bisexual Community at a Private Roman Catholic University." College Student Journal 40.4 (2006): 857+. Academic OneFile. Web. II May 20 II.

Gleason, Barbara. "Remediation Phase-Out at CUNY: The 'Equity versus Excellence' Controversy." College Composition and Communication $5 \mathrm{I} .3$ (2000): 488-9I. Print.

Gortmaker, Valerie J., and Robert D. Brown. “Out of the College Closet: Differences in Perceptions and Experiences Among Out and Closeted Lesbian and Gay Students." College Student Journal 40.3 (2006): 606-I9. Print.

Grahn, Judy. Another Mother Tongue: Gay Words, Gay Worlds. Boston: Beacon Press, I984. Print.

Hall, Jeffrey A., and Betty H. La France. "Attitudes and Communication of Homophobia in Fraternities: Separating the Impact of Social Adjustment Function from Hetero-Identity Concern." Communication Quarterly 55.I (2007): 39-6o. Print.

Harden, Blaine. "Reading, Writing and Ruckus: City University of New York's Tougher Standards Anger Many." Washington Post 2 June I998: A3. Print.

Heaney, April. “The Synergy Program: Reframing Critical Reading and Writing for At-Risk Students." Journal of Basic Writing 25.I (2006): 2652. Print.

Hemphill, Essex, ed. Brother to Brother: New Writings by Black Gay Men. Boston: Alyson Publications, I99I. Print.

Hull, Glenda, et al. "Remediation as Social Construct: Perspectives from an Analysis of Classroom Discourse." College Composition and Communication 42.3 (I99I): 299-329. Print.

Iconis, Rosemary. "Reducing Homophobia Within the College Community." Contemporary Issues in Education Research 3.5 (2010): 67-70. Print.

Ikas, Karin. "Interview with Gloria Anzaldua.” Aunt Lute. Aunt Lute, n.d. Web. Io Aug. 2 oIo. 
Katz, Jonathan Ned. Gay American History: Lesbians and Gay Men in the USA. Rev. ed. New York: Meridian, I992. Print.

kynard, carmen. “'New Life in This Dormant Creature': Notes on Social Consciousness, Language, and Learning in a College Classroom." Schroeder, Fox, and Bizzell 3I-44. Print.

Lipka, Sara. "For Gay Students, More Room on Campuses." Chronicle of Higher Education 6 Mar. 20II, sec. A: I-6. Academic OneFile. Web. 7 May 2 OII.

Lu, Min-zhan. "Conflict and Struggle: The Enemies or Preconditions of Basic Writing?" Landmark Essays on Basic Writing. Eds. Kay Halasek and Nels P. Highberg. Mahwah, NJ: Lawrence Erlbaum, 200I. I35-57. Print.

Maxson, Jeffrey. “'Government of da Peeps, for da Peeps, and by da Peeps': Revising the Contact Zone." Journal of Basic Writing 24.I (2005): 24-47. Print.

McCrary, Donald. “Represent, Representin', Representation: The Efficacy of Hybrid Texts in the Writing Classroom." Journal of Basic Writing 24.2 (2005): 72-9I. Print.

Mlynarczyk, Rebecca. "Personal and Academic Writing: Revisiting the Debate." Journal of Basic Writing 25.I (2006): 4-25. Print.

Mutnick, Deborah. "Rethinking the Personal Narrative: Life-Writing and Composition Pedagogy." Under Construction: Working at the Intersections of Composition Theory, Research, and Practice. Eds. Christine Farris and Chris M. Anson. Logan, UT: Utah State UP, I998. 79-92. Print.

Nelson, Cynthia. "Sexual Identities in ESL: Queer Theory and Classroom Inquiry." TESOL Quarterly 33.3 (I999): 37I-9I. Print.

Olano, Pamela J. “The Unclaimed Self: Valuing Lesbian and Gay Diversity in the Writing Environment." Situated Stories: Valuing Diversity in Composition Research. Eds. Emily Decker and Kathleen Geissler. Portsmouth, NH: Boynton/Cook, I998. 72-89. Print.

Queen, Carol, and Lawrence Schimel. Pomosexuals: Challenging Assumptions about Gender and Sexuality. San Francisco: Cleis Press, I997. Print.

Renn, Kristen A. "Lesbian, Gay, Bisexual, and Transgender Students in the College Classroom." Sanlo 23I-37. Print.

Robison, Matthew W. "The Residence Hall: A Home Away from Home." Sanlo 53-66. Print.

Royster, Jacqueline Jones. "When the First Voice You Hear Is Not Your Own." College Composition and Communication 47.I (I996): 29-40. Print.

Salkever, Katya, and Roger L. Worthington. "Creating Safe Space in College Athletics." Sanlo I93-202. Print. 
Sanlo, Ronni L. Working with Lesbian, Gay, Bisexual, and Transgender College Students: A Handbook for Faculty and Administrators. Westport, CT: Greenwood Press, I998. Print.

Schroeder, Christopher, Helen Fox, and Patricia Bizzell. ALT Dis: Alternative Discourses and the Academy. Portsmouth, NH: Heinemann-Boynton/ Cook, 2002. Print.

Shilts, Randy. And the Band Played On. New York: Penguin, I988. Print.

Simmons, Ron. “Tongues Untied: An Interview with Marlon Riggs.” Hemphill 200-205. Print.

Sloane, Sarah. "Invisible Diversity: Gay and Lesbian Students Writing Our Way into the Academy." Writing Ourselves Into the Story: Unheard Voices from Composition Studies. Eds. Sheryl I. Fontaine and Susan Hunter. Carbondale, IL: Southern Illinois UP, I993. 29-39. Print.

Thaiss, Chris, and Terry Myers Zawacki. Engaged Writers, Dynamic Disciplines: Research on the Academic Writing Life. Portsmouth, NH: HeinemannBoyton/Cook, 2006. Print.

Villanueva, Victor. Bootstraps: From an American Academic of Color. Urbana, IL: NCTE, I993. Print.

_. "Theory in the Basic Writing Classroom? A Practice." Journal of Basic Writing I6.I (I997): 79-90. Print.

Weston, Kath. Families We Choose. Rev. ed. New York: Columbia UP, I997. Print.

Williams, Mark T., and Gladys Garcia. "Crossing Academic Cultures: A Rubric for Students and Teachers." Journal of Basic Writing 24.I (2005): 93-II9. Print.

Yagelski, Robert P. “"Radical to Many in the Educational Establishment': The Writing Process Movement after the Hurricanes." College English 68.5 (2006): 53I-44. Print.

Young, Art. "Writing Across and Against the Curriculum." College Composition and Communication 54.3 (2003): 472-85. Print. 


\title{
Reflection Revisited: The Class Collage
}

\author{
Jeff Sommers
}

\begin{abstract}
Through the regular use of what Donald Schön has termed reflection-in-action and reflection-on-action, students can learn to improve their "reflection-in-presentation," in Kathleen Blake Yancey's term. Students are often asked to do this type of reflection-inpresentation as a capstone to first-year or basic writing courses. However, a number of critics have articulated reservations about reflective writing assignments that ask students to assess their progress in writing and, in essence, their cognitive development as they complete a composition or BW course. Laurel Bower (JBW 22.2, 2003), in particular, notes that such end-of-term written work is frequently superficial. This essay focuses on an alternative approach to reflective writing, one that asks students to examine their own beliefs about writing as well as those of their classmates rather than examining their cognitive development. This shift to reflecting on the epistemological grounding of their experiences as writers, coupled with a semester-long practice in reflection, seems to produce rich, fully developed reflectionin-presentation that offers some anecdotal evidence of knowledge transfer by the students as well as providing an informal outcomes assessment of course objectives for the professor.
\end{abstract}

KEYWORDS: reflection; epistemology; beliefs; outcomes assessment; knowledge transfer

"Formulating an organized assignment is difficult enough; reflecting on the process and describing the changes is the ultimate challenge. But I will lasso my metacognitive thoughts and attempt to put them on paper."

—Kyle, a first-year composition student

\section{Reservations about Reflective Writing}

Metaphorical lassos in hand, students have been asked to reflect on their writing and on their learning in first-year and basic writing courses for some time now. But skeptics have been expressing reservations about the role of reflection in composition courses for more than twenty years at the same time that advocates, especially portfolio supporters, have been

Jeff Sommers is Assistant Professor of English at West Chester University, where he teaches undergraduate courses in basic writing, first-year writing, and research writing, and graduate courses in editing a professional journal and writing assessment. He is currently editor of the National Council of Teachers of English journal Teaching English in the Two-Year College. 
urging its centrality to the purposes of writing instruction (see Sommers, "Bringing") and learning itself (see Moon). Why? Donald A. Schön defines "reflecting-in-action" as thinking about something while immersed in the act of doing it, offering examples of how baseball pitchers explain " 'finding the groove" and how jazz musicians "manifest a 'feel for' their material" ("Reflective" 54-55). Schön is also careful to point out that at times people "reflect on action, thinking back on what ... [they] have done" after the action is completed (Educating 26). But the "ultimate challenge" in many writing courses, as Kyle, quoted in the epigraph above, has described it, may be neither reflecting-in-action nor reflecting-on-action. Instead, students are asked to perform what Kathleen Blake Yancey terms "reflection-in-presentation: the process of articulating the relationships between and among the multiple variables of writing and the writer in a specific context for a specific audience..." (Reflection I4). Yancey adds that reflection-in-presentation is a public act: "the image of the writer that is projected by the composer to an other" (Reflection I4).

Reflection-in-presentation in the form of end-of-term capstone pieces is challenging for student writers, I believe, because they are often asked to reflect in this manner as a one-time-only task. It is not difficult to imagine how daunting it might be for students to visualize themselves "going public" before "an other" who is their very own instructor, or possibly an unknown professor (a portfolio reader), particularly if they have not been asked to do so throughout the writing course. But as Carol Rodgers points out in her analysis of John Dewey's work on reflection, "[B]ecause reflection is a particular, defined way of thinking, it can be practiced, assessed, and perfected" (864). It is the notion of "practicing" reflection that I wish to stress in this essay, of engaging in a series of both reflections-in-action and reflections-on-action that can make reflection-in-presentation less daunting for students.

However, incorporating more practice by itself does not fully address the critiques of reflection-in-presentation. Barbara Tomlinson cites research in cognitive science that casts doubt on the ability of individuals to describe their own cognitive processes retrospectively. So, she argues, student accounts of "how they composed" should be viewed skeptically (43I). Tomlinson's skepticism is focused on learning about student composing processes through self-report, but others have noted additional reservations about self-reflection through retrospection. Jane Bowman Smith, Laurel L. Bower, and Glenda Conway all stress the influence on student reflection of the writers' desire to please their teachers. Smith observes that "The fact that 
the teacher reads these self-assessments affects what students will write" (I28). She acknowledges that this effect can be for the good in underscoring to students the significance of the activity, but she continues, "The negative is that the fact of our reading may change what the student writes in ways that are not beneficial to the student" (I28). Bower agrees. "For the most part ... students seem more concerned with pleasing the teacher and appealing to his/her set of values than analyzing their priorities and thinking" (60), she concludes in her recent study of portfolio cover letters, echoing a concern voiced a decade earlier by Conway, who explored the degree to which students make a deliberate effort to say what they anticipate the teacher wishes to hear (85).

Additionally, because students may not be thoroughly prepared to produce effective reflection-in-presentation, they tend to generalize or write in vague terms when they reflect. In her study, Bower observes more than a half-dozen occasions when the eighty-eight portfolio cover letters she analyzed simply lacked enough specific details to explain convincingly students' assertions about their writing experiences. Peggy O'Neill echoes that criticism, pointing out that in her case study, the student's self-assessment has not been specific in referring to her own written text (65). Both Bower and Conway speculate that student writers may not have taken the task seriously enough, given that their cover letters are often merely one page in length (Bower 63) and may have been viewed by students as "not much more than a formality, in the sense that it may not have seemed very important. ." (Conway 88).

Bower concludes that "To demonstrate true metacognition, however, the student needs not only to indicate places where change has happened but also to specify how his/her perspectives have changed" (62). In casting a critical eye on the role of student reflection in her analysis of portfolio cover letters, Bower links her analysis to basic writers. Reflective writing is difficult for many student writers, but Bower notes that basic writers in particular may struggle with the challenges of writing reflectively: basic writers “ ... often have developed detrimental behavioral patterns in school writing or ... may become blocked, feeling that they don't know what is expected" (50). Yet she seems to advocate reflective writing for basic writers when she argues that "A monitoring of self through reflection helps a learner determine the value system of a particular community and integrate his/her own abilities into the existing system" (5I). She cites Yancey's claim that "self-knowledge through assessment can affect what one believes it takes to be a college writer" ("Dialogue" 99). 
Jeff Sommers

\section{Belief, Epistemology, and an Alternate View of Reflection}

But Bower also points the way, perhaps, to a more effective inclusion of reflection-in-presentation in our curricula when she comments that "Some basic writers need to develop new positive writing identities in order to reconstruct or reconcile their present learning with previous beliefs about themselves as writers or about a writing class" (5I) (emphasis added). In referring to "beliefs" about writing, Bower hints at a strategy to include effective reflection in the writing classroom, a strategy that I plan to flesh out in the balance of this essay by sharing a specific end-of-term assignment and the multiple steps taken to integrate the assignment into the fabric of the entire writing course along with an analysis of the assignment's value.

Shifting the students' focus from an exploration of their cognitive development, about which Tomlinson had expressed severe reservations, to an examination of their beliefs about writing and writing courses and the impact of those beliefs on a semester's writing experiences, can, I argue, permit writing students at all levels to engage in meaningful reflection about themselves as writers. Bower elaborates throughout her essay that students "must reexamine previously held beliefs and decide if those beliefs are beneficial or inhibiting or something in-between" (49) (emphasis added). As she expands on this idea, she calls for students to assess their "previous beliefs" and "determine the value system" of the classroom community (5I), the goal being to persuade the teacher that they have experienced "epistemological growth in the areas of writing and learning" (52).

Davida Charney, John H. Newman, and Mike Palmquist similarly argue that student behavior in a writing course may be driven by “students' attitudes and beliefs about themselves, about the nature of such skills as reading and writing, and about knowledge itself" (299). These beliefs, they continue, can affect the degree to which students are willing to expend effort, persist on task, attempt new approaches, and pay attention to teaching and response. Their essay focuses on how students' beliefs can affect their performance, and their most significant conclusion is that "students' attitudes toward writing are not completely unrelated to their epistemologies. How students think about writing and about the nature of knowledge deserves further attention" (327). That conclusion is echoed several years later by John D. Bransford, Ann L. Brown, and Rodney R. Cocking, who argue that "Teachers must draw out and work with the preexisting understandings that their students bring with them" (I9). Even Susanmarie Harrington's analysis of an extraordinarily successful piece of student reflective writing, which 
concludes, "I have learned that my original views of reflection were too limited, geared only toward understanding why and how a student revised from draft I to draft 3 or 4 " (50), suggests that a broader view of reflection may be called for in examining students' self-reports.

\section{The Class Collage Assignment}

At this point, I want to describe an assignment in reflective writing that is explicitly designed to focus students' attention on their own epistemologies by requiring them to explore their belief systems. The assignment is a final reflective letter at the end of the writing course that involves the use of a class collage of writing beliefs, or credo statements. (See the Appendix for a copy of the assignment for the final reflective letter.)

At my former institution, where students were advised to take basic writing but not required to do so, my first-year composition courses were heterogeneous, including students who had been identified as basic writers but who chose to take FYC instead. The activities described in this essay were devleoped for use in this heterogenous class and have been used, therefore, with basic writers. I believe the class credo collage is appropriate in basic writing courses because it provides the type of scaffolded approach that basic writers may need in order to engage in effective metacognition. I continue to use a version of this assignment in my first-year composition courses at my current institution, and excerpts from student writing that appear later are from these FYC students. My primary motivation for writing this essay for the Journal of Basic Writing has been to continue the conversation about reflective writing begun by Laurel Bower in this journal and to suggest ways that basic writers as well as first-year comp students can learn to reflect effectively on their own writing and their beliefs about writing.

Because my experience has been that final reflective assignments only work if the students have been engaged in reflection throughout the semester, my final assignment actually begins on the very first day of the term with a reflection-on-action activity: I distribute index cards to the students and write the word "credo" on the blackboard, explaining that it means "belief" in English but that in the original Latin its meaning is "I believe." I then ask them to write out their beliefs about several topics related to our course: "Please make a complete sentence out of each of the following three sentence-starters. Because I'd like you to express your honest opinions, do not put your names on the cards so that I won't know who has written any of them. I'll be collecting these cards, and we'll be using them again later 
Jeff Sommers

in the semester." I write the first sentence-starter on the board, giving the class 60-90 seconds to finish the credo statement, and then I repeat the process with the second and third statements. The three sentence-starters are

"I believe writing..."

"I believe revising..."

"I believe writing courses..."

At our next class meeting, I have the students participate in a four-corners activity, placing a post-it note in each corner of the classroom; the notes represent a traditional Likert scale: Strongly Agree/Agree/Disagree/Strongly Disagree. I then show the class a series of credo statements culled from past students and ask the class members to gravitate to the corner that best represents their opinion about that credo. My purpose is to generate an open discussion about their opinions and experiences with writing, revising, and writing courses. They can freely accept or reject the credos, knowing that no one in the class will take offense because the statements were not written by any of the class members. Although I deliberately choose thought-provoking credo statements, even the credo statements about writing courses are relatively "safe" to talk about because the discussion looks into the students' past experiences, thus any critical stance taken is not directed at me (yet!) but at previous teachers. This activity asks students to engage in reflectionon-action as they think back to their previous writing experiences in order to discuss their current perspectives. Here is a sampling:

I believe writing is complicated and takes talent.

I believe writing is like every skill: the more you practice, the better you become.

I believe revising is a small part of the writing process. What you wrote the first time is what you meant.

I believe revising is difficult to do on your own, and it is helpful to have an outsider point of view.

I believe writing courses are helpful at times, but I believe you are either good at writing or not.

I believe writing courses are important for any student, no matter what major, to take in order to get a general background of writing. 
The session concludes with all the students, again anonymously, jotting down one idea they heard during the discussion that they want to remember and one idea that they want $m e$, as the teacher, to remember as the course moves forward, comments that I collect and read.

These opening activities serve several purposes. The students are introduced to reflection-on-action in the very first week of class. They are exposed to the range of opinions held by other students, not only their classmates' ideas as expressed in class discussion but also by their anonymous predecessors who have authored the credos to which they are responding. They read, think, move, discuss, and write about their beliefs during this class session, one that they tend to remember because of all the varied activities involved. They engage in a low-stakes reflection-in-presentation as they explain to each other and me their reasons for their beliefs without being evaluated for doing so. At this point, our class moves on with the semester's work, work that includes repeated practice in reflection-in-action through the use of the writer's memo (Sommers, "Writer's Memo"; Yancey, Reflection 26). I devote an entire class session to explaining the writer's memo activity. During that class meeting, I not only share some writer's memos from former students but also writer's memos that I have written myself to colleagues who have graciously volunteered to read my drafts in progress, and I share actual letters from authors with whom I correspond in my own work as an editor. The purpose of the examples is to illustrate that writer's memos are not tiresome busy work but a valuable tool often used by writers and editors in multiple forms to communicate about intentions and revisions.

Over the next several weeks and months, the course proceeds, and students write drafts, revisions, writer's memos, reading response journals, peer review comments on one another's drafts, and, in many cases, other writing assignments for their other courses. As we near the end of the term, I produce a class collage by publishing all of the credo statements the students wrote at the beginning of the semester in a single document. Of course, these are anonymous credo statements, but I assign each anonymous author a letter of the alphabet, making it easy to refer to the statements and to connect the three disparate statements as the credos of a single author. After I post the class collage online in our course management system, I assign the final homework journal of the term, asking the students to read their class collage and to select one belief with which they agree and one with which they disagree, explaining their reasoning for each in a substantial paragraph. This reflection-on-action continues in class as we generate two quick lists on the blackboard of which statements the students have chosen to agree 
with and disagree with, using the letters to identify them. A class discussion follows in which the students exchange their opinions, continuing to practice reflection-on-action as they are pressed to explain the choices they have made (and once again engaging in a low-stakes effort at reflection-inpresentation as they share their thoughts through interaction with each other). This discussion, however, differs from the earlier four-corners activity in two important ways: the credos now under analysis have been produced by the class members themselves, and the course is now near its conclusion rather than its beginning, so their reflections grow out of their experience during the term. The discussions are usually spirited-partly because it is not unusual for the same credo statement to spur both agreement and disagreement. Also of interest is that quite a few students will confess that they cannot recall which credos they have written themselves, but I find that understandable because they have written these credos several months earlier and spent a very brief time writing them. They are also usually struck by how similar-and generic-many of the credos are. Some students do recognize their own statements and will preface their explanations by saying, "I wrote this one, and I still agree with it" or "I wrote that one, but I don't exactly believe it any more." And, perhaps most important, the students learn from each other's beliefs. Rodgers argues that "collaborative reflection" has "benefits" and identifies three hallmarks of this type of reflection: "affirmation of the value of one's experience: In isolation what matters can be too easily dismissed as unimportant ... [;] seeing things 'newly': Others offer alternative meanings, broadening the field of understanding ... [; and] support to engage in the process of inquiry" (857). My objective at this point in the term is to prompt students to think about their beliefs in the context of a full semester's work, comparing what they now believe to what they may have believed at the start of the term, but also comparing their beliefs to those articulated by the other members of their writing community in the class. The written credo statements offer this opportunity as does the class discussion that follows.

This journal assignment and class activity serve as scaffolding for the final reflective writing assignment, a reflection-in-presentation capstone writing assignment in the form of a letter to me about the class collage. But I engage the class in one final activity as a group before the term is over. Bringing to the final class meeting several one-page excerpts from previously written letters (all A and B+ papers), I divide the class into small groups, each of which receives one of these samples. I ask them to analyze the sample by addressing two issues: 
- What point is the author trying to make about the chosen credo statement?

- In your group's sample paper, how does the author show rather than tell? What examples or illustrations does the author provide to support the arguments of the paper? What is the source of the examples? What form does the writer use to provide evidence? For instance, does s/he use direct quotations or some other method of providing examples?

Each group then makes a brief presentation to the class, contextualizing the letter excerpt and answering the questions. I project the sample onto the screen in front of the class and point to any passages as instructed by the group. The object of this activity, I explain to the students, is to enable them to leave class with a broader conception of the array of sources from which they can draw evidence to explain their beliefs and opinions in the assigned reflective letter, and with a deeper understanding of the varied strategies available to present that evidence. At this point in the term, I leave it to the students to teach one another. When a group isn't clear enough, other class members will ask questions for clarification because they are motivated to learn what they can from these successful excerpts.

The idea of the activity is not to critique but to allow the students to expand their own writing repertoires. The samples illustrate different sources of information that could be used in the reflective letters, for example: discussing papers written in other classes, and sometimes quoting those papers; comparing experiences in writing two of the assigned papers in the course through a narrative about choices made; quoting a passage written in a draft and then quoting a revision of the same passage, followed by an explanation of the changes; quoting extensively from the student's own writer's memos as a means of exploring her evolving experiences as a writer in the course; citing one of the course readings and applying a quoted passage to an experience in revision; excerpting the writer's own journal response to an assigned reading and then explaining how that response influenced a revision; focusing on the responses the student writer received from others in the class such as quoting from teacher comments on a draft or describing and quoting peer comments on the draft.

\section{Why the Assignment Works: Distance and Heuristics}

According to Kathleen Blake Yancey and Jane Bowman Smith, "the request for self-assessment ... relies on a student distancing himself from 
the processes he is using, from the learning he is gaining, from the text he is writing, from himself as one with the text. Thus a shared identity of text and writer is disrupted" (I72). Bower also points out the need for students to "detach themselves from their writing selves ... [to] become spectators of ... [their] writing experience" (50). The assignment I have described incorporates such distancing in two ways: First, in time: the project begins in the first days of the course and concludes in the final days, providing months of distance between the initial thinking and the final reflecting. As the students remember back to the early days of the semester, they cannot help but filter their views through the lens of memory. Second, in authorship: the class collage provides students with material and ideas to discuss that were written by others, building into the assignment a kind of detachment of perspective on the beliefs. Students can critique the ideas of anonymous authors, should they wish to do so, providing a platform for their own newly thought-out beliefs that does not require them to critique themselves.

If distance between the students and their experiences is vital to effective reflection, so is contiguity, at least in the sense of "intersection" with their own experiences as writers/readers. Yancey discusses "intersections" as crucial to reflection (Reflection I8) if students are to work through their experiences in meaningful ways, and the class collage assignment encourages such intersections by asking students to plumb their varied experiences and beliefs as writers throughout the term. They "intersect" with their own experiences as writers/readers in multiple ways: with their reading journals as they comment upon the course readings; with writing in their other courses; with the instructor (through his response to their drafts and class lessons); with classmates through peer review discussions; with texts written by classmates both in peer group review sessions and by reading the class collage; with multiple drafts of their own writings; with reflection-on-action classroom activities such as those related to the credo statements; with their own previous reflection-in-action work in the class, including writer's memos; and with previous instruction they have received prior to the current college writing course.

Unlike many portfolio cover letter assignments, which focus the students' attention on the work selected for final assessment in the portfolio, the class collage letter provides a broader palette of options from which students can paint the picture of their experiences and beliefs. In other words, the assignment turns back to the students the decision of which emphases they wish to choose in reflecting back upon the course instead of insisting that they discuss their selection process for a final portfolio. The value, I believe, 
is that the assignment asks students to take the initiative for their own metacognition, requiring them to take agency for their writing. (See Sommers, "Self-Designed Points" for a discussion of the role of student initiative in a first-year writing course.) Additionally, on a practical level, I can use the letter assignment even in courses where I have not used a portfolio approach with its end-of-term choices.

Another significant difference between the class collage assignment and more traditional end-of-semester reflective capstone writing assignments lies in the heuristics that are part of the design for the assignment. In Harrington's analysis of her student's exceptional reflective letter, she comments at one point that the student has produced the letter "without much explicit prompting from me..." (49), implying that this is a virtue of the letter. And it may well be, but that student's letter is not typical. If we hope to move students away from resorting to "description and explanation, techniques they are more comfortable with and more experienced at, rather than analysis, which is a more abstract and complex process" (Bower 53), then we must build preparation into the process. I find Conway persuasive when she asserts “... I most emphatically do not believe that it is either fair or appropriate for an end-of-semester cover letter to be given the burden of conveying the only reflection on a whole semester's work. Required reflection is ethical only if it exists as an ongoing component of a course and if the teacher of that course openly discusses his or her reactions to the reflections with students" (92).

The writer's memos required of my students create an ongoing, semester-long conversation about their reflections on specific drafts, a conversation that forms a backdrop to the course experience for the students. The opening week activities I have described along with the final journal entry and the inclass analysis of sample letters serve as heuristics for the students as they plan, draft, and revise their letters for submission at the end of the course. To cite Rodgers again, I would also point out that some of the reflective activities are communal, allowing students to generate ideas about their own experiences in concert with their classmates. It is such integration of the assignment into the entire course that sets the groundwork for successful reflection.

\section{The Class Collage Letter as Social Activity}

Because this reflective writing assignment assumes that students are part of a writing community - the writing class that has collaboratively created the class collage-the student writers do not have to fall back entirely 
on their own ideas, and that seems to provide a starting place for many of their letters. ${ }^{2}$ A common strategy that the students use is to write about their classmates' beliefs. One student begins her letter by making an explicit connection to her classmates: "Looking back at them [the credo statements] after these three months have passed, I don't even remember which ones I wrote ... , but I noticed more interesting ones that my peers wrote." And another opens her letter by noting "It is a pleasure for me to express my deepest feelings about two of our class credos, created by the students, distinctly showing our thoughts about writing and writing classes." This second student's use of first-person plural shows a strong sense of a class community. These two excerpts exemplify what Bower calls the "appeal to nomos" because they "center on commonly held sets of values, established ... by the students, the teacher, and the classroom culture. An appeal is classified as nomotic when it primarily focuses on the value system of that particular classroom" (54).

Yancey and Smith insist that "self-assessment is dialogic; its very nature demands that the self call on others to help in its development" (I72). And so some students, by engaging in a dialogue with their classmates, find a heuristic value in contrasting their own ideas with those of other students. Bryan begins his letter by writing that "There really is no downside to revising besides that it may not be the most entertaining thing in the world, but like many things that aren't the most fun or appetizing, they must be done for improvement (much like kids eating their vegetables.)" Later in his letter, he returns to his analogy: "Here is a credo statement from one of those kids who didn't like their vegetables. The statement that I found and I disagree with is: 'I believe writing courses do not let you be who you are. They make you who the teacher wants you to be.' I can't find anything about that statement that I agree with." From there Bryan goes on to explain why he has taken issue with his classmate. For me, what really matters here is not so much the specific grounds of Bryan's disagreement but the fact that he has thought deeply enough about the issues to form his own position-and found a colorful way to "show me" where he now stands. I think that the move he makes is facilitated in part by having his classmates' ideas as a potential counterpoint, a strategy that seems to provide substance in a number of the letters because it moves reflection away from being a solitary act.

There is another heuristic value to the class collage-it provides ample ideas for students to discuss. Yancey observes that the typical shortcoming of such reflection-in-presentation is that it focuses on "text that parrots the context of the class or the teacher without demonstrating the influence of 
either"(82). Some of the reflective letters, of course, are relatively empty of content and offer generalizations without substantiation; however, this assignment as designed explicitly invites students to provide evidence that shows what they have learned about their own beliefs. And many letters do just that. (Unlike the single-page efforts critiqued by Bower, last semester's reflective letters averaged four typewritten pages.) One way that students avoid writing Yancey's "text that parrots" is by demonstrating how their classmates have influenced their beliefs. Thus, a number of students choose to offer the structured interaction with their classmates that had occurred through peer review as a means of explaining the influence of the course on their beliefs.

For example, Erik agrees with the credo statement "I believe revising other people's papers is a good way to improve your writing skills." He describes two occasions, both peer review sessions, where he came to this belief. About the first workshop, he describes his own writer's block and how reading the varied approaches taken by his group members helped him decide on an appropriate genre for his paper. His letter explains how one of his peers had decided that rather than writing an explanatory essay, she would compose a letter to her former high school principal about a run-in with a faculty member. Her choice prompted Erik to move away from the essay format also, instead composing a retirement speech to honor his favorite high school teacher. In a second example, he explains that when he noticed in a classmate's draft that he could not follow the student's narration of important memories because the events had not been explained fully enough, he applied that lesson to his own draft and expanded on his ideas. Both examples are intended to illustrate why he believes in the value of reading and responding to the papers of classmates.

\section{Self-Reflexivity and “Going Meta” in the Class Collage Activity}

Because reflection has been ongoing throughout the course, students have begun to develop the practice of reflecting on their writing. That manifests itself in letters in which students comment on the letter not only as a product but also as part of a process. Some students recognize that their claims about their writing ought to apply to the reflective letter, and they "go meta." In effect, they make the reflection-in-presentation double as reflection-in-action, commenting upon the document they are composing. Clara chooses to write about this credo statement: "I believe writing courses are mandatory at WCU and only a few really help." She explains that 
Jeff Sommers

she gradually learned to abandon the five-paragraph-theme template she had been taught in her earlier writing classes, and so she found the course helpful. She concludes her discussion by noting that in her reflective letter, some nine paragraphs in length, she has devoted three paragraphs alone to a discussion of revision. "That is something I would have never done while I was under the reign of the five-paragraph format," she concludes, offering the reflective letter itself as evidence of her new beliefs in action.

Perhaps the most notable recent example of a student's reflection-inaction is in Joyce's conclusion to her letter:

This entire letter is really just a memo in a letter's disguise, or a masked-meta-memo-cognitive piece of writing, if you will (cause I always will!). I am reflecting in writing about my thinking about my writing, all sandwiched between a salutation and closing. Only instead of one assignment this addresses the whole semester. I find that I have learned a great deal and had a great deal of fun doing it. Perhaps the last statement from the class collage that supports how I feel is about writing in general. "I believe writing can be fun." It was fun and it was work, but in the end I enjoyed the whole process of being challenged, gathering ideas, organizing information, telling stories, finding what works and trashing what doesn't and just working to get it right. It is a satisfying feeling, to get it right.

Joyce concludes by explicitly linking the letter to the more familiar task of writing a writer's memo. And when she claims to be having fun, we can see that she has been doing so, both in her playful string of adjectives describing her letter and her parenthetical joke.

Additionally, these letters sometimes provide insight into the writer's process of composing the letters themselves. Ashleigh, who has begun her letter by quoting the course objectives from the syllabus, a way of involving my beliefs in her discussion, observes, "I originally believed in the statement 'I believe revising is not helpful because I never know how to fix my mistakes.' Throughout this course, however, my perception of revision was radically changed." She attributes her changed perception to writing the required writer's memos throughout the term:

The biggest reason for this adjustment would have to be the memos you assigned us to do.... At first I assumed these memos were just more busy work attached to an already lengthy paper. Yet, once 
I started answering the questions, I began to see the point. The questions allowed me to understand what I was writing about. If I couldn't figure it out, how was the reader supposed to? In addition, sometimes when I answered these questions, I figured out a whole new point I didn't even realize I had made. It was a type of revising I had never heard or seen before....

One student produced a remarkable letter in which she takes her reader through a semester-long reflective journey. Leslie, while not a basic writing student, was also not one of the "stars" of her first-year composition class, yet her letter stunned me with its sophisticated reconsideration of her experiences in the course. In her letter, she discusses no fewer than six different reflective activities in which she had engaged: her self-addressed letter about her goals for the course written on the first day; three credo statements; her writer's memos; her writing process timeline composed in class during the first week of class; her reading of an assigned essay on reflection; and her journal responses reflecting on reading assignments.

Leslie also understands that she needs to offer evidence to support her assertions about her experiences and beliefs, and she does so in a variety of ways. She cites her own writing six different times, both quoting herself and describing her decision-making in her self-addressed letter, two of her writer's memos, one of her revised papers, her writing process timeline, and one of her journal responses to the course reading. She also cites her classmates' writing twice by reference to specific credo statements and to peer review comments.

Most noteworthy in Leslie's letter, perhaps, is her successful ability to meld disparate materials into a focused reflection. Yancey identifies a number of "moves" that successful reflective pieces employ, including "multiple contexts, multiple narratives, answers to 'what did I learn?', answers to 'how did this course help me learn it?' (82) and “synthesis" (2O2). One of my course objectives also identifies the ability to synthesize as a goal for the students. In her letter Leslie weaves multiple narratives of her prior reflective experiences into an explanation of what she learned and how the course helped her. As she draws materials from multiple contexts-her reading, her writing, her interaction with her classmates and teacher-she ably synthesizes these strands into a single coherent reflection-in-presentation. Here is one excerpt from her letter in which Leslie makes a generalization, refers indirectly to a credo statement ("I believe revision means figuring out what the teacher is looking for and simply doing that to get a good grade."), cites one of the 
course readings, quotes her own journal response to the reading, and then begins an anecdote about one of her papers:

Through your assigned readings I have learned a lot about myself as a writer. In the beginning of the year I would have agreed with the idea that all a student needs to do is figure out what their teacher is looking for in their papers and simply do that to get a good grade. In the essay, "Unteaching the Five-Paragraph Essay," the author states, "the formula reinforces the writing-to-please-the-teacher syndrome that turns students against the system." You have striven to instill in our class the importance of adapting to write different genres and to be aware of our discourse community. In my journal after reading the article, "Understanding Discourse Community," I wrote, "Being that an ethnography contains many numbers and could potentially entail some very fancy word choice, if I myself were an expert, I must understand that my audience is a college class. Being a college class I must write my paper according to the class's level of comprehension." I did just that for assignment three, our ethnography....

Leslie is, in short, what Chris Anson describes as a writer "in control" (69), one who has produced just what I as an instructor was hoping to see in a class collage letter: a compelling explanation of why she holds her current beliefs about writing.

Of course, I do not expect all of the letters to rival Leslie's in their depth and complexity, whether written by a first-year composition student or a basic writing student. However, the reality is that I generally look forward to reading these final letters-even when confronted with seventy-five of them in some teaching terms-because although they cannot always surprise me as Leslie's work did, there are enough moments of genuine insight, sometimes from unlikely sources (such as Erik, quoted above about his peer review experiences, who concluded the course with a C), that I continue to read the letters with anticipation.

\section{The Class Collage as a Vehicle for Dissent}

Speaking of surprises, a less typical, but in some ways equally encouraging development with the letters has been that the opportunity to disagree with a classmate's belief seems to provide some students with a strategy for 
expressing dissent from the typical growth narrative of reflection-in-presentation that paints the rosy picture of a happy and demonstrable improvement in the course. The class collage letter gives students a viable means to express disagreement. One student chooses to take issue with a classmate's credo statement in order to write a letter about how the course had failed her. She focuses on a credo statement that reads "I believe writing can be easy if you enjoy the topic you are writing about" and points out that the credo may describe how she felt as the term began, but her opinions changed over time. In fact, thanks to the disillusionment caused by working hard on a first essay that earned a grade of $\mathrm{D}$, followed by another essay that earned a $\mathrm{C}+$, she now rejects the cited credo statement. Her writing strategy is to explore her dissenting opinion by setting it up in opposition to her past experience and to her classmates' beliefs. She never refers directly to me, even though I am obviously the one who issued the troubling grades, using her discussion of the credo statement as a distancing mechanism that enables her to reflect on her changed beliefs.

Another notable example demonstrates how a student can use a disagreement with a fellow student's credo not only to explore her own beliefs but also to offer a critique of the teacher, albeit in a muted way. This student chooses the credo statement "I believe revising can only make your work better, not worse." She is unpersuaded by this belief because, as she explains, revision often takes a writer far away from her original intent. She sets herself up in opposition to the credo and acknowledges that her commentary probably constitutes a minority opinion in her class. She has become a firm believer that the spontaneous nature of good writing can be-and often is-ruined by extensive revision. As an example, she relates an anecdote of a conflict between my specific revision recommendation on one of her papers and the comments offered by her peer group, deciding that she would not revise as I suggested because her intent was to appeal to her peers, who had evidently expressed satisfaction with that specific aspect of her paper. Unlike the other example of course critique, however, this student is willing to position herself oppositionally in regard to me, the instructor. She is careful to note that she is not criticizing either my teaching or my editorial skills so much as she wants to explain the fallacy of the credo she has chosen. Both of these examples suggest that this assignment allows students to take risks, in these cases by taking positions likely to be in conflict with the teacher's position. 
Jeff Sommers

\section{The Class Collage and Transfer of Learning}

Bransford, Brown, and Cocking argue that in general "Transfer can be improved by helping students become more aware of themselves as learners who actively monitor their learning strategies and resources and assess their readiness for particular tests and performances" (67). But Linda S. Bergmann and Janet Zepernick observe that writing students tended to push aside the notion that learning about writing in a composition course could have application in other disciplinary course writing assignments (I24). With the continued concern in composition about transfer of learning, I want to pose the question "Does the class collage assignment encourage any transfer of knowledge?" Elizabeth Wardle has argued that, given the complexity of the issue and the multiple definitions of transfer oflearning, "if we look for but do not find direct evidence that students use specific previously-learned skills in new situations, we cannot necessarily assume that students did not learn them, have not used them, or will not use them in the future" (69). She is highlighting the complexity of attributing the lack of a demonstrated skill in a later writing situation to the activities in a previous composition course. Dianne Fallon, Cindy J. Lahar, and David Susman make a similar point in observing that it seems "optimistic" to attribute a demonstrated skill directly to one learned or practiced in a composition course and, perhaps, more "realistic" to acknowledge that the student may have arrived in college already habituated to using the skill (43). Wardle is also concerned that her findings are entirely reliant upon student self-reports of what they have done in subsequent writing situations and that the students may in fact be reporting only what they think she, their former instructor as well as the primary investigator, wishes to hear (7I). Unfortunately, Wardle discovers that her students did not make much use of their learning because they did not "perceive the need" to do so in less challenging writing assignments in later courses (76).

These studies, and previous ones that these investigators cite, are longitudinal, designed to measure later behavior demonstrated after the writing course has been completed. What happens, however, if the students choose to report on simultaneous behavior demonstrated in other writing situations while the writing course is still ongoing? Several significant differences surface:

- When students choose to describe in their letters how they have applied concepts from their writing course to other writing situations, it is because they have evidently "perceived a need" to do so. 
- The difficulty of linking one behavior in a subsequent writing situation to a previous one in our writing course no longer requires an "optimistic" interpretation because in their letters the students themselves explicitly assert the specific connections that have occurred.

- When students report on such experiences in their letters, I would argue that it does not matter that they might be telling me what they think I want to hear because if they are smart enough to explain the transfer of learning in concrete, specific terms, then whether they have actually done as they say is not really of paramount importance. What matters, I would argue, is that they have learned what might transfer and how and when - and that explanation itself is, I believe, a meaningful transfer of learning expressed in a reflection-on-action.

So there appears to be some evidence in the class collage reflective letters that the assignment allows students to demonstrate how they have transferred learning-beliefs and behavior-from the writing course into other courses across the disciplines. One student chooses this credo statement: "I believe writing can be fun if it is about something that interests me." She explains that at first she had continued to experience significant anxiety about her writing until she developed a "new skill": finding a way to generate personal interest in the assigned writing. She recounts an anecdote about her "least favorite subject," history, a course in which she was required to write one page per week. Her story continues, "In an assignment due about midway through the semester I had to write about a person from the Enlightenment.... Initially this seemed like some rare form of torture. And then suddenly I realized I knew something about one of those people and I began writing." She discovered that she shared opinions with Voltaire, her chosen historical figure. She quotes one of Voltaire's written opinions and asserts, "I became interested in this paper and even did a lot more research that was not required," concluding, "This paper really made me see that finding even a small aspect of an assignment that is interesting is enough to make a paper fun and ultimately good."

One of her classmates focused on the belief that "writing is determined by who you are writing for." She explains that her major is athletic training, and she had never expected that "writing would actually help me in any of it." She then narrates a story about having to write two observation reports for one of her major courses based on spending time with both a certified and a student athletic trainer. She writes, "As I went to sit down and finally write my paper, the first thing that came to my mind was who my audience 
Jeff Sommers

is... [S] omething I have learned from this writing class is that who you are writing for determines the way the paper will be set up and the language used. I also thought 'do I use subheadings to help the readers?' which I learned in writing class is a way of transitioning and helping the readers." A third student relates a story about how he overcame his trepidation over writing an eight-page essay in his Italian culture class by employing pre-writing and invention strategies learned in his composition course, illustrating how his confidence in his ability to complete the paper grew as he generated more ideas. Such examples suggest that some students recognize that the underlying beliefs they hold can have a positive impact on their writing performance outside the composition classroom as well as that there is value in transferring specific strategies and methods from the writing course to their other disciplinary studies.

More striking is that in the most recent semester in which I made this reflective letter assignment, of the seventy-two students who completed the assignment, seventeen of them, $24 \%$, refer in detail to writing situations outside of our class to help explain their current beliefs. Students cite papers written in women's studies, Italian, educational psychology, literature, philosophy, political science, geography, and speech. Most memorable, however, is the young man who uses his letter to explain why he has chosen to write about the credo "I believe that writing can give a voice to the voiceless and change history." He himself, he confesses, feels voiceless. He goes on to explain that he has had a very dissatisfying interaction with one of the administrative offices on campus and wishes to write an editorial for the school paper in order to put into effect what he has learned in the course in order finally to "give voice" to his anger.

Of course, the need for longitudinal studies of transfer of learning remains a strong one for those of us who teach writing courses. The letters I have described, however, suggest that we can sometimes see, admittedly in an imprecise manner, whether students are transferring their learning during their writing courses. Of course, $76 \%$ of the letters do not describe such transfer, either because it has not occurred or has not occurred to the writer to describe it, or because the student has not been asked to write in other courses. Nonetheless, it seems worthwhile to design reflective capstone activities in our writing courses that encourage students to look for connections to their outside-of-class writing experiences if only to plant the seed that such connections are desirable. ${ }^{3}$ 


\section{The Class Collage as a Form of Outcomes Assessment}

As a teacher, I also "transfer" learning from these reflective letters because they serve me as an outcomes assessment in two ways: the students' explicit statements about the class collage share their perspectives on the course; and my evaluation of the letters serves as an assessment of the degree to which course objectives have been met. For instance, two of the specific course objectives in my syllabus are that "students will become more skilled in synthesis, that is, effectively bringing together materials in their writing from a variety of sources" and "students will become more successful in making claims in their writing." As I grade the letters, it is a relatively easy matter to note the degree to which the students have been successful in achieving these objectives. While Leslie's letter is a triumph of synthesis, many other letters have similar moments in successfully blending sources. Similarly, the examples I have offered illustrate, to varying degrees, students' success in making claims, rather than merely narrating or describing events. As a consequence of reading these letters over a period of time, I have modified my approach to preparing students for the class collage letter in response to what I have seen, primarily by sharing with them some of the successful letters that appear in this essay.

Here is one example of what I have learned about my own teaching that will influence change in my teaching:

These conclusions about my writing came to my realization not from my own reading over of my papers, but from the suggestions from others that read over and analyzed my pieces. That is why I agree with the statement "I believe revising works best when someone else first does it then the writer." The revisions I received from other students during the peer workshops and from you, the teacher, have made my papers so much stronger and have brought things to my attention that I would have never noticed.... I received help with titles for my papers, examples I had provided, and wordy sentences. These were all things that greatly improved my papers and are all things that might not have necessarily been brought to my attention through my own revisions.

While I find it encouraging that Karli not only emphasizes how her classmates' suggestions helped her revise, a realization of the social aspects of the revision process, there is also a lesson for me: this writer agrees with 
the credo that someone else can "revise" for an author, implying, I think, that "revision" equals "editing." Karli is not alone in thinking this way about revising/error correction. I have seen other students, such as Erik, quoted earlier, embracing this same credo in similar ways. So my teaching will be adjusted next time to make greater distinctions between revising and editing or proofreading.

Sometimes, however, I learn that an activity has in fact paid off as planned, encouragement to continue its use. In this passage, Maureen refers to an early-semester activity designed to promote students' reflection about their own writing processes:

As a student who never felt confident in my writing, I never used to enjoy revising. I always thought it was tedious and pointless, but after this class I realized how very important revising is in our writing process. As I look back on this class, I remember one of the first days when we had to draw a timeline of when we think revising is necessary. As a person who disliked every part of revising, I put the slash on the line towards the very end showing that I would revise only a day or two before the due date. When you showed us your timeline, you were revising right after you started writing and to be honest, I couldn't believe that revising played this much of a role in the writing process. Now I can see how we should be revising early on in the ... process. My timeline in the beginning of the semester:

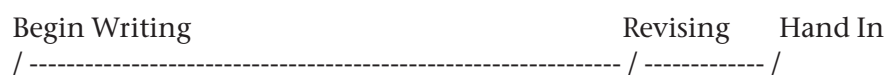

My new timeline after the course:

Begin Writing Revising Hand In

Because Maureen was not the only student in the class to comment on this timeline activity - an additional seven students pointed to this brief exercise-and because the references to the timeline suggest that it was an activity that had the desired impact, I plan to continue using it in future terms. It is worth noting that this activity itself is reflection-on-action, so it is gratifying that a number of students found it important.

In the fall of 2010 thirty-five student letters (49\%) referred at some point to the impact of something I had said to the student. Most of these 
references were to comments I had made on their drafts, but letters also identified comments on journal entries, a grading rubric I had used, a lesson plan on genre. One writer remembered that when she had asked me in class "Can we use 'I' in this paper?," I had answered, "You tell me. It's your paper," and then she explored the significance of that conversation to her beliefs about genre. Five students found our class discussions of the fiveparagraph theme format's limitations to be influential experiences. Four letters observed that my continued adjuration to peer response groups to "Fry the biggest fish" in their commentaries instead of focusing on minor surface errors had influenced them. One of those writers told a story about her evolving belief in the credo "I believe revising is always necessary because there's always room for improvement" and related how she had learned to "fry the biggest fish" when her roommate, not a member of our class, had asked her to look over a draft she was revising. Another student reported on an influential conversation with his roommate: he was astonished to learn that his friend routinely produced a half-dozen drafts before submitting a final paper to his professors, behavior that reinforced what my student had been hearing in our class and that prompted more introspection on his part about his own writing processes.

Additionally, close to $20 \%$ of the letters referred to the writer's memos in some fashion, often using their own reflective comments about work in progress to illustrate their current beliefs about writing, revising, and writing courses. One student chose to write about a credo that stated "I believe writing courses will give me skills I will use forever." She wrote about how the writer's memos helped her to "evaluate herself," and then related an anecdote about how she had come to see that at times she was articulating her ideas and arguments with more clarity and force in her memos, at which point she would substitute those reflections for fuzzier phrasing in her drafts.

A substantial number of students, $29 \%$, referred to journal-writing assignments as having been instrumental in their course experience, often describing the journals as having served as invention activities for the fulllength assigned papers. Three students referred favorably to the journals as effective "practice" for the graded writing, and one labeled the journal writing as "getting in shape" for the major projects.

My course clearly emphasized the importance of revision, even devoting one of the three assigned credo statements to revision. Noteworthy, however, is that $8 \mathrm{I} \%$ of the students chose to discuss at least one of the revision credos as they explored their current beliefs in the letters. During the semester, revision was optional except for one required revision of the very 
Jeff Sommers

first paper in the course. A majority of the letters, 54\%, chose to offer that required revision as an example that explained why the author embraced the chosen revision credo.

But my point is not intended to be about any specific class activities; it is that reading the reflective letters about the class collage and examining the students' beliefs inevitably influence my own evolving beliefs about writing, revising, and writing courses, which, of course, affects the way I subsequently teach the course. The students' self-assessment thus becomes part of a dialogue with me, both explicitly in the form of their letters that continue the semester-long conversation we have been having and implicitly in what I learn from reading scores of these letters at the end of each term. Fallon, Lahar, and Susman conclude that “... the most significant finding from our research is that listening to what our students tell us when we ask them directly about their learning can yield useful information that has an impact on teaching and learning" (49). The letters I have been discussing can provide much worth listening to and can lead to further reflection on action by me, the instructor of the class, an entirely salutary outcome.

\section{Conclusion}

The class collage letter assignment is a direct response to Ann Berthoff's exhortation: "Students do not need to learn to interpret nor do they need to learn how to interpret their interpretations: they are born interpreters. But they must discover that this is so. We should offer them assisted invitations to discover what they are doing and thereby how to do it" (59). The assignment does indeed provide an invitation to reflection. That invitation brings students in direct contact with their own lived experiences in the course. Kathleen Yancey has outlined three curricula that students encounter in every class - the "lived curriculum" of their prior experiences, the "delivered curriculum" designed by the instructor, and the "experienced curriculum" of "what each individual student experiences in the class" (Reflection I8). The class collage letter not only encourages students to reflect upon their own experienced curriculum but upon their classmates' as well, to the degree that their peers' credo statements embody their experienced curricula.

At this point in my original draft, I returned to quote Joyce, the student excerpted earlier in the paper, as my conclusion. But one $J B W$ reviewer advised me as follows: “The quote from Joyce's letter is very effective. But I'd like to hear your voice here at the end as well. As you end the article, I would recommend that you shift the readers' focus from what is happening in one 
... teacher's classroom to the larger issues that are reflected in this classroom. What can readers take away from this discussion even if they don't adopt the class collage and the other aspects of your practice in their entirety?" And so, upon reflection, I have decided to do both. What can be taken away from this discussion, other than a wholesale adoption of all of these activities? I would suggest that there are two main points, the first more familiar than the second:

- Reflection cannot be isolated as a solitary final act in a writing course with any great degree of hope for success. Rather, students need practice in the skills of reflection so that a culminating piece of writing can draw upon what they have learned about reflection and experienced throughout the course.

- $\quad$ Focusing on students' beliefs about the activities and work of the writing course seems to be a more comfortable-and productive-entry point for students to engage in reflection than a focus on cognitive development in terms of generating meaningful discussions of what they have experienced.

But the main thrust of this essay has been to argue that our students can-and do-have much of value to tell us about their experiences as writers when they are asked to ground their reflections on their beliefs. So I very deliberately want to give the final say to one of my students. Joyce, quoted earlier in this paper, also wrote to me about her experiences in my writing course approximately one year after the course had ended. Her letter concluded:

The final letter really just serves as a personal detailed account of my own learning journey.... I felt this was a powerful learning tool for the professor/teacher/ editor/person reading the writing in that it gave insight into thinking of the writers ... drawing attention to where they believed they needed help or where they were successful. Also, and more significant to me, its use as a learning tool for the writer is really unparalleled. The final letter ... serves as a personal "metacognition journal" to reference and reread at will. It reflects on my personal process of learning, drawing on examples from my own writing and not from some textbook. I make the point that I typically will write in the same voice, patterns, and styles and therefore be subject to making the same kinds of mistakes over and 
Jeff Sommers

over. The ... letter really just provided me with an account of my patterns. And once these patterns are spotted, they can be looked for and ultimately, changed.

Joyce proved to be a strong writer but one whose playfulness and sense of humor imbued every piece of writing, no matter how serious its purpose. Earlier in this essay when I quoted a typical comment of hers, it was smart, insightful, and self-consciously amused: "This letter is a ... masked-metamemo-cognitive piece of writing, if you will (cause I always will!)." In looking back from the vantage point of more than a year, she asserts that she has seen the patterns in her work and learned to change them, as these final observations illustrate in the very different tone she has chosen. When she concludes that the letter was "not only a very personal account of what I was thinking and writing, but an account of what I learned and how," I believe her. And the learning apparently extended beyond the end of the course, as exemplified in yet another reflection-in-presentation completed a year later when she wrote to me. Obviously, the class collage letter assignment did not have the same power for every student that it had for Joyce, but I am certainly encouraged to continue asking my classes to complete this final writing assignment. Writing the class letter provides all of my students with the opportunity to "lasso" their metacognitive thoughts as meaningfully as Joyce has done.

\section{Notes}

I. I routinely assign writer's memos in all of my writing courses. Basic writers and first-year composition students alike have much to tell me-and to learn themselves-by methodically reflecting on their recently completed drafts.

2. The student examples quoted in the remainder of this essay have been drawn from my most recent first-year composition courses at West Chester University. While some of the student writers in those courses have progressed from our basic writing course into FYC, most have not. In the interests of transparency, I will also concede that I have not chosen "typical" responses but instead have selected outstanding ones in an effort to illustrate how this approach can work. Of course, not all students excel with this letter assignment any more than all students respond successfully to any assignment. All student names used in this essay are pseudonyms. 
3. Schön discusses what he terms "reflective transfer" ("Causality," 97), which occurs when someone employs a strategy "in the next situation." Joyce's letter, quoted earlier, asserts that writing the writer's memos all semester long, a reflection-in-action activity, has made it possible for her to write the final reflective letter, suggesting that, at least for her, the scaffolding of the memo-writing has "paid off" in the new situation of composing the class credo letter.

\section{Works Cited}

Anson, Chris M. "Talking about Writing: A Classroom-Based Study of Students' Reflections on Their Drafts." Self-Assessment and Development in Writing: A Collaborative Inquiry. Eds. Jane Bowman Smith and Kathleen Blake Yancey. Cresskill, NJ: Hampton Press, 200o. 59-74. Print.

Bergmann, Linda S. and Janet Zepernick. "Disciplinarity and Transfer: Students' Perceptions of Learning to Write." WPA: Writing Program Administration 3I: I-2 (2007): I24-49. Print.

Berthoff, Ann E. Forming Thinking Writing: The Composing Imagination. Montclair, NJ: Boynton/Cook, I982. Print.

Bower, Laurel L. "Student Reflection and Critical Thinking: A Rhetorical Analysis of 88 Portfolio Cover Letters." Journal of Basic Writing 22. 2 (2003), 47-66. Print.

Bransford, John D., Ann L. Brown, and Rodney R. Cocking, eds. Committee on Developments in the Science of Learning. How People Learn: Brain, Mind, Experience, and School (Expanded Edition). Washington, DC: National Academy Press, 200o. Print.

Charney, Davida, John H. Newman, and Mike Palmquist.“ 'I'm Just No Good at Writing': Epistemological Style and Attitudes Toward Writing." Written Communication. I2:3 (1995) 298-329. Print.

Conway, Glenda. "Portfolio Cover Letters, Students' Self-Presentation, and Teachers' Ethics." New Directions in Portfolio Assessment: Reflective Practice, Critical Theory, and Large-Scale Scoring Eds. Laurel Black, Donald A. Daiker, Jeffrey Sommers, and Gail Stygall. Portsmouth, NH: Boynton/Cook, I994. 83-92. Print.

Fallon, Dianne, Cindy J. Lahar, and David Susman. "Taking the High Road to Transfer: Building Bridges between English and Psychology.” Teaching English in the Two-Year College 37.I (2009): 4I-54. Print. 
Jeff Sommers

Harrington, Susanmarie. "The Role of Reflection in First-Year Writing Course Outcomes." Teaching/Writing in the Late Age of Print. Eds. Jeffrey Galin, Carol Peterson Haviland, and J. Paul Johnson. Cresskill, NJ: Hampton Press, 2003. 39-52. Print.

Moon, Jennifer A. A Handbook of Reflective and Experiential Learning. London: Routledge, 2004. Print.

O’Neill, Peggy. “From the Writing Process to the Responding Sequence: Incorporating Self-Assessment and Reflection in the Classroom." Teaching English in the Two Year College 26.I (I998): 6I-70. Print.

Rodgers, Carol. "Defining Reflection: Another Look at John Dewey and Reflective Thinking." Teachers College Record I04.4 (2002): 842-66. Print.

Schön, Donald A. "Causality and Causal Influence in the Study of Organizations." Rethinking Knowledge: Reflections across the Disciplines. Eds. Robert F. Goodman and Walter R. Fisher. Albany, NY: SUNY P, I995. 69-IO3. Print.

. Educating the Reflective Practitioner: Toward a New Design for Teaching and Learning in the Professions. San Francisco: Jossey-Bass, I987. Print.

. The Reflective Practitioner: How Professionals Think in Action. New York: Basic Books, I983. Print.

Smith, Jane Bowman. “'Know Your Knowledge': Journals and Self-Assessment." Self-Assessment and Development in Writing: A Collaborative Inquiry. Eds. Jane Bowman Smith and Kathleen Blake Yancey. Cresskill, NJ: Hampton Press, 2000. I25-38. Print.

Smith, Jane Bowman, and Kathleen Blake Yancey, eds. Self-Assessment and Development in Writing: A Collaborative Inquiry. Cresskill, NJ: Hampton Press, 200o. Print.

Sommers, Jeff. "Bringing Practice in Line with Theory: Using Portfolio Grading in the Composition Classroom." Portfolios: Process and Product. Eds. Patricia Belanoff and Marcia Dickson. Boston: Heinemann-Boynton Cook, I99I. I53-64. Print.

"Self-Designed Points: Turning Responsibility for Learning over to Students." Teaching English in the Two-Year College 38.4 (2OII): 403-I4. Print.

_. "The Writer's Memo: Collaboration, Response, and Development." Responding to Student Writing: Models, Methods, and Curricular Change. Ed. Chris M. Anson. Urbana, IL: NCTE, I989, I74-86. Print.

Tomlinson, Barbara. "Talking about the Composing Process: The Limitations of Retrospective Accounts." Written Communication I.4: I984. 429-45. Print. 
Reflection Revisited: The Class Collage

Wardle, Elizabeth. "Understanding 'Transfer from FYC': Preliminary Results from a Longitudinal Study. WPA: Writing Program Administration. 3I:I-2 (2007): 65-85. Print.

Yancey, Kathleen Blake. "Dialogue, Interplay, and Discovery: Mapping the Role and the Rhetoric and Reflection in Portfolio Assessment." Writing Portfolios in the Classroom: Policy and Practice, Promise and Peril. Eds. Robert C. Calfee and Pamela Perfumo. Mahwah, NJ: Lawrence Erlbaum, I996. 65-85. Print.

_. Reflection in the Writing Classroom. Logan, UT: Utah State UP, I998. Print.

Yancey, Kathleen Blake, and Jane Bowman Smith. "Reflections on Self-Assessment." Self-Assessment and Development in Writing: A Collaborative Inquiry. Eds. Jane Bowman Smith and Kathleen Blake Yancey. Cresskill, NJ: Hampton Press, 2000. 169-76. Print. 
Jeff Sommers

\section{Appendix: The Assignment Sheet: Final Reflective Letter}

\section{What is it?}

Please write a letter to me in which you look back on your semester of writing in college. The point of writing this letter is to give you an opportunity to think about the writing you've done this term and reflect on its significance. In other words, this is intended to be a final piece of metacognitive writing.

\section{What are you supposed to write about?}

When we began the course, I asked everyone to finish these three sentences: "I believe writing ..." "I believe revising ..." "I believe writing courses ...." I've collected your comments and typed them up into a collage, which I've posted on the course website. It's now more than three months later; you've attended more than forty classes, written close to twenty journal entries, four papers, some revisions, multiple memos, etc. I'm very interested to know how the class collage looks to you now, based on these experiences. Please read over your class collage, and choose two or three of the credo statements to write about. Using your experiences in our course, write me a letter in which you explain why you've chosen those credo statements (perhaps your attitude has changed or maybe you still hold the same beliefs or perhaps you still reject them, etc.). You don't have to write about your own credo statements. I'd encourage you to write about what you're thinking currently that will be useful to you in the future as you look ahead to the rest of your college career.

\section{What now?}

Be sure that your letter talks about the work you did in this course. Even if you select a belief statement that you have always held, your discussion of it should be in light of what happened this semester in this course (and/or in your other college courses). How can you go about writing this letter? If you took time and wrote substantial writer's memos, you'll probably find them rather useful in beginning to think about this assignment. I'd recommend that you begin by looking over all of your written work: drafts, revisions, memos, journal entries. See what you can learn about your own experiences.

This is one of the most significant writing assignments of the term because by writing this letter you'll learn more about your experience in this course as well as teaching me something about your writing. This letter 
is important; it receives a final grade that counts along with your other two graded papers to determine your final average in the writing component of the course. Don't write a one-pager; it will hurt your final grade. This is not a journal entry or a memo but is intended to be a well-organized, well-written piece of writing.

\section{Show, Don't Tell/Organized and Planned}

Remember that even in this letter, showing is more powerful than telling. I expect to see specific references to your other writing: quotations from other papers, memos, journal entries; stories about specific choices you made; comparisons of specific aspects of your work, and so forth. NOTE: I also expect to read a well-planned, intelligently organized letter with transitions connecting the different parts.

\section{Final Note}

The purpose of this letter is not to write a course or instructor evaluation. You've already had an opportunity to do that when you completed the official university student evaluation form last week. The idea here is to explore and explain some of your beliefs about writing as a student about to finish this composition course and move on, rather than as a student ready to begin the first writing course of your college career. It's also an opportunity for you to demonstrate what you know about developing and organizing a piece of writing. 


\title{
Defining and Experiencing
}

\section{Authorship(s) in the Composition}

\author{
Classroom: Findings from a
}

Qualitative Study of Undergraduate

Writing Students at the City

University of New York

\author{
Johannah Rodgers
}

ABSTRACT: Theories of authorship and models of the author have been influential in shaping various approaches to composition theory and pedagogy. While discussions of the role of the author and authorship in composition studies have been going on for some time, tensions between the theoretical (author as social construct) and practical (author as agent) dimensions of authorship remain unresolved. Presenting the findings of a qualitative study of undergraduate writers at The City University of New York, this article explores student perspectives on models of authorship, the relationships between these models and student experiences of authorship in different writing situations, and proposes the importance of distinguishing between the multiple models and definitions of authorship and the rhetorical contexts associated with each.

KEYWORDS: authorship, authorships, Romantic author, authorial construction, audience construction, students, writers, authors

\section{Authorship in Composition Studies and Basic Writing: A Brief Overview}

There are few terms or concepts as central to literary and composition studies as the author. However, to ask the question of what an author is raises a number of questions: Is an author the same thing as a writer? Is everyone

Johannah Rodgers is Assistant Professor of English at The City University of New York's New York City College of Technology. In addition to her research projects related to communication studies, the history and anthropology of literacy, authorship studies, and book and media history, she is a working fiction writer who is particularly interested in innovative approaches to narrative and storytelling. Her short stories and essays have been published in Women's Studies Quarterly, Fence, Fiction, Pierogi Press, and The Brooklyn Rail, where she is a contributing editor. 
Defining and Experiencing Authorship(s) in the Composition Classroom

an author? Is anyone an author? The apparent simplicity of these questions masks a deeper complexity, which results from a profound tension between theoretical and practical concerns related to authorship. At the center of theoretical discussions about authorship lies the question of whether an author is best described as an individual solely responsible for the creation of a unique body of work, or as a cultural function that emerges out of the circulation and interpretation of work attributed to one individual. While the Author as originary genius may, almost forty years after Roland Barthes pronounced the death of the author, have some defenders in certain fields, within composition studies, the poststructural model, which proposes that the author is best defined as a convenient fiction, or character, produced by various discourses, has received wide acceptance by leading critics in the field. Yet when it comes to the practical reality of actual student subjects and writing classrooms, compositionists would largely agree that enabling students to achieve a sense of authorship is a primary goal of courses in writing. But what is authorship if the author herself is conceived as a product, as opposed to a producer, of various discourses?

Theories of authorship and models of the author have played an important role in thinking about writing processes and writing subjects in each of the three major periods of composition theory and pedagogy-current-traditional, expressivist/cognitivist, and social. While the specific ways in which models of the author have been used in each are not entirely uniform, a somewhat rough overview might depict the Romantic author as a gatekeeper for current-traditionalists, as a model of the writing subject for expressivists and cognitivists, and as a socio-historical construct for social theorists who, motivated by theoretical, rhetorical, and practical concerns, have explored and proposed alternate models and conceptions of the writing subject (LeFevre, Miller, Bizzell, Bartholomae). By the I99os, composition scholars were moving away from a focus on models of the writing subject as either centered and solitary (Romantic), or decentered and socially constructed (poststructural), and towards a consideration of the implications of various models of authorship for writing students and for composition as a discipline. Stuart Greene looked at the ways in which students engage in acts of authorship in his I995 article, "Making Sense of My Own Ideas: The Problems of Authorship in the Beginning Writing Classroom," while Kay Halasek considered the relationships between student identity and models of authorship in her I999 A Pedagogy of Possibility, drawing attention to the way in which any approach to composition pedagogy that seeks to empower students by assuming the identity of writer for them "marginalizes and 
renders subordinate students' other subjectivities and self-representations" (46). Susan Miller's Textual Carnivals (I99I) analyzed the importance of models of authorship in defining and maintaining the high status of literary studies versus the low status of composition; while Bruce Horner looked at the factors that contribute to the enactment and continuation of an Author/ student binary both within and outside the composition classroom in his I997 article, "Students, Authorship, and the Work of Composition"; and Lisa Ede and Andrea Lunsford investigated models of collective and collaborative authorship in their Singular Texts/Plural Authors (1990).

Growing out of this work and Martha Woodmansee and Peter Jaszi's research on the socio-historical and economic construction of the Romantic author, the most recent scholarship in authorship studies in composition has been focused on the power dynamics and implications of what many have identified as an evident Author/student binary, a function which renders and defines students as error-makers in order to maintain and protect the status and prominence of literary studies and canonical texts. Whether it is analyzing this binary and the construction of authorship in the writing classroom (Robillard, Murnen), creating opportunities for students to participate in and publish work related to the discourse and research methods of composition studies (Grobman, Spigelman, Wardle and Downs), exploring a model of the author as producer based on the work of Raymond Williams and Walter Benjamin (Trimbur), or how, as a result of this binary, students have become equated with plagiarists (Howard), work focused on authorship and its function within the composition classroom and in composition as a discipline has continued into the 2Ist century.

Interestingly, there is tremendous overlap in the issues involved in discussions of the Author/student binary and those that have occupied scholars involved in the study of basic writing for some time. For instance, we find the clear divide separating literary scholars' interpretive methods and reading strategies for approaching complex literary texts versus their reactions to and reception of the written work of basic writers (Shaughnessey, Bartholomae), as well as basic writing's dialectical relationship to literary studies in which the power and prestige of the latter is consolidated via the author function and defined in opposition to the former (Stygall). While recent work on authorship in composition has not been focused on basic writers per se, it nevertheless addresses many of the concerns of this cohort as it promotes the rights of students to their own texts, explores student writing practices in relation to new technologies, and advocates an elevation in status for student writers in general. 
After almost thirty years of work on authorship in composition, there now appears to exist a strong consensus among theorists regarding how they would like to see students position themselves in relationship to academic writing ${ }^{\mathrm{I}}$, namely with responsibility and engagement, and how student writing should be received by instructors, namely with respect and consideration. However, there remain questions related to how these two goals are to be reached in light of the complexity of the relationships between the theoretical and practical dimensions of authorship, as well as of how students actually define and experience authorship. For some, such as Miller and Rebecca Moore Howard, there is no need to fix any of the terms of the discussion. Rather, the terms in their theoretical and practical instantiations exist in relation to one another, each socially constructed and historically dependent, at any moment inflected by disciplinary, technological, cultural, and institutional factors. As Howard explains, a lack of consensus regarding the definition of authorship is evidence that "the heterogeneity of theories of authorship, the contradictory definitions that exist simultaneously, render impossible any sort of unitary representation" ("Plagiarisms" 793). However, for others, such as Kelly Ritter, contested notions of the author threaten to not only complicate students' understanding of authorship but to undermine students' sense of agency and ownership in relation to academic writing. In her 2005 "The Economics of Authorship: Online Paper Mills, Student Writers, and First-Year Composition," Ritter proposes "understanding how and when students see themselves as authors" (603) as one crucial element of preventing plagiarism and suggests that "instead of further sublimating the author ourselves, we should work to solidify our students' ideas of authorship, and their identities as writers" (625-26). Both approaches, each based on a distinct model and understanding of authorship, raise several questions: How do students define and understand authorship and models of the author in general and in relation to themselves? Do they rely more on received notions of authorship or new models presented in the writing classroom? What relationships exist between authority and authorship and how are they configured both in relation to textual production and reception?

In order to further explore student perspectives on authorship, I developed a qualitative study focused on analyzing how students conceive of themselves in different scenes of writing and whether these conceptions have any relationship to models of the author. While I did not necessarily expect the 2005 study to help refine and clarify some of the terms involved in discussions of authorship, nor to bridge certain theoretical and practical concerns, the findings have offered some insights related to both issues. 
Johannah Rodgers

Focused on student definitions and experiences of authorship in academic writing as expressed and encapsulated in definitions of the terms author and writer, the study allowed me to begin to understand how students define themselves and the rhetorical context of academic writing when they are writing with authority and how these conceptions relate to various models of authorship.

\section{Developing a Qualitative Study: Project Background, Methodology, and Participants}

My research began with a question derived from my interest in David Bartholomae's work on the ways in which writing students negotiate with and construct authority in academic discourse communities and from my experience teaching composition courses at an urban, public university: Why is it that some students operate from a position of authority in academic writing and in the composition classroom and others do not? My initial working hypothesis, in other words, what it is that I set out to "prove" (it is difficult, though important, to admit that I did, initially, plan on proving something definitive about the use of the term author in the composition classroom), was that students who were comfortable referring to themselves as authors might have a different sense of authority in relation to writing than those who did not. If this were, in fact, the case, how and from where was this sense of authority derived? Did authority vary based on the way in which a student identified him or herself? Were students who considered themselves authors able to see their writing with a greater degree of clarity and objectivity and therefore better attend to the rhetorical structure of their writing than those students who did not consider themselves authors? My goal in undertaking a qualitative study was not "simply" to prove my hypothesis, but also to investigate whether it was possible to move or change the self-definitions of students who did not readily conceive of themselves as authors.

Having been an adjunct lecturer at The City College of New York's Center for Worker Education (CWE) during the initial planning stages of the qualitative study and for several years prior, I decided that I would interview students enrolled there. ${ }^{2}$ An extension campus of The City College of New York, CWE was founded in collaboration with public employee unions and its programs were designed and created specifically for working adults seeking to complete their Bachelors degrees. ${ }^{3}$ Classes are offered in the evenings and on Saturdays, and the registration and advising processes are tailored to fit the lives of working adults. CWE has approximately 800 students in 
Defining and Experiencing Authorship(s) in the Composition Classroom

attendance, eighty percent of whom are female; the students' average age is 40, and a large number of students enroll with some transfer credit, either from two-year or four-year colleges. The student body is made up of a diverse, multicultural population and many CWE students are not only returning to school after a long absence, but are commonly the first members of their families to attend college.

Based on the model of a small, liberal arts college, CWE's curriculum was designed to be highly interdisciplinary. As a result, all CWE students must enroll in what are called "core courses," which are comprised of two semesters each of Core Humanities, Core Social Science, and Core Science. Although there is an English Composition course offered at CWE, it is not a required course. Instead, the college's formal introduction to college writing, or composition, is included in Core Humanities Ioo and IOI, a sequence of courses that are focused on the study of literature from a range of genres and historical periods. Though somewhat different in the types of literary works studied and in the scope of essay assignments, both courses include an introduction to academic writing.

Having considered the advantages and disadvantages of including students whom I had taught versus those I had not had in my classes, I decided to interview students who were not currently being taught by me, but who had been enrolled in my Humanities Ior course in the Fall 2003 or Spring 2004 semester. I made the decision to interview students whom I had taught for several reasons. First, I felt that because I had some relationship with these students and had worked with them as writing students, they would feel more comfortable discussing their thoughts about writing with me. Second, having collected formal essays from these students, I could then consider these in relation to their comments about writing. Third, the ability to talk about specific texts-Homer's Odyssey, Shakespeare's Othello, Zora Neale Hurston's Their Eyes Were Watching God-that we had read, specific classroom experiences that we had shared, and specific essays that students had written, would enhance my understanding of a student's comments in the interview. Fourth, one goal of the project was to offer a rich profile of these students and their relationship to writing, both of which were facilitated by my having an established relationship with them. Finally, there was the logistical consideration that adult students are very busy juggling academic studies with full-time jobs and family responsibilities, so that having some relationship with students would facilitate the scheduling and completion of interviews.

Realizing, even before the study was initiated, that with the small 
size of the study and the complexity of the terms being discussed, I should broaden the scope of the study, I developed an interview guide focused more on student definitions of terms, the derivations of these definitions, and their functions within and outside of the composition classroom, rather than on proving the predominance of one term over another. The interview guide, which was used in the hour-long interviews with students, was designed to generate dialogue and be highly interactive while at the same time collecting information that could be analyzed and compared. The first section of the guide collected significant background information about the student, including their age, ethnic identity/identities, educational and work histories, their parents' occupations and educational backgrounds, college writing courses completed, and the types of writing performed at work and at home. The body of the interview began with a focus on definitions. I asked students to define, in their own words, the terms author and writer, whether they were comfortable applying these terms to themselves, the reasons why these terms may or may not be appropriate designations, and finally to compare and contrast the meanings of these terms in general, as well as when applied to themselves. From a focus on definitions, I then posed more open-ended questions, asking students to reflect on their specific experiences with academic writing, and the ways in which reading literary texts may have influenced their writing processes, or the ways in which they conceived of themselves during their writing processes. The third section of the interview guide asked students to consider issues of audience awareness in academic and non-academic writing contexts; the fourth, and final, section posed a series of questions related to how having work published might alter a student's relationship and understanding of audience and, as a result, his or her sense of authority and definitions or conceptions of him or herself during the writing process. Questions related to the last issue included whether a student had had a piece of writing published in the past and, if so, whether this had changed his/her relationship to writing and if not, whether he/she would like to have a piece of writing published and how he/she might foresee this changing his or her conception of him or herself. This section also asked students to reflect on which piece of writing they might consider publishing and what their specific relationship to this piece of writing was.

The one-hour interviews took place over a one-month period in the winter of 2005 and participants received a twenty-dollar honorarium. In addition to the interviews, which were tape recorded and transcribed, informal writing samples, three formal essays, and essay drafts with student revision 
Defining and Experiencing Authorship(s) in the Composition Classroom

notes and instructor marginal comments were collected and also included in the analysis and interpretation of the results of the study.

The group of students interviewed represented the overall CWE student body not only in terms of age and gender, but in terms of their overall conscientiousness, and on the basis of having been, for the most part, educated in New York City public schools. Furthermore, though those involved in the qualitative study were from a range of ethnic, racial, and economic backgrounds, like all CUNY students, each shared a surprisingly consistent sensibility, which you could call "street-smart," though that is something of a misnomer since it is more accurately described as a kind of urban-and at times urbane-intelligence and humor. All were returning to college after some hiatus and, as is the case with many adult learners, all were very committed students.

Though representative of CUNY students in general and CWE students in particular, the participants ${ }^{4}$ all, of course, had their own unique personalities and perspectives: Celia Fitzpatrick admitted to sometimes writing funny stories dedicated to her cat to overcome writer's block and had had a letter of complaint published many years prior in Billboard magazine. Christine Cummings aspired to write a memoir of her childhood even though she doubted she could do it well. Eliza Edwards was very focused on whether or not someone was being paid for his/her writing in her definitions of the terms author and writer and believed she had "mastered the rules" for academic essay writing. Lisa Monroe seemed somewhat surprised by her own academic success after her long absence from school and believed that, for many reasons, not just because she was a single parent, her life had been "interesting enough to write about." Daniel Stein had been an undergraduate at a SUNY college and a contributor to the college newspaper before dropping out to join the military, a move that was, considering the liberal leanings of his parents, a somewhat unusual choice. John Hernandez was in his early 2os, very proud to be a student at CWE, where his father had completed his B.A., and expressed an interest in publishing some of his essays to a wider audience. James Harrison had been born and raised in Harlem, was the first of his eight siblings to graduate from college, and had a strong belief in traditional approaches to writing education. Patricia Johnson was focused mainly on writing as a creative expression of who one is, though was, at the same time, highly attuned to the variations in stylistic demands of each and every professor. Susan Patterson had dropped out of a private liberal arts college before enrolling at CWE, once had her poems read by Toni Morrison as part of a writing program at her private high school, and 
was very interested in doing further research on Haitian Creole. Jennifer Stevens, who had been born in the Dominican Republic and was the first member of her family to attend college, hoped not only to complete an M.A. and teach ESL after graduating from CWE, but commented on how much her own struggles with learning English had influenced her approach to written communication.

Despite the small size of the interview sample, there were numerous ways to categorize the students involved. There were three men (Hernandez, Harrison, Stein) and seven women (Cummings, Edwards, Fitzpatrick, Johnson, Monroe, Patterson, Stevens), ranging in age from 26 to 50. With the exception of Stevens, who was in her mid-3os, and Edwards, who was 50 , the students were either in their mid-to-late 20 (Hernandez, Johnson, Patterson,) or mid-to-late 4os (Cummings, Fitzpatrick, Harrison, Monroe, Stein). Three were born outside of the U.S.: Cummings, who was born to Chinese parents in Guyana, Fitzpatrick, who was born in England to Jamaican parents, and Stevens, who was, like her parents, born in the Dominican Republic. All but three (Stein, Patterson, Edwards), who had been educated in the tri-state area, were graduates of New York City public schools. Two students identified themselves as African Americans (Johnson, Harrison), one as Dominican-American (Stevens), one as Jamaican (Fitzpatrick), one as Haitian-American (Patterson), two as Caucasian (Stein and Edwards), one as Puerto-Rican-American (Monroe), one as Latino (Hernadez), and one as Chinese-American (Cummings). There were three students employed as teacher's assistants (Monroe, Stevens, Johnson); two security guards (Stein and Hernandez); one program officer with a non-profit (Patterson); two city workers: one data processing supervisor with the Metropolitan Transportation Authority (Cummings), and one site supervisor for a neighborhood improvement squad (Harrison); one bookkeeper with an international fashion conglomerate (Fitzpatrick); and one legal assistant (Edwards).

In terms of their relationships to writing, all were engaged by and interested in it, though some were more self-deprecating than others (Fitzpatrick, Cummings), some more confident (Hernandez), some quite practical and grade conscious (Edwards, Stevens), some with more experience with writing and publishing (Stein, Patterson), one more interested in creative writing than academic writing (Johnson), and one basic writer (Harrison). Also noteworthy was the fact that a consistent differentiating factor among project participants and their relationships to writing related to whether a student had attended a community college prior to enrolling in a four year college. Those who had completed Associates Degrees tended to be more 
Defining and Experiencing Authorship(s) in the Composition Classroom critical of their writing abilities than those who had either dropped out of four-year colleges (Stein, Patterson), not attended any college prior to enrolling at CWE (Hernandez), or attended only some community college or adult education classes (Edwards, Monroe).

After completing ten interviews, I transcribed the contents of the audio-taped interviews and the hand-written transcripts of the telephone interviews. Next, I began the process of analyzing the data collected by transcribing the interviews from the audio tapes and written notes into Microsoft Word. I then collated responses to each interview question, using both Microsoft Word and Microsoft Excel to collect and organize the responses. Though I relied primarily on the transcripts of the interviews and the information collected in the cumulative data file for my analysis, there were times when I also referred to the following materials: audio tapes of the interviews, informal writing samples, and essays written by the students interviewed.

\section{Defining Authorship(s) and Their Rhetorical Context(s)}

The findings from the CWE study affirmed not only the dominance of the Romantic model of authorship 5 in student definitions of the term author, but offered insight into the attributes of the rhetorical context students associated with that model. In their interviews, students defined authors as individuals who write for a large audience and without prompting. Reflective of the findings from Timothy Murnen's 200I/2002 survey of undergraduates and Ritter's 2004/2005 survey ${ }^{6}$, the comments from students involved in my 2005 study suggested that for the vast majority of students, author is a high status term applicable only to those who compose effortlessly and effectively, publish books, and write for a large audience:

\section{Student Definitions of the Term Author}

\begin{tabular}{ll} 
Student & Definition \\
\hline $\begin{array}{l}\text { Christine Cummings } \\
\text { Eliza Edwards }\end{array}$ & $\begin{array}{l}\text { A writer of books....I don't come to mind! } \\
\text { When you're an author you're writing knowing that } \\
\text { others are going to be reading your works. } \\
\text { Celia Fitzpatrick }\end{array}$ \\
$\begin{array}{l}\text { Someone who is able to put their thoughts onto } \\
\text { paper that can relate to others. I wish I could. }\end{array}$
\end{tabular}


John Hernandez

Patricia Johnson

Lisa Monroe

Susan Patterson

Daniel Stein

Jennifer Stevens
When I think author I think of someone who's published. Because we don't make ourselves authors. If I write a paper, it doesn't make me an author. If it says Harper Collins on it then obviously somebody else thought it was good enough to publish.

[For] authors [writing] is something they love to do.

An author is someone who writes a book and puts his ideas on paper.... [I don't consider myself an author because] I'm thinking about the selling part....I don't consider that anything I write would have any buyers.

An author is someone who sees [writing] beyond a hobby, it is who they are, it is a career

I generally associate authors with somebody who has a published work but not always. I associate authors with larger works.

Author has more prestige attached to it [compared to writer]. When I think of an author I'm thinking about more formal work. I guess more complex.

Informed by their understanding of the publishing market, as well as by various received notions of the author inside and outside of the composition classroom, students defined authors as "[people] who see writing as being beyond a hobby," and as a term that should be applied only to those individuals for whom writing is "something he or she has to do," "a career," or "an act that will lead to something being published."

The idea that a set of external conditions must be in place for an individual to consider him or herself an author was one that many students expressed. Students were generally unable to situate themselves in the rhetorical context they associated with the term author and described this context as one that they would probably never participate in, citing, in particular, their lack of inspiration and originality, as well as the absence of a large and receptive readership, as reasons why they would not be comfortable applying the term to themselves. In their discussion of why they did not consider themselves authors, three students, Edwards, Hernandez, and Monroe directly linked authorship with publishing, while the remaining six explained that what differentiated them from authors was a lack of inspiration, motivation, or ability. 
Defining and Experiencing Authorship(s) in the Composition Classroom

\section{Attributes Required for Student to Conceive of Him- or Herself as an Author}

Christine Cummings I don't feel that I'm capable of producing something so wonderful and imaginative [as authors are]. When I read other peoples' writing you can picture the events when you read it. They can picture the whole room first and visualize the whole atmosphere and no I can't do that. I'm a factual writer.

Celia Fitzpatrick Because a lot of the thoughts I have I do not put to paper. They sound good in my head. But they just stay in my head and I don't write anything down.

Patricia Johnson I don't think I work as hard as authors do. I kind of do my writing, read it over and hand it in. I don't look back to it.

Susan Patterson I've never written anything outside the purview of class or work, which has just been for me to share myself.

Daniel Stein

I've only written shorter pieces. Basically everything I've written has been assigned except for when I was young. When I was younger I did write [without it being assigned].

Jennifer Stevens It makes me nervous because I think I want to write someday but I don't know if I will be able to. There is so much that I would like to write about. It is really big, like wow, an author.

Eliza Edwards My name is not on a publication.

John Hernandez

When I think author I think of someone who's published.

Lisa Monroe

I'm thinking about the selling part. I don't consider that anything I write would have any buyers.

Though students cited a range of reasons why they were not comfortable referring to themselves as authors, the one constant that all shared was the fact that they were lacking access to something - a certain kind of purpose or audience-that would allow them to position themselves as authors. ${ }^{7}$

One of the hypotheses of the study was that the two terms-author and writer-might be defined and used by students in distinct ways depending on a student's sense of authority in the rhetorical context of academic writing. While two distinct groups emerged in the study, rather than dividing into groups of authors and writers, as was my hypothesis, the students instead divided into two groups: one group made up of those students who were 
comfortable consistently referring to themselves as writers (Hernandez, Patterson, and Stein) and another made up of those students who described themselves as non-writers (Cummings and Fitzpatrick), not-yet-writers (Edwards and Stevens), or sometimes-writers (Harrison, Johnson, and Monroe).

\section{Student Definitions of the Term Writer}

John Hernandez

Susan Patterson

Daniel Stein

Christine Cummings

Celia Fitzpatrick

Eliza Edwards

Jennifer Stevens

James Harrison

Patricia Johnson

Lisa Monroe
Someone who's able to communicate and convey.

I think anyone could be a writer, it's just an expression of ideas and thoughts. I don't think everyone is a writer; not everyone writes, not everyone has the ability to write.

[I define writer] much more broadly [than author], somebody who writes anything. It is a self-definition.

I write, but I am not a writer.... When I say writer or when you say writer I think of something published. Anyone who writes something professionally.

I generalize a writer as something that is a natural thing and for me it is a struggle

If you got paid for it, [if] you could earn a living [then you are a writer]. Most people have to make a living and if you're serious about writing it takes a lot of your time and time is your most precious commodity.

Someone who doesn't procrastinate, who knows what they are doing and just does it.

If I'm writing [a] professor a letter as a friend, I can write my thoughts and maybe there's some bad grammar. If I'm writing [to] my instructor, then my grammar and everything has to be correct and that's when I'm a writer... So sometimes I'm a writer and sometimes I'm not.

I'm a writer when I'm in that mood.

[I'm] not always [a writer]. My own writing is OK but my own writing versus college writing I don't live up to that standard. The standard is to write a paper, you know, it is like the end of the rainbow, I'm dreaming of it, I can see what the goal is, but even with the third draft, I was still edited and that third draft is what I would have liked to have written on the first draft.

Discerning the similarities and differences amongst and between the two groups-those students who were comfortable consistently identifying 
Defining and Experiencing Authorship(s) in the Composition Classroom

themselves as writers and those who were not- became the focus of my analysis. What emerged as a key difference between the groups was the extent to which each clearly separated the definitions of the terms author and writer. Those students who were comfortable consistently identifying themselves as writers defined the term writer as separate and distinct from the term author, whereas those students who did not clearly separate the two terms, but instead used elements of one definition to inform their definition of the other, were not comfortable consistently identifying themselves as writers.

In the former group, students not only clearly separated their definitions of the terms author and writer, but they also assigned a unique rhetorical context to each term. In their definitions of the term writer, students mentioned, each in his or her own way, that "everybody writes" and "everybody is a writer" or "everybody could be a writer." ${ }^{8}$ They considered being a writer a role that "anyone" could play, as opposed to an identity reserved for unique individuals, or "someone." In contrast, students who were not comfortable consistently applying the term writer to themselves defined a writer as a subject position that they might attain based on some type of change or the acquisition of certain attributes, in other words, in terms strikingly similar to the terms they used to define the term author. Two of the three students who considered themselves writers "sometimes," defined a writer as one who adheres to standards of correctness: Harrison explained that he considered himself a writer only when he was "writing correctly," and Johnson perceived herself as a writer only when she had "attained a certain academic standard." Likewise, the four students who answered "no" or "not yet" to the question all defined the term writer as demarcating a subject position or identity they might attain if something changed. For instance, if they were published or paid for their writing, or if they did not procrastinate with their writing.

During the course of my analysis, I came to realize that it was not the term author or writer per se that was significant, but the model of authorship that informed a student's individual understanding of each term. What became evident was that while a Romantic model of authorship was uniformly informing student definitions of the term author, this was not the case in student definitions of the term writer. Instead, some students used the Romantic model of authorship as the basis for their definition and others did not. Importantly, those students who did not use the Romantic model in their definitions of the term writer relied on an alternate model of authorship to define the term. In this alternate model, students emphasized the experience of authorship as an act, series of acts, or process, as opposed 
to authorship as ownership of a unique product. In their definitions of the rhetorical context associated with this alternate model, students commented that it was possible for anyone with the ability to write to participate in such a rhetorical context. In contrast, students made it clear that only some can participate in the rhetorical context associated with the Romantic model of authorship. Thus, whereas one aspect of authorship-authorship-as-experience-was one that some students had access to, none of the students in the study reported having access to authorship-as-ownership.

\section{"Authorships and Audience: Dialogic vs. Performance-Based Constructions"}

Students who clearly distinguished between an alternate model of authorship and the Romantic model of authorship that described their relationship to audience in an academic writing context in ways that were distinct from those students who did not distinguish between the two models and aspects of authorship. The first group described their relationship to audience as dialogic; in other words, they were able to project themselves not only as writers but also as imagined readers of their own work. In both their interviews and in their writing samples, these students approached the writing of academic essays from a place of knowing how to position themselves as interlocutors with their audience/reader and with the purpose and language of academic writing. These students described themselves "talking with" an audience and purpose, which they had in some manner internalized. They also mentioned, each in their own way, that they wrote these papers not only for the teacher but also for other imagined audience members and, what was most noteworthy, for themselves.

\section{Student Comments on Audience in An Academic Writing Context: Students Who Distinguish Between a Romantic Model of Author- ship and an Alternate Model}

Daniel Stein The professor is the audience for an academic essay and I try to anticipate what is expected of me and the points that are expected and stylistically as well. But in terms of the overall piece I have to satisfy myself and the professor. I also shouldn't forget my wife; she is also part of the audience.

Susan Patterson [With academic writing] the audience is the professor but I know what is expected of me. 
John Hernandez [At school] the audience is the professor. But it is also for my friends and family. They read my papers. I wrote a paper in 2003 and it was an "A" paper and I gave it to friends and family because I thought it was good work.... Writing the paper I imagine the professor but I also imagine that I'm working at Time magazine or something like that. That it is high quality and it can be conveyed to anybody. I try to put myself at a high level and get myself to a point where I can write the paper.

From these comments, it is apparent that these students, who all express the fact of having internalized their audience, place themselves at a level of parity with their audience, including the professor, and are able to identify with their audience in an academic writing context.

In contrast, those students whose definition of authorship is informed by the Romantic model defined audience as a controlling authority that they were either unable or rarely able to establish communication with in an academic writing context. This group also defined their experience of writing academic discourse as being primarily monologic, or an act of "reciting for" an audience:

\section{Student Comments on Audience in An Academic Writing Context: Students Who DO NOT Distinguish Between a Romantic Model of Authorship and an Alternate Model}

$\begin{array}{ll}\text { Christine Cummings } & \text { I'm writing to make sure that I'm supporting my po- } \\ & \text { sition. I make sure it is grammatically correct. We all } \\ & \text { write for the teacher. At school, I can't say that I do put } \\ & \text { myself in the professor's position. } \\ \text { Eliza Edwards } & \text { I pay attention to my academic work and look at gram- } \\ \text { mar and clarity with an eye on getting a good grade. } & \text { Audience is the professor. I wasn't thinking about } \\ \text { Celia Fitzpatrick } & \text { anyone reading [my essays] except the professor. I } \\ & \text { sometimes visualize what [a professor will] say about } \\ & \text { certain things, and I think "oh no, she's not going to } \\ & \text { like that so delete." } \\ & \text { With [academic essays], it is always "is it enough," is it } \\ & \text { the right grammar, is it the right paragraph structure. I } \\ \text { James Harrison } & \text { don't want to graduate unless my professors know that } \\ & \text { I have achieved good academic writing skills. } \\ \text { My audience for my academic essays is the professor. }\end{array}$


Lisa Monroe

Jennifer Stevens
I wrote these papers for my professors. This is something I wrote to get a grade. If a professor is my audience, and one person can be an audience, then I guess the professor was that. These [papers] were put together to perform for the professor.

[The professors] are all different, they all want something different in their papers. And when I don't sound or express what they want the grade is lower.

The emergence of a clear distinction between one group of students defining their relationship to audience in an academic writing context as dialogic and another defining their relationship to audience as monologic relates quite closely to one of the key findings from a longitudinal study of freshman writers at Harvard University. Discussing the findings from the study, which began in I997, Nancy Sommers and Laura Saltz write:

When students begin to see writing as a transaction, an exchange in which they can "get and give," they begin to see a larger purpose for writing.... If there is one great dividing line in our study between categories of freshmen, the line falls between students who continue throughout the year not to "see a greater purpose in writing than completing an assignment" and freshmen who believe they can "get and give" when they write--between students who make the paradigm shift and those who don't. Students who continue to see writing as a matter of mechanics or as a series of isolated exercises tend never to see the ways in writing can serve them as a medium in which to explore their own interests. (I39-I4O)

In the CWE study, there was also a clear difference between those students who described their relationship to audience in an academic writing context as dialogic, or an exchange, and those who described their relationship to audience as monologic, or following directions. Those in the former group appear to no longer be objectifying the audience and purpose of academic writing, but to have in some sense internalized both. Thus, rather than performing for the instructor in the sense of trying to reach a certain externally imposed goal or standard, these students were performing the role of an academic writer in, as Miller explains, the same way "an actor who concretizes a script when performing in the face of unstable but enabling theatrical conventions" (Rescuing the Subject I5). 
Defining and Experiencing Authorship(s) in the Composition Classroom

Some methods for helping those students who do not currently experience their relationship to audience in academic writing as dialogic towards an experience of audience as dialogic did emerge. Students reported that they had established a dialogic relationship to audience with specific writing projects and in experiences with non-academic writing. Of the seven students who generally experienced audience as a controlling authority in academic writing, three students described a change in their relation to their audience when they were particularly engaged in a topic:

With My Their Eyes Were Watching God paper, I wrote that last paragraph with me in it, and I felt that no matter what I got for that paragraph it didn't matter... The teacher said to move it to the beginning [to use it as a thesis statement] and I needed it at the end. I love this paragraph and I didn't know where else to put it. I couldn't find a place for it and I left it there and it was important to me. I was a rebel at that moment. I'm not usually a rebel. I usually try to do my best. It felt different. I was in it. Even if it was one paragraph I put myself in there. (Monroe)

In this particular instance, Monroe was not willing to let the instructor be the authority; instead, she decided to stand up to the instructor. And it was at that point when she had found a place for herself as a participant in the rhetorical context of academic writing. At that moment, Monroe had internalized the audience and purpose of this specific act of writing, as she indicates by her comment that she had been able to make the purpose of the essay her own, i.e., "no matter what I got for that paragraph it didn't matter," and to place herself at a level of parity with her professor/audience, i.e., "the teacher said to move it to the beginning and I needed it at the end." Monroe, who had explained that in an effort to improve her academic essays she is always eager to respond to suggestions made by the professor, acknowledges that something has changed for her in the writing of this particular essay.

Harrison also described a difference in his relationship to purpose, audience, and language when he was writing about a topic that he felt he not only could relate to, but one to which he brought a sense of authority:

The writing [in the Their Eyes Were Watching God essay] was the best writing I did in your class. I got angry there in that paper. And it helped me. To me, it was alright me being angry. These people [i.e., critics] had written books themselves but they had not gone through 
Johannah Rodgers

what she had gone through. They attacked the story. What other identity can they relate to other than what they've seen. They were saying Teacake was the average black person at that time. At the end of the story she went back to Mr. Starks. She went back to the town, she went back to her porch there with her friend, at the end of the book she goes back to his house. This critic is saying Teacake is representing the typical African American guy. To me Teacake is a fool.

The internalization of authority that Harrison describes is profound and surprisingly similar to that described by Monroe. In both instances, Monroe and Harrison mention first standing up to the authority of the instructor, choosing to continue with their projects on their terms, and then finding a new kind of authority in relation to the academic discourse community.

Stevens described a change in her relationship to audience in her experience of writing of an opinion essay on the topic of the atomic bomb.

[After] writing an opinion paper on the atomic bomb, [which] I thought was a callous act on behalf of the U.S., the professor challenged my opinion and asked me things like "well, what if your son was there, and hindsight is always $20 / 20$ " and I said, "well, my son wasn't there and maybe I don't have $20 / 20$ hindsight, but this is my opinion and this is what I think." I guess I was like, this is my opinion and this is what it is. I felt like I'm not going to change it just to comply with what I think you want me to say.

Her ability to challenge the authority of the instructor appears to translate into a different relationship to the academic writing context with this particular writing project.

Similarly, a sense of authority was achieved in relationship to audience for Cummings and Johnson when they described their experiences of writing at work, where they appear to be more confident putting themselves in the position of the reader:

At work, yes [there is an audience.] I try to be objective. I do read what I've written as though I'm out there in the field as if I'm the recipient of the writing. I have to have two-views: the employee view and the policy view since the union will read this and will make an appeal if there is anything wrong with what is being written. I imagine transit workers reading this. I stay away from large words. 
Defining and Experiencing Authorship(s) in the Composition Classroom

I try to be as clear as possible. I have to write step procedures, really explain things. (Cummings)

When I'm at my job and I know I have to write a parent a note, I think about what their reaction is going to be when I write "because [your child] didn't nap they're in a cranky mood." Will they be OK, will they be upset? (Johnson)

When asked why they were unable to achieve the same relationship to audience when writing in an academic context, Cummings and Johnson remarked that they were not able to put themselves in the professor's position. Both also clearly differentiated between the purpose of writing at work and the purpose of academic writing and saw few relationships between the two scenes of writing.

While Johnson and Cummings compared their ability to establish a dialogue and place themselves at a level of parity with their audience in different scenes of writing, Fitzpatrick discussed the impact instructor comments have on her ability to establish an open line of communication with her audience in an academic writing context:

To take criticism is very hard, particularly if you feel that you've done a lot of work. With my thesis statement [in a recent class], the professor started by saying: "Well, I don't know how much time you spent on this" which to me was a negative right away. And I shut down immediately when he said that. I thought: "this man does not like me" and I didn't even hear what he was saying after he said that because I know that I had spent a great deal of time on it and showed it to a couple of people and they had said "it's ok, it's interesting." but the bottom line was that he said it was too broad and I felt that he could have said that in a nicer way and he had written notes and it was this whole thing just to tell me it was too broad. Now I'm staring at a blank piece of paper. I've been intimidated to the point where I cannot write.

Linking her ability to compose freely with her relationship to audience, Fitzgerald contrasted this experience to those she has had with writing when she feels there is an open line of communication with the professor. In these instances, she explained that she derived a sense of authority from this relationship and it actually enabled her to write. 
Johannah Rodgers

\section{Towards a Pedagogy of Authorial Construction}

The findings from the CWE study align closely with those from Murnen's ethnographic study of authorship in the composition classroom. In his study, Murnen also identifies multiple authorships operating in the discourse of the composition classroom. One, which he refers to as "Authorship as Status," is "a right and a privilege of an elite group of writers who have been published" and the other, "Authorship as Process," is "an act or series of activities that writers (including student writers) engage in" (26). Furthermore, just as the CWE study confirms the change that occurs in a student's relationship to audience when she is writing with a sense of engagement and authority derived from writing about something she has a unique perspective on, Murnen emphasizes the importance of crafting writing assignments that present students with the opportunity "to stake out ideological positions in the process (and product) of writing" (266). The importance of how these student texts are received by instructors in reinforcing student experiences of authorship was another finding shared in both Murnen's study and the CWE study. For, as Murnen found in his ethnographic study and as was confirmed by the CWE study, "what was being composed in the composing process was not simply a text, but also student identity" (I9). Concurring that text and identity formation are linked, Howard likewise proposes that "student writing must be accorded the same respect as professional writing: it must be treated as subject rather than object formation" ("Plagiarisms" 796).

While there is no easy answer to the question of how to assist students in experiencing authorship, pedagogies that allow students to participate in the construction of the rhetorical context that they are writing for may enable students to experience writing as a transactional activity, which appears to be an integral part of authorial construction. Creating writing situations in which students understand that their writing has a clear purpose and audience, as all writing in the world does, will reinforce their experiences as actual writers and, ultimately, of authorship-as-experience. In such a pedagogy, being a writer is not an identity, but a role that one inhabits when involved in the act of writing. This then shifts the emphasis of writing pedagogy away from one based on exhortation, which is meant to aid students in the revelation of an identity that is presumed to be already latent, to one based on conversation, which asks students to consider how subject positions that they currently use to define themselves might be expressed through the act of writing and how certain writing situations may require the creation of 
Defining and Experiencing Authorship(s) in the Composition Classroom

new subject positions. Such a pedagogy is simultaneously informed by social constructivist and expressionist theories, particularly through its focus on voice, which is conceived not as a quest for one essential voice, but as multivocality. By modeling conversations with specific audiences and purposes and by making the audience and purpose of the academic writing context malleable fictions, as opposed to fixed standards or facts, students may be able to redefine what they thought was an exclusive rhetorical context as one that is actually much more like rhetorical contexts where they have experienced a sense of responsibility and belonging.

\section{Acknowledgments}

This article would not have been possible without the participation and input of the ten students involved in the 2005 qualitative study. I remain not only grateful to them for their insights and time, but I would like to acknowledge each as a contributor to this article. For their support of and contributions to my research, I am grateful to Sondra Perl, Ira Shor, and David Greetham. For feedback on early drafts of this article, I would like to thank John Schilb, Stephanie Wade, Aaron Barlow, and several anonymous reviewers at $J B W$. I cannot thank Hope Parisi enough for her comments and feedback on several later drafts. Without her guidance, I do not believe this article would have reached its full potential. Finally, and as always, for his patience, love, and humor, I thank Donald Breckenridge.

\section{Notes}

I. For the purposes of the qualitative study, "academic writing" was defined as writing that was being written for a college course that would be evaluated and assessed by an instructor. While I do not believe that "academic writing" can or should be defined uniformly, for the purposes of the study, it was necessary to adopt a single definition of the term which was appropriate to the student writing being discussed.

2. Having been appointed Assistant Professor at CUNY's New York City College of Technology in 2008, it is my hope to re-create a version of the qualitative study with students enrolled there.

3. The extent to which data from a qualitative study focused on adult-learners can be interpolated and related to undergraduate writing students of traditional age is open to interpretation. While there are many differences 
between adult-students and traditional-age-students, a recent national study of college freshmen at two-year colleges indicates that in terms of their attitudes towards confidence in writing, the two populations are almost identical. See Noel-Levitz "20Io Freshman Attitudes at Two Year Colleges: A Closer Look."

4. Permission to use student comments in reports and discussions of the research findings was granted by the students involved in the study with the understanding that actual student names would not be used. Based on the work of Amy Robillard and others regarding the status and treatment of student subjects in composition research, I plan, in future studies, to ask permission of students to use their real names. For reports from this study, I have assigned pseudonyms to each student and I have made the decision to refer to students using their last names in the interest of treating student comments as I would other primary or secondary source material.

5. While definitions and discussions of the Romantic model of authorship are very complex, as a functional definition for the qualitative study, I use Woodmansee's definition in "The Genius and the Copyright": "In contemporary usage an author is an individual who is solely responsible - and therefore exclusively deserving of credit - for the production of a unique work." (426). For further discussion of the term, see Jaszi (I99I), Woodmansee and Jaszi (1994), McGann, and Saunders.

6. It is noteworthy that almost half of the students in Ritter's survey defined an author according to the Romantic model and well over half (6I\%) of the students did not perceive writing on the internet to be authored. As Ritter points out, this is leading to a situation in which students are both alienated from authorship in the writing classroom and defining textual artifacts online as part of a cultural commons or, to phrase it in less idealistic terms, not belonging to anyone and therefore not subject to laws against theft.

7. One student, James Harrison, defined the term author in terms that were distinct. He defined the term as one that applies to "anyone who authors anything."

8. For a discussion of dialectics/paradoxes similar to the one described here of authority in writing existing not as a sense of ownership but of contribution and communication, see Spiegelman on the dialectic of public/private in writing groups and Bazerman on the communality/ originality paradox. 
Defining and Experiencing Authorship(s) in the Composition Classroom

\section{Works Cited}

Bartholomae, David. "Inventing the University." When a Writer Can't Write: Studies in Writer's Block and Other Composing-Process Problems. Ed. Rose Mike. New York: Guilford, 1985. I34-65. Print.

Bartholomae, David, and Peter Elbow. "Interchanges: Responses to Bartholomae and Elbow.” CCC 46.I (1995): 84-92. Print.

Bazerman, Charles. "Paying the Rent: Languaging Particularity and Novelty." RBLA, Belo Horizonte Io.2 (2010): 459-469. Web. 5 May 2011.

Barthes, Roland. "The Death of the Author." Image, Music, Text. New York: Hill and Wang, I977. I42-I48. Print.

Bizzell, Patricia. "Cognition, Convention, and Certainty: What We Need to Know about Writing." Academic Discourse and Critical Consciousness. Pittsburgh: U Pittsburgh P, I992. Print.

Carrick, Tracy Hamler, and Rebecca Moore Howard, eds. Authorship in Composition Studies. Boston: Thomson Wadsworth, 2006. Print.

Crowley, Sharon. Composition in the University: Historical and Polemic Essays. Pittsburgh: U of Pittsburgh P, I998. Print.

. "Writing and writing." G. Douglas Atkins and Michael L. Johnson, eds. Writing and Reading Differently: Deconstruction and the Teaching of Composition and Literature. Lawrence, Kansas: UP Kansas, 1985. Print.

Ede, Lisa and Andrea A. Lunsford. Singular Texts/Plural Authors: Perspectives on Collaborative Writing. Carbondale: Southern Illinois UP, 1990. Print.

Foucault, Michel. "What Is an Author?" Language, Counter-Memory, Practice: Selected Essays and Interviews. Ed. Donald F. Bouchard. Ithaca, NY: Cornell UP, I977. II3-38. Print.

Greene, Stuart. "Making Sense of My Own Ideas: The Problems of Authorship in a Beginning Writing Classroom." Written Communication I2.2 (I995): I86-2I8. Print.

Grobman, Laurie. "The Student Scholar: (Re)Negotiating Authorship and Authority." CCC 61:I (2009): Wi75-Wig6. Web. I June 2011.

Halasek, Kay. A Pedagogy of Possibility: Bakhtinian Perspectives on Composition Studies. Carbondale: Southern Illinois UP, 1999. Print.

Horner, Bruce. "Students, Authorship, and the Work of Composition." College English 59.5 (1997): 505-29. JSTOR. Web. 4 October 2005.

Howard, Rebecca Moore. "The Binaries of Authorship." Authorship in Composition Studies. Ed. Tracy Hamler Carrick and Rebecca Moore Howard. Boston: Thomson Wadsworth, 2006. I-I2. Print. 
. "Plagiarisms, Authorships, and the Academic Death Penalty." College English 57.7 (November I995): 788-806. Print.

Jaszi, Peter. "Toward a Theory of Copyright: The Metamorphoses of 'Authorship'." Duke Law Journal I991. 2 (Apr., I99I): 455-502. Web.

LeFevre, Karen Burke. Invention as a Social Act. Carbondale: Southern Illinois UP, I987. Print.

Lunsford, Andrea A., and Lisa Ede. "Collaborative Authorship and the Teaching of Writing." The Construction of Authorship: Textual Appropriation in Law and Literature. Ed. Martha Woodmansee and Peter Jaszi. Durham: Duke UP, 1994. 4I7-38. Print.

Miller, Susan. Rescuing the Subject: A Critical Introduction to Rhetoric and the Writer. Carbondale: Southern Illinois UP, I989. Print.

. Textual Carnivals: The Politics of Composition. Carbondale : Southern Illinois UP, I99I. Print.

Murnen, Timothy J. "Constructing Authorship in the Composition Classroom: An Ethnographic Approach." Diss. U of Michigan, 2002. ProQuest Digital Dissertations. Web. I2 October 2005.

“2oIo Freshman Attitudes at Two Year Colleges: A Closer Look.” Noel-Levitz. 20I0. Web. I5 August 20II.

Ritter, Kelly. "The Economics of Authorship: Online Paper Mills, Student Writers, and First-Year Composition." CCC 56.4 (2005): 60I-3I. JSTOR. Web. 6 May 20II.

Robillard, Amy. "Students and Authors in Composition Scholarship." Authorship in Composition Studies. Ed. Tracy Hamler Carrick and Rebecca Moore Howard. Boston: Thomson Wadsworth, 2006. 4I-56. Print.

Rodgers, Johannah. The Social Construction of Authorship: An Investigation of Rhetorical Authority and Identity in the College Writing Classroom. Saarbrucken: VDM Verlag, 2009. Print.

. "The Social Construction of Authorship: An Investigation of Subjectivity and Rhetorical Authority in the College Writing Classroom." Diss. The CUNY Graduate Center, 2007. Print.

Saunders, David. Authorship and Copyright. New York: Routledge, I992. Print.

Spigelman, Candace. Across Property Lines: Textual Ownership in Writing Groups. Southern Illinois UP 200o. Print.

Stygall, Gail. "Resisting Privilege: Basic Writing and Foucault's Author Function." CCC 45 (I994): 32O-4I. JSTOR. Web. 4 October 2005.

Trimbur, John. "Agency and the Death of the Author: A Partial Defense of Modernism." JAC 20.2 (2000): 283-298. Web. Io October 2006. 
Defining and Experiencing Authorship(s) in the Composition Classroom Woodmansee, Martha, and Peter Jaszi. The Construction of Authorship: Textual Appropriation in Law and Literature. Durham: Duke UP, I994. Print. 


\section{News and Announcements}

\section{NEWS FROM THE COUNCIL ON BASIC WRITING (CBW)}

\section{New CBW Mission Statement*}

The Council on Basic Writing (CBW) is an organization that advocates for students in basic writing and supports the professional endeavors of teachers, scholars, administrators, and students involved with basic writing.

CBW promotes appropriate support for basic writing that fosters college access and success for students who might otherwise be denied admittance. It pursues these ends through

- Supporting dissemination and application of, and advancing, best practices for the teaching and learning of writing, language, and literacy across two- and four-year post-secondary institutions;

- Promoting student success within a range of disciplinary, professional, and social contexts;

- Fostering a network of teacher-scholars, especially through BWe (an e-journal), our listserv, and an annual workshop at the Conference on College Composition and Communication, which encourages the development of research and collaborative strategies to enhance teaching excellence;

- Advocating for student diversity in all its many and complex forms, especially in terms of language, race, ethnicity, class, background, and ability;

- Promoting collaborations with

- secondary education faculty to facilitate smooth transitions from high school to college for students served by basic writing,

- adult and community education programs to facilitate successful transitions to college for non-traditional students served by basic writing, and

- post-secondary ESL and academic support services;

- Working to raise the visibility of basic writing within the academy and the larger public; and

- Influencing policies, including public policy, private foundations, and corporate sponsors in ways benefiting basic writing and the students it supports.

* This statement evolved from a day-long CBW workshop and visioning meeting where participants provided ideas and language for the new mission 
statement. The statement was drafted by Susan Naomi Bernstein, Kathleen Baca, Marisa Klages, and Steve Lamos. It was then revised by members of the CBW Executive Board and others from the CBW community. It was endorsed by the CBW community in June 2011.

\section{CCCC 2012 Pre-Conference CBW Workshop}

"Gathered at the Gate: Basic Writing in Evidence"

Wednesday, March 21, 2012, 9 a.m. to 5 p.m.

\section{St. Louis, MO}

Each year the Council on Basic Writing sponsors an all-day workshop the day before the opening of the Conference on College Composition and Communication (CCCC). This year the workshop will feature presentations by Bruce Horner, Mike Rose, and Peter Adams. An open call for additional presentations will be posted on the listserv (CBW-L), the CBW Facebook page, and the CBW blog (see below for more details). To register to participate in the workshop, add "Full Day Preconference Workshop" when registering to attend CCCC 2012.

\section{CBW Contact Information}

Listserv: CBW-L is a listserv focused on basic writing and related issues and welcomes anyone who wishes to participate in an ongoing discussion of basic writing as it is studied and practiced in its historically rich and varied contexts. To subscribe to this listserv, send an e-mail message to: listserv@ umn.edu. The content of the message should read: subscribe CBW-L firstname lastname. For example: subscribe CBW-L jane doe. Leave the subject line blank and remove your signature. In response, you will receive e-mail confirmation of your subscription and instructions for sending future mail.

Facebook: http://www.facebook.com/groups/50538806660/

Blog: http://cbwblog.wordpress.com/ 
How is this publication thinking about the future?

By becoming part of the past.

This publication is available from ProQuest Information and Learning in one or more of the following ways:

- Online, via the ProQuest ${ }^{*}$ information service

- Microform

- CD-ROM

-Via database licensing

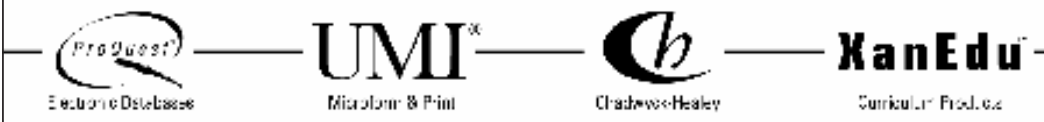

Fur aruse inforration, riall

I-800-52I-0600, cxt. 2888 (US) ur OI-734-76I-4700 (1utcrustionat)

sine.il.procjucst.rom

From:Pro Quest 


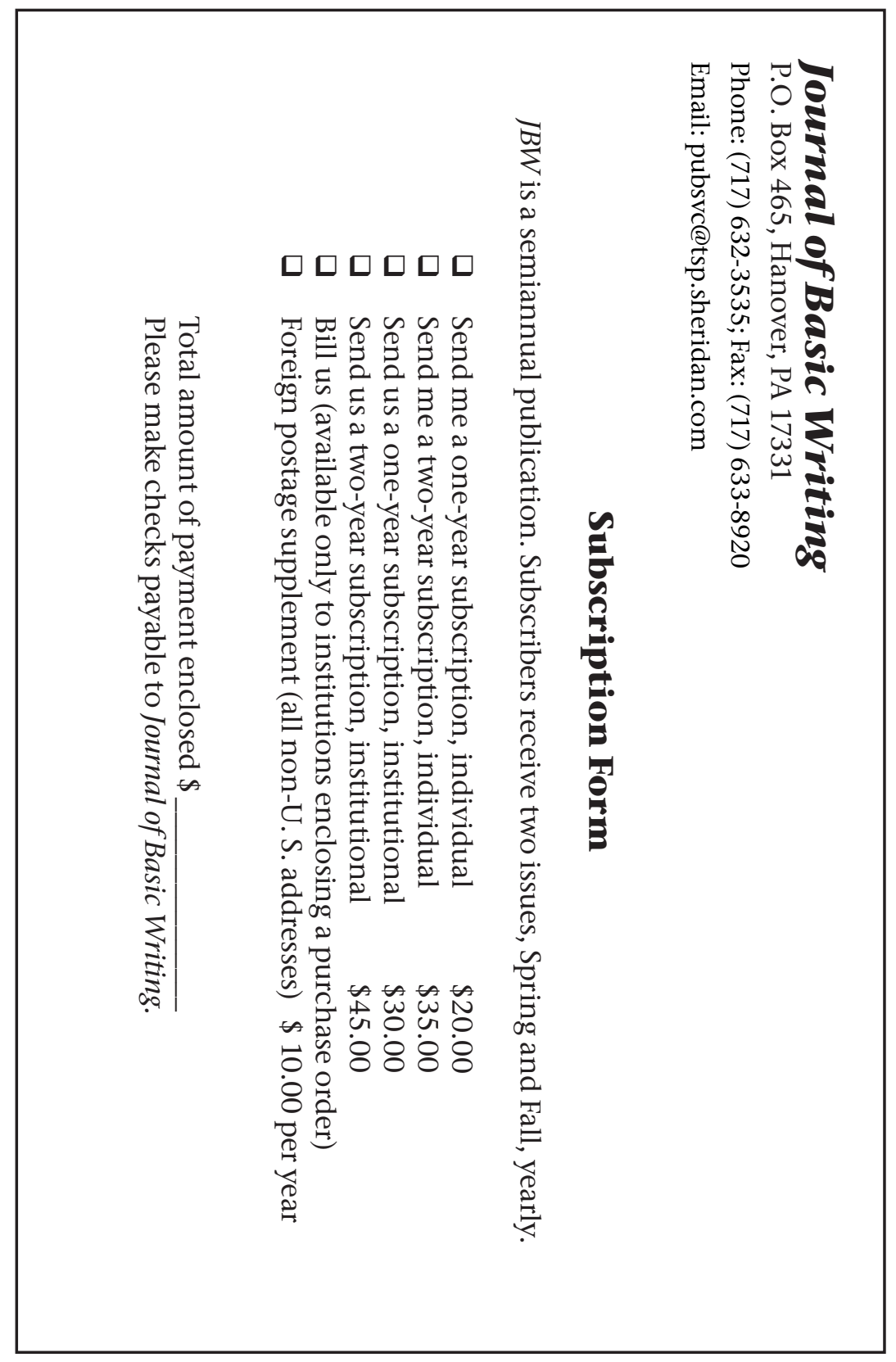




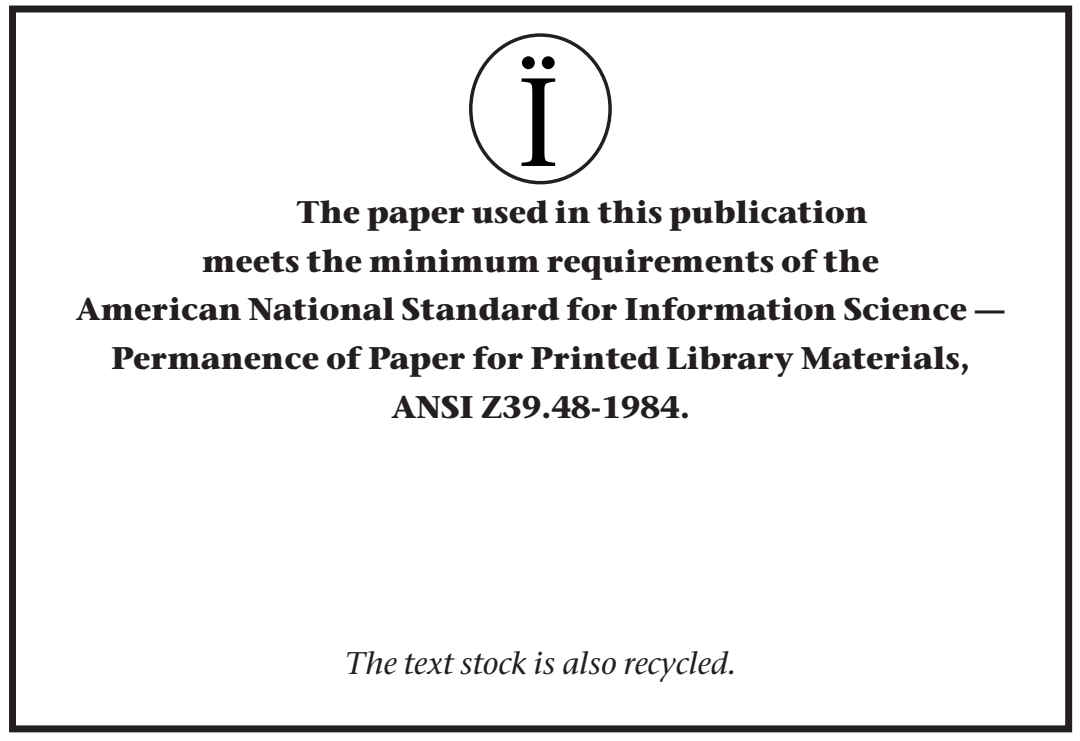




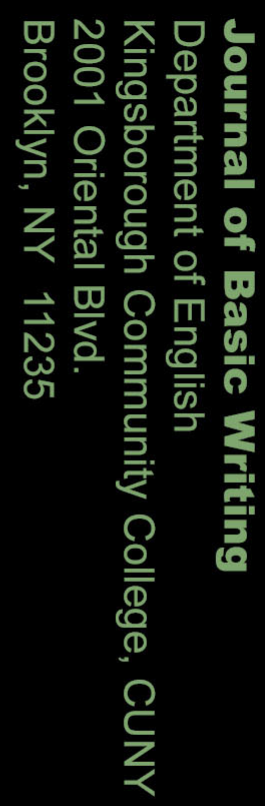

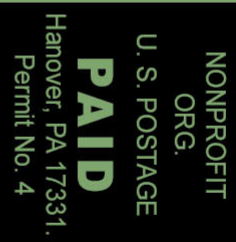

